\title{
ANÁLISE GENÉTICA DA REAÇÃO DA SEMENTE DE SOJA AO DANO MECÂNICO AVALIADA EM UM DIALELO DO CICLO PRECOCE
}

\author{
SÉRGIO AUGUSTO MORAIS CARBONELL \\ Engenheiro Agrônomo
}

Orientador: Prof. Dr. NATAL ANTONIO VELLO

Tese apresentada à Escola Superior de Agricultura "Luiz de Queiroz", da Universidade de São Paulo, para obtenção do título de Doutor em Agronomia. Area de Concentração: Genética e Melhoramento de Plantas.

PIRACICABA

Estado de São Paulo - Brasil

Outubro - 1995 


\title{
ANÁLISE GENÉTICA DA REAÇÃO DA SEMENTE DE SOJA AO DANO MECÂNICO AVALIADA EM UM DIALELO DO CICLO PRECOCE
}

\author{
SÉRGIO AUGUSTO MORAIS CARBONELL
}

Aprovada em 15/12/1995

Comissão Julgadora:

Prof. Dr. Natal Antonio Vello

ESALQ/USP

Dr. Francisco Carlos Krzyzanowski

EMBRAPA/CNPSoja

Dr. Romeu Afonso de Souza Kiihl

EMBRAPA/CNPSoja

Dr. Luciano Lourenço Nass

EMBRAPA/CENARGEN

Dr. Manoel Albino C. de Miranda

Instituto Agronômico/SAA

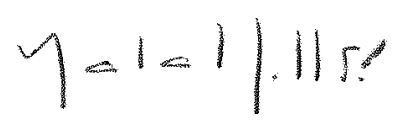

Prof. Dr. Natal Antonio Vello

- orientador - 
"Aquele que permanece em mim e Eu nele produz muitos frutos; porque, sem mim, nada podeis fazer." 
Ao meu Pai José Antônio da Silva Carbonell

À minha Mãe Araci Moraes Carbonell

À minha Esposa Gleize Villela Carbonell

\section{DEDICO}

À Deus, 


\section{AGRADECIMENTOS}

- Ao Professor Natal Antonio Vello, pela confiança, orientação, respeito pessoal e profissional na excelência dos conhecimentos transmitidos;

- Ao Conselho Nacional de Desenvolvimento Científico e Tecnológico - CNPq, pela concessão da bolsa de estudos no período de agosto de 1991 a agosto de 1995;

- À EMBRAPA/Centro Nacional de Pesquisa de Soja pela construção do aparelho danificador de sementes utilizado nesta pesquisa;

- À Escola Superior de Agricultura "Luiz de Queiroz" - ESALQ/USP, Departamento de Genética, através de todos os seus funcionários e professores, pela dedicação na condução dos experimentos de campo e disciplinas ministradas;

- Ao Instituto Agronômico do Estado de São Paulo - IAC, pela liberação e apoio para o desenvolvimento desta pesquisa;

- Ao CNPq, CAPES e FAPESP pelo apoio aos projetos de pesquisa relacionados à tese;

- Ao Dr. Antonio Sidney Pompeu, que com sua dedicação conduziu muitas vezes sozinho o Programa de Melhoramento de Feijoeiro por nós desenvolvidos no IAC, permitindo que $\mathrm{Eu}$ me dedicasse muitas vezes, em determinados períodos, exclusivamente para esta pesquisa;

- Aos amigos Nelson Fonseca Júnior, Cláudio Takeda, Daniel Furtado e Antônio Augusto Franco Garcia, pelas sugestões e auxílio nas análises estatísticas;

- Ao Professor Roland Vencovsky pelas sugestões e auxílio nas análises estatísticas;

- À colega e amiga Maria Beatriz Perecin Calheiros pelo auxílio na versão do resumo;

- Aos amigos do grupo de soja, José Baldin Pinheiro, Joaquim Adelino de Azevedo Filho, Regina Lúcia Ferreira Gomes, Gilberto Ken-Iti Yokomizo, Dario Minoru Hiromoto, Luis Fernando Alliprandini, Juan Carlos Montaño-Velasco, Wagner Pereira Reis, João Tomé Farias Neto, Francilene Leonel Campos, Milton Krieger, Lafayete Luís da Silva, Angela Celis de Almeida Lopes, Mônica C. Martins pelo auxílio e constante apoio nos trabalhos experimentais de campo e laboratório, possibilitando assim a conclusão deste trabalho; 
- Ao colega e amigo Joaquim Adelino de Azevedo Filho, pela colaboração na revisão dos manuscritos desta pesquisa;

- Aos funcionários do laboratório de soja, Antônio Roberto Cogo, Claudinei Antônio Didoné, Osmair José da Silva, José Guerreiro, José Roberto Alonso, Marco Custódio Nekatschalow, pela colaboração nos trabalhos experimentais;

- A todos que de uma maneira ou de outra, contribuíram para que este trabalho fosse realizado. 


\section{SUMÁRIO}

página

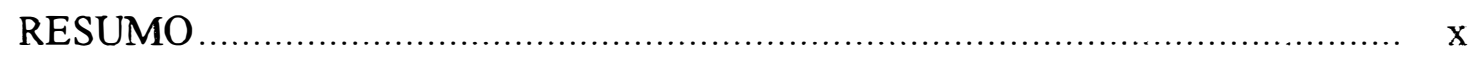

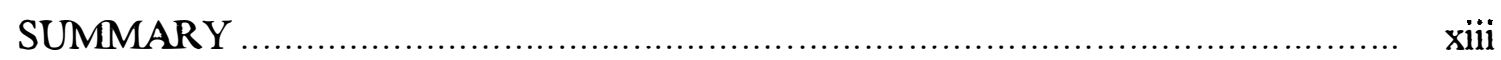

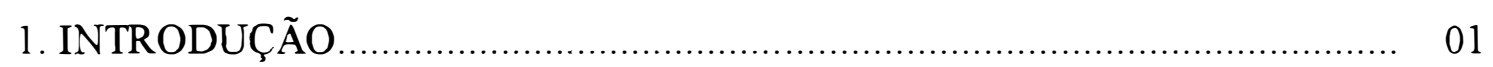

2. REVISÃO DE LITERATURA ......................................................... 03

2.1. Origem da soja e do germoplasma brasileiro f................................... 03

2.2. Dano mecânico ................................................................................ 05

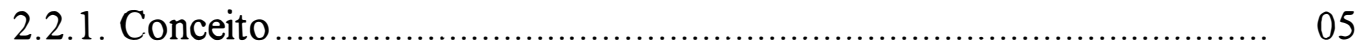

2.2.2. Relação com a qualidade fisiológica da semente.......................... 06

2.2.3. Relações no processo industrial e consumo humano ....................... 09

2.2.4. Relações com empresas de sementes e agricultores ....................... 10

2.2.5. Relações com suscetibilidade e resistência da semente ................... 11

2.2.6. Relações com a estrutura celular da semente .............................. 15

2.3. Variabilidade existente no germoplasma de soja ............................... 17

2.4. Melhoramento para qualidade fisiológica de sementes com ênfase no dano

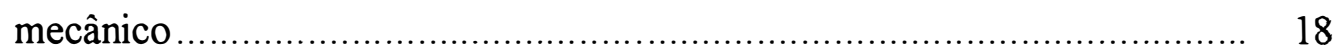

2.5. Genética da qualidade de semente e resistência ao dano mecânico ............. 20

3. MATERIAL E MÉTODOS …............................................................ 22

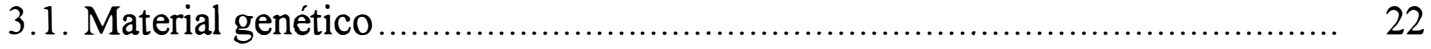

3.1.1. Obtenção de sementes $F_{1}$ e gerações segregantes ........................ 22

3.1.2. Material genético utilizado nos experimentos ............................. 23

3.2. Delineamento e características dos experimentos ............................. 23

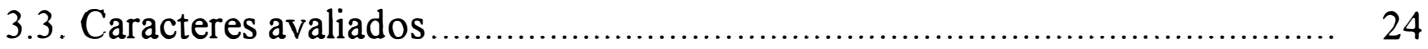

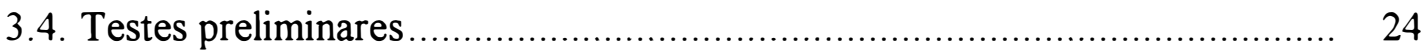

3.5. Metodologia do 'teste do pêndulo' ........................................... 25

3.5.1. Procedimentos no campo .............................................. 26

3.5.2. Procedimentos no laboratório ........................................... 27

3.5.2.1. Obtenção das amostras .......................................... 27 
página

3.5.2.2. Dano mecânico .......................................................... 28

3.5.3. Procedimento para quantificar o valor de dano mecânico ................ 29

3.6. Análises estatístico-genéticas ................................................ 30

3.6.1. Análise de resíduos ......................................................... 31

3.6.2. Análises de variância ........................................................... 32

3.6.2.1. Análise individual por experimento ............................. 33

3.6.2.2. Análise conjunta dos experimentos............................... 34

3.6.3. Correlações entre caracteres ............................................... 35

3.6.3.1. Correlação fenotípica de ordem.................................... 35

3.6.3.2. Correlações genotípica, fenotípica e de ambiente................ 36

3.6.4. Regressão linear múltipla .............................................. 38

3.6.5. Contribuição relativa de efeitos genéticos vs. efeitos (genéticos +

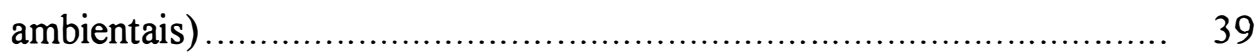

3.6.6. Relação entre os coeficientes de variação genética e experimental .... 39

3.6.7. Progresso esperado na seleção ............................................ 40

3.6.8. Herdabilidade .............................................................. 41

3.6.9. Resposta correlacionada à seleção........................................... 42

3.6.10. Progresso genético observado ............................................. 43

4. RESULTADOS E DISCUSSÃO _....................................................... 44

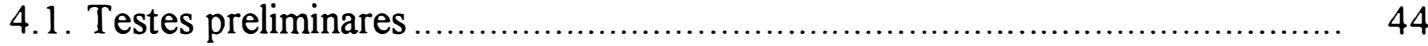

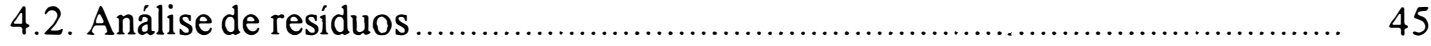

4.3. Análises de variância ..................................................................... 45

4.3.1. Análise individual por experimento ....................................... 45

4.3.1.1. APM (altura de planta na maturação) e PG (produção de grãos) .................................................................. 46

4.3.1.2. DM (dano mecânico) ............................................ 47

4.3.2. Análise conjunta dos experimentos..................................... 48

4.3.2.1. APM (altura de planta na maturação) e PG (produção de grãos) f.................................................................... 49

4.3.2.2. DM (dano mecânico ) .......................................... 52 
página

4.4. Análise de médias e componentes genéticos ...................................... 53

4.4.1. APM (altura de planta na maturação) e PG (produção de grãos) 53

4.4.1.1. Relação entre os coeficientes de variação genética e experimental........................................... 56

4.4.1.2. Progresso esperado na seleção ............................... 57

4.4.1.3. Herdabilidade ................................................. 58

4.4.2. DM (dano mecânico) ..................................................... 59

4.4.2.1. Relação entre os coeficientes de variação genética e experimental ........................................................ 61

4.4.2.2. Progresso esperado na seleção............................... 62

4.4.2.3. Herdabilidade .................................................. 63

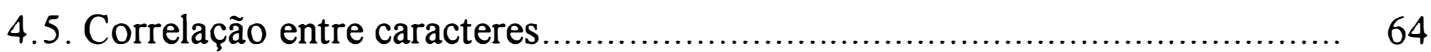

4.5.1. Correlações relacionadas a qualidade fisiológica das sementes......... 64

4.5.2. Correlações genotípica, fenotípica e de ambiente.......................... 65

4.6. Resposta correlacionada à seleção ................................................... 65

4.7. Regressão linear múltipla aplicada ao valor de DM .............................. 67

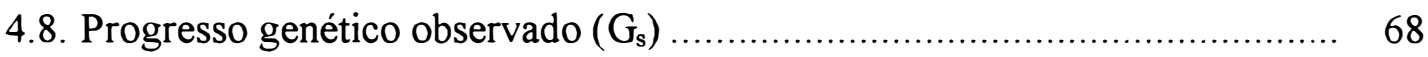

4.8.1. $\mathrm{G}_{\mathrm{s}}$ - baseado em número de linhagens................................ 68

4.8.1.1. G $G_{s}$ - APM (altura de planta na maturação) e PG (produção de

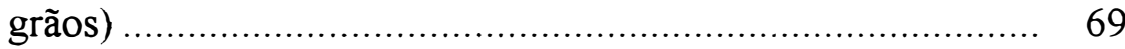

4.8.1.2. $\mathrm{G}_{\mathrm{s}}$ - DM (dano mecânico) ....................................... 72

4.8.2. $\mathrm{G}_{\mathrm{s}}$ - baseado na média das linhagens.................................. 73

4.8.2.1. G - APM (altura de planta na maturação) e PG (produção de

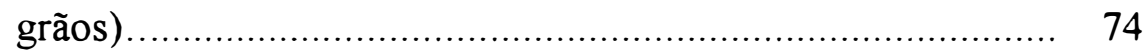

4.8.2.2. $\mathrm{G}_{\mathrm{s}}$ - DM (dano mecânico)................................... 75

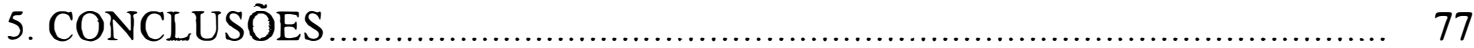

6. REFERÊNCIAS BIBLIOGRÁFICAS ................................................ 79

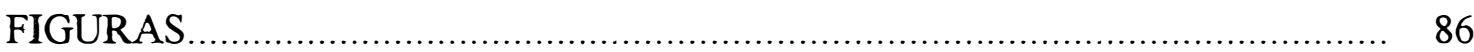

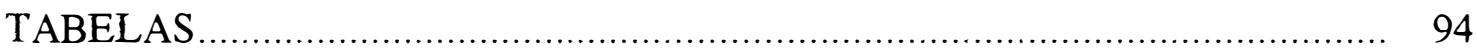

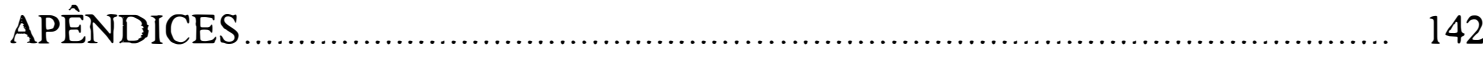




\section{ANÁLISE GENÉTICA DA REAÇÃO DA SEMENTE DE SOJA AO DANO MECÂNICO AVALIADA EM UM DIALELO DO CICLO PRECOCE}

Autor: Sérgio Augusto Morais Carbonell Orientador: Prof. Dr. Natal Antonio Vello

\section{RESUMO}

Esta pesquisa faz parte do programa de melhoramento genético de soja em andamento no Departamento de Genética da ESALQ/USP e objetiva conhecer a expressão genética do caráter reação ao dano mecânico (DM) em sementes de soja, bem como o estudo da variabilidade existente e de sua correlação com os caracteres altura de planta na maturação (APM) e produção de grãos (PG). Assim, através de estimativas de médias e variâncias dos cruzamentos, procura-se verificar a possibilidade de se reunir em um mesmo genótipo os alelos favoráveis para resistência da semente ao dano mecânico, APM e PG, bem como o estudo de suas relações.

Cruzamentos dialélicos envolvendo dez parentais de ciclo precoce, num total de 45 combinações, foram avaliados nas gerações $F_{7: 5}$ e $F_{8: 5}$ para os caracteres APM e PG. Para DM, na geração $F_{7: 5}$, somente cinco cruzamentos aleatoriamente amostrados foram avaliados, além dos parentais e testemunhas segundo a metodologia do 'teste do pêndulo'. Na geração $F_{8: 5}$ foram avaliados os 45 cruzamentos. 
Testes preliminares foram realizados para determinação de uma metodologia adequada para acondicionamento das amostras de sementes na umidade de $13 \% \pm 0,5$, importante na determinação da suscetibilidade da sementes ao dano mecânico.

Análises estatístico-genéticas foram realizadas para os três caracteres, compreendendo: análises individuais e conjunta (experimentos com semeadura em 03/12/1991 e 02/12/1992) de resíduos e variâncias, as de correlações fenotípicas de ordem e genéticas, contribuição relativa de efeitos genéticos vs. (genéticos + ambiental), relações entre os coeficientes de variação genética e experimental, progresso esperado à seleção, herdabilidade, resposta correlacionada na seleção e progresso genético observado baseado no número de linhagens superiores e valor médio do caráter.

As conclusões obtidas com esta pesquisa com soja precoce foram as seguintes: a) o acondicionamento das amostras de sementes em câmara de crescimento com temperatura de $25^{\circ} \mathrm{C}$ e umidade de $85 \%$ por um período de $72 \mathrm{hs}$, elevou o teor de umidade inicial de $7 \%$ para $12,74 \% \pm 0,34$, ideais para a realização do 'teste do pêndulo'; b) a suscetibilidade da semente ao dano mecânico é mais influenciada por fatores de campo (condições climáticas e fitotécnicas responsáveis pela produção e formação da semente) do que propriamente pela idade da semente; c) existe variabilidade na população para promover ganhos de seleção para altura de planta, produção de grãos e resistência ao dano mecânico; d) os cultivares Paraná, Hale-321, IAC-Foscarin-31 e Primavera, foram considerados com o mesmo nivel de resistência ao dano mecânico do cultivar IAS-5, utilizado como padrão de resistência; os cultivares Palmetto, Coker-136, FT-81-1835 e Forrest foram considerados como cultivares suscetíveis, embora superiores ao padrão de suscetibilidade IAC-2; e) o caráter DM apresenta herdabilidade considerada média/alta $\left(h^{2}=0,739\right.$ no experimento com semeadura em $\left.02 / 12 / 1992\right)$; deste modo, é considerada promissora a obtenção de linhagens transgressivas para resistência da semente ao dano mecânico; f) o valor numérico de DM pode ser composto somente pelo número de sementes quebradas (SQ) e danificadas (SD), combinados em um índice de resistência; o valor de sementes intumescidas (SI) obtidas com o auxílio de hipoclorito de sódio, não é importante na determinação do nível de resistência ao dano mecânico de um genótipo; g) a qualidade fisiológica da semente, expressa em germinação, é importante na suscetibilidade da semente ao dano mecânico; a correlação entre 
germinação (G) e DM embora considerada baixa a média, foi negativa; h) os caracteres PG, APM e DM apresentaram baixos valores de correlação genética, deste modo, podese reunir em um genótipo todas as combinações possíveis para estes caracteres; i) a resposta correlacionada à seleção pode apresentar valores altos para os três caracteres estudados em todas as combinações; no entanto, ela é extremamente dependente dos parentais envolvidos no cruzamento; j) para os três caracteres avaliados foram obtidas linhagens transgressivas (39\% em APM, 34\% em PG e 31\% em DM do total de linhagens) superiores ao melhor parental no cruzamento; k) o progresso genético observado na média das linhagens apresenta superioridade em relação ao parental superior no cruzamento em até $30,5 \%$ para altura de planta $(\mathrm{cm}), 18 \%$ para produção de grãos $\left(\mathrm{g} / \mathrm{m}^{2}\right)$ e $40 \%$ para resistência ao dano mecânico (udm). 


\title{
GENETIC ANALYSIS OF SOYBEAN SEED REACTION TO MECHANICAL DAMAGE EVALUATED BY A DIALLEL OF THE EARLY CYCLE
}

Author: Sérgio Augusto Morais Carbonell

\author{
Adviser: Prof. Dr. Natal Antonio Vello
}

\section{SUMMARY}

These research is part of the soybean breeding program in development by the Departament of Genetics of ESALQ/USP. Its aim is to understand the genetic expression of the reaction to mechanical damage (DM) in soybean seeds, and also to study the available variability to this characteristic and its correlation with plant height at maturity (APM) and seed yield (PG). Through the estimate of the means and variances of the crosses, it was investigated the possibility of jointing in a genotype the favorable alleles for the mentioned characteristics (PG, APM and DM) and also the genetic correlation between them.

Diallel crosses involved ten early maturation parent, in 45 different combinations. The evaluations of characters APM and PG were done in $F_{7: 5}$ and $F_{8: 5}$ generations. For the character $\mathrm{DM}$ in $\mathrm{F}_{7: 5}$, only five crosses sampled at random were 
evaluated in addition to the parent and checks. In the generation $\mathrm{F}_{8: 5}$ all 45 crosses were evaluated.

Preliminary tests were made in order to determine an adequate methodology for the maintenance of the samples in a moisture of $13 \% \pm 0.5$, an important requisite for the application of the test named 'pendulum test', that estimates the reaction of the seeds to mechanical damage.

The genetic analysis were made for the three characters, comprising individual and combined analysis (for the experiments sowed on December 03, 1991; and, December 02, 1992) for residual and variances, phenotypic rank correlation, genetic correlation, relative contribution of the genetic effects vs. (genetic + environmental effects), relationships between the genetic and environmental variation coefficients, estimate of genetic progress based on the number of superior lines and average value for the character.

The results of this research with early soybean were the following: a) the seed maintenance in chamber of germination at $25^{\circ} \mathrm{C}$ and moisture of $85 \%$ for a period of $72 \mathrm{hs}$, has raised the initial seed moisture of $7 \%$ to $12.74 \% \pm 0.34$, that is ideal for the performance of the 'pendulum test'; b) the susceptibility of soybean seed to mechanical damage is influenced more by field factors (climate and cultural conditions for the production and formation of the seed) than by the seed age itself; c) there is enough variability in soybean population to improve plant height, grain yield and resistance to mechanical damage; d) the cultivars Paraná, Hale-321, IAC-Foscarin-31 and Primavera, were considered as in the same level of resistance to mechanical damage as IAS-5, that is frequently used as a resistant check; the cultivars Palmetto, Coker-136 and FT-81-1835 and Forrest were considered as suscetible cultivars, however better than IAC-2 that is considered a susceptible check; e) the character DM presents a heritability that is considered medium to high $\left(h^{2}=0.739\right.$ in the experiment sowed on December 02, 1992), showing the possibility to obtain transgressive lines for resistance to mechanical damage in the seed; f) the numerical values of DM can be proposed to be the number of broken seeds (SQ) and damaged seeds (SD) combined in a resistance index; the value for imbebed seeds (SI) usually obtained with sodium hypoclorite test, is not important in the definition of the resistance level of a genotype; $g$ ) the physiological quality of the seed, expressed as germination rates $(G)$ and DM had a low to medium, was negative; $h$ ) the 
characters APM, PG and DM had a low score of genetic correlation, so one can combine in a single genotype all possible allelic combinations for these traits; i) in a similar way, the correlated response to selection can show high values for the three characters studied in all combinations, although highly dependent of the parental line used in the crosses; j) for the three evaluated characters it was obtained transgressive lines (39\% in APM, $34 \%$ in $P G$ and $31 \%$ in DM of all lines) that were superior to the best parental in the cross; k) the genetic progress observed in the average of the lines is greater than its parental lines as much as $30.5 \%$ for plant height $(\mathrm{cm}), 18 \%$ for grain yield $\left(\mathrm{g} / \mathrm{m}^{2}\right)$ and $40 \%$ for resistance to mechanical damage. 


\section{INTRODUÇÃO}

O cultivo da soja (Glycine max (L.) Merrill), vem se destacando nos últimos anos no Brasil, devido principalmente à sua adaptação em regiões onde o seu cultivo era limitado por problemas de fotoperíodo e, também, devido ao incremento da comercialização de seus derivados com o comércio exterior. Assim, a soja tornou-se rapidamente um dos principais produtos da exploração agrícola e da economia nacional.

Devido a esta grande expansão na área de cultivo e as exigências de um produto de alta qualidade no mercado exterior, os melhoristas de soja têm uma função de destaque para a obtenção de cultivares desta espécie que possam elevar ainda mais os patamares de produtividade e adaptação da cultura, em regiões onde a qualidade do produto comercializado é extremamente importante.

$\mathrm{Na}$ obtenção de um produto de alta qualidade, seja ele grãos, sementes ou subprodutos destes, o primeiro passo é a obtenção de uma lavoura de alto padrão. Para isso, o estabelecimento de uma adequada população de plantas com o uso de sementes de soja de alta qualidade (expressas em germinação e vigor), irá mais tarde se refletir na produtividade e qualidade do grão e/ou semente produzida.

O estádio de máxima qualidade das sementes é alcançado quando esta atinge a maturação fisiológica $\left(\mathrm{R}_{7}\right)$, após a qual, todos os eventos que ocorrerem resultarão em gradual, às vezes rápida, mas sempre contínua perda de qualidade na semente e/ou grão. Destes eventos, uma das principais causas desta redução de qualidade nas sementes é o dano mecânico provocado durante as operações de colheita e beneficiamento das sementes.

O dano mecânico em sementes de soja tem sido a causa de condenações de vários lotes por baixa germinação e, também, responsável pelo baixo vigor e desempenho de suas sementes no campo, ocasionando um fraco desenvolvimento de plântulas na fase de estabelecimento da cultura e posterior perdas na produtividade e qualidade do produto. 
$\mathrm{Na}$ indústria que utiliza o produto ou subproduto da soja para a alimentação humana, o dano mecânico constitui um fator extremamente importante no controle da qualidade do grão para a sua industrialização, pois tais danos colocam as enzimas lipoxigenases em contato com o substrato (ácidos graxos livres poliinsaturados), e na presença de pequenas quantidades de água há uma reação de hidrólise e oxidação desses ácidos, desenvolvendo-se odor e sabor desagradáveis nos grãos de soja.

Vários trabalhos de pesquisa evidenciam a variabilidade genética existente na soja quanto à resistência da semente ao dano mecânico, como também metodologias para avaliação deste dano. Entretanto, considera-se o estudo de metodologias para seleção de genótipos resistentes ao dano mecânico bastante recente, sendo poucos os trabalhos reportados com este objetivo, dentre os quais: 'drop test' em feijão (DICKSON \& BOETTGER, 1977; KUENEMAN, 1989), uso de trilhadoras estacionárias (COSTA et al., 1987), teste do pêndulo (CARBONELL, 1991) e relação entre o conteúdo de lignina no tegumento da semente de soja e sua reação ao dano mecânico (ALVAREZ, 1994). Destes, somente o trabalho de DICKSON \& BOETTGER (1977) estuda geneticamente o caráter dano mecânico em feijão. Em soja não foram encontrados registros.

Tendo-se em vista a inexistência do conhecimento da expressão genética do dano mecânico em sementes de soja, bem como o estudo da variabilidade existente e de correlações entre caracteres, esta pesquisa tem por objetivo principal a avaliação genética deste caráter através de um esquema de cruzamentos dialélicos envolvendo dez parentais de ciclo precoce. Assim, através de estimativas de parâmetros genéticos, tais como, médias e variâncias dos cruzamentos, procura-se verificar a possibilidade de reunir em um mesmo genótipo os alelos favoráveis para resistência ao dano mecânico e outros caracteres, bem como o estudo de suas correlações.

Devido aos testes existentes desenvolvidos para a seleção de genótipos resistentes ao dano mecânico em soja não serem totalmente práticos para uso rotineiro em programas de melhoramento, como objetivo complementar, busca-se nesta pesquisa, aperfeiçoar o 'teste do pêndulo' proposto por CARBONELL (1991) para que este se torne um método plenamente aceito, prático, flexivel e confiável nos programas de melhoramento de soja, que visem a melhor qualidade de semente e/ou grão. 


\section{REVISÃO DE LITERATURA}

\subsection{Origem da soja e do germoplasma brasileiro}

A soja é uma das plantas cultivadas mais antigas do mundo. Sua história e origem se perdem em tempos remotos. A literatura chinesa antiga revela que a soja pode ter sido cultivada extensivamente na China e Manchúria pelo menos à 2.500 anos a.C.. Devido à falta de um sistema de controle cronológico antes do ano 814 a.C., é dificil definir uma data exata e, por isso, pode ter sido mais recente, cerca de 1.000 anos a.C. (HYMOWITZ, 1970). De qualquer forma, desde as primeiras menções, sempre foi considerada uma das mais importantes leguminosas cultivadas no Oriente, sendo que suas sementes são utilizadas em muitas formas para fins alimentícios (na forma líquida e de pó ou coalhada), inclusive medicinais (MULLER, 1981).

O estudo de todas as informações existentes ainda não permite conclusões definitivas a respeito do lugar exato de origem. Pode ser aceito com segurança que é originária da Ásia Oriental, especialmente da China (MULLER, 1981).

Em seus estudos relacionados com os respectivos centros de genes, visando à evolução das plantas cultivadas, Vavilov classificou a soja como planta alimentar primária, pertencente ao Centro 1 , que corresponde geograficamente à área montanhosa da China Central e Ocidental, pois naquela região ocorre a maior diversidade de tipos. Este fato é interessante, pois das 96 espécies do gênero Glycine citadas no Index Kewensis como válidas, somente seis são classificadas como originárias da China e outras cinco de Formosa (Taiwan) e do Japão (MULLER, 1981).

A Glycine soja é considerada ser um dos ancestrais da soja cultivada $G$. max, no entanto, não se sabe com certeza os ancestrais da $G$. soja. Até o presente, supõe-se que as espécies G. tabacina e G. tomentella estejam envolvidas neste processo evolucionário, compartilhando áreas geográficas em comum com G. soja na Província de Fujien (China), Ilhas Ryukyu (Japão) e Taiwan. Supostamente, estas regiões poderiam ser 
consideradas o centro de origem da soja, no entanto, devido ao pequeno número de acessos de G. tomentella e G. tabacina à disposição em BAGs e utilizadas nestes estudos evolucionários, tem-se a necessidade de estudos adicionais e mais expedições de coleta destas espécies nestas regiões, para confirmar esta hipótese (HYMOWITZ \& SINGH, 1987).

Com base nas evidências existentes na área geográfica e nos aspectos taxonômicos e históricos, HYMOWITZ (1970) concluiu que a soja cultivada deve ter sido domesticada no nordeste da China, o que corresponde, atualmente, à região de Kaoliang de trigo de inverno. A época provável de domesticação, segundo o mesmo autor, deve ter sido o século XI a.C., ou seja, durante a Dinastia Chou. HYMOWITZ (1970) admitiu que, com certa probabilidade, a Manchúria representa um centro secundário de diversidade genética, ou seja, um centro de diversificação e uma área geográfica com a maior probabilidade da formação de G. gracilis, devido à sobreposição das áreas de distribuição de seus ancestrais, G. max e G. ussuriensis (G. soja).

A soja é uma planta autógama e anual que pertence à família Leguminosae, subfamilia Papilionoideae, tribo Phaseoleae, subtribo Phaseolinae (Glycininae), gênero Glycine L., subgênero soja (Moench) F.J. Germ. e à espécie Glycine max (L.) Merrill, tendo $2 n=40$ cromossomos. $O$ nome deste gênero deriva do grego 'glykys' que significa doce.

Hoje, a soja é a mais importante oleaginosa em produção sob cultivo extensivo, sendo que produz mais proteina por hectare que qualquer outra planta de lavoura. A qualidade como fonte de calorias faz desta leguminosa um alimento básico potencial na luta contra o espectro da fome, que já se vislumbra em certas áreas densamente populosas e menos desenvolvidas (BONETTI, 1981).

Admitindo-se que a soja tenha surgido na China no século XI a.C., ela teria atingido, a partir dali, outros paises do Oriente com o transcorrer dos séculos. Acreditase que durante a Dinastia Chou a soja cresceu de importância e, com o crescimento do comércio, houve a sua movimentação para o Sul da China, Coréia, Japão e Sudeste da Ásia (HYMOWITZ, 1970).

A primeira menção sobre soja na literatura norte-americana data de 1804, quando Mease recomendou seu cultivo na Pensilvânia. Nos 50 anos seguintes, a soja foi introduzida em muitos jardins botânicos no Estado de Massachusetts. A partir de 1880, a 
soja adquiriu alguma importância nos E.U.A. como cultivo forrageiro e somente em 1914, a área para a produção de grãos superou aquela para cultivo como forrageira. A primeira importação de óleo de soja pelos E.U.A. ocorreu em 1910, a partir da Manchúria. Até 1916, os E.U.A. ainda importaram soja da Manchúria (BONETTI, 1981).

A primeira referência sobre soja no Brasil data de 1882 em cultivo na Bahia. Em 1908, imigrantes japoneses introduziram a soja em São Paulo e, em 1914 foi oficialmente introduzida no Rio Grande do Sul. Em 1949, o Rio Grande do Sul realizou a primeira exportação de soja brasileira (18.704 toneladas) (BONETTI, 1981).

No início do cultivo da soja no Brasil a introdução de linhagens e cultivares, seguida de seleção constituiu-se no principal método de melhoramento adotado. VELLO (1985) relata que os grupos de maturação V a X, cultivados no sul dos Estados Unidos, são os que apresentam maiores chances de adaptação em condições subtropicais e tropicais, ressaltando que este fato tem sido muito bem explorado por melhoristas brasileiros.

Geralmente, têm sido utilizados repetidamente os materiais mais adaptados como parentais. Esta limitação foi relatada por HIROMOTO \& VELLO (1986), onde os autores constataram que a base genética do germoplasma cultivado é estreita, representado por 11 ancestrais asiáticos com contribuições individuais variando de $3 \%$ a $15 \%$ de genes ao germoplasma. Estes autores também mencionam que os programas de melhoramento de soja no Brasil podem ser considerados como um terceiro ciclo de seleção recorrente.

\subsection{Dano mecânico}

\subsubsection{Conceito}

O conceito de injúria mecânica é restrito aos distúrbios resultantes dos fatores destrutivos ocorridos durante as operações de trilha e transporte. Injúria mecânica 
é, muitas vezes, citado como distúrbio mecânico ou dano (PEREIRA \& ANDREWS, 1985).

Conforme o tipo de dano mecânico provocado nas sementes, ele é classificado em duas categorias: uma, é chamada de "dano visivel" ou imediato, que pode ser observado pela análise visual (olho desarmado) e corresponde a tegumentos quebrados, cotilédones separados e/ou quebrados. A outra categoria é chamada de "dano invisivel" ou latente (trincas microscópicas e abrasões), correspondendo ao dano que irá se manifestar no período de armazenamento, com a queda do vigor e da viabilidade de semente (FAGUNDES, 1971; COPELAND, 1972; FRANÇA NETO \& HENNING, 1984)

A resistência à compressão, definida como a energia absorvida por grão de soja antes da ruptura do tegumento por sua unidade de volume, é máxima quando o grau de umidade na semente está entre $11 \%$ e $14 \%$. Esta resistência diminui quando os graus de umidade são menores que $11 \%$ ou maiores que 14\% (PAULSEN, 1977; PAULSEN, 1978).

\subsubsection{Relação com a qualidade fisiológica da semente}

Com a expansão da cultura de soja para as regiões tropicais do Brasil Central, tem se exigido dos melhoristas de plantas cultivares mais produtivas e de melhor adaptação. Um dos fatores de fundamental importância para a obtenção de altas produtividades, é o estabelecimento da lavoura com adequada população de plantas (NAVE et al., 1977), assim o uso de sementes com alta qualidade fisiológica (expressas geralmente em valores de vigor e germinação) é fundamental.

As sementes de soja apresentam o grau mais elevado de qualidade quando atingem a maturação fisiológica $\mathrm{R}_{7}$ (COSTA et al., 1979; FRANÇA NETO \& HENNING, 1984; KUENEMAN, 1989). No entanto, os eventos que ocorrem posteriormente, resultam em gradual, muitas vezes rápida, mas sempre contínua perda de vigor da semente até a próxima semeadura (PAULSEN, 1978; FRANÇA NETO \& HENNING, 1984; KUENEMAN, 1989). 
As perdas de qualidade das sementes devem-se, principalmente, às adversidades ambientais no campo, à rápida deterioração no armazenamento em ambientes úmidos e quentes e ao dano mecânico causado à semente nas operações de trilha, transporte, manuseio, beneficiamento e semeadura (DELOUCHE, 1972; DASSOU \& KUENEMAN, 1984; BARTSCH et al., 1986; KUENEMAN, 1989; VIEIRA et al., 1994). No processo de produção de sementes, a injúria mecânica é uma das maiores causas de redução da viabilidade da semente de soja, sendo que estas injúrias não podem ser totalmente evitadas, mas sua extensão e sua severidade podem ser atenuadas significativamente (MOORE, 1972; POPINIGIS, 1972).

Deste modo, qualquer que seja a lesão mecânica, esta reduzirá a qualidade da semente, e quanto maior a sua intensidade maior será a redução. A intensidade, número e local de impactos na semente, têm muita influência sobre o grau de dano, embora o local de impacto seja um fator sobre o qual não se pode exercer nenhum controle (JIJÓN \& BARROS, 1983).

Dentre os diversos fatores externos que influenciam a qualidade da semente de soja, observou-se que o dano mecânico é o fator externo que mais contribuiu para a queda de germinação em lotes de sementes do cultivar Viçoja, seguido do dano por percevejos e danificações climáticas, dentre nove fatores estudados (MAEDA et al., 1977).

Deste modo, um dos fatores limitantes da produção de sementes com alta qualidade é muitas vezes a integridade fisica da semente, onde quebras (danos) no tegumento apresentam correlação positiva com a anormalidade de plântulas e negativas com a germinação e a emergência no campo (ZAPPIA, 1972; LUEDDERS \& BURRIS, 1979). Segundo BURRIS (1979), todas as práticas possíveis de beneficiamento de sementes seriam promotoras do aumento destes danos.

Durante a operação de colheita, a velocidade do cilindro é o fator que mais influencia na qualidade da semente, sendo que em maiores velocidades ocorre geralmente um aumento na eficiência da colheita. Entretanto, há também um aumento de sementes rachadas e quebradas (GREEN et al., 1966; FAGUNDES, 1971; BYG, 1974; MOORE, 1972; POPINIGIS, 1972). Logo, a obtenção da qualidade ideal de sementes e o pico de eficiência de rendimento na colheita não são compatíveis. Os agricultores, geralmente, têm a tendência de buscar a maximização dos rendimentos e não a qualidade 
(DELOUCHE, 1972; BYG, 1974), no entanto, atualmente há também uma tendência no comércio, em exigir um produto de melhor qualidade, com pagamento diferencial por este produto.

A detecção do nível de semente com tegumento rachado em soja é importante devido ao fato destas não serem retiradas por processos de beneficiamento. Separando-se estas sementes, observa-se que em média 50\% produzem plântulas anormais em teste padrão de germinação. Logo, nos lotes contendo $18 \%$ de sementes com tegumento rachado, após o beneficiamento, a germinação poderá cair $9 \%$ diretamente como resultado do dano mecânico (DELOUCHE, 1972).

ZAPPIA (1972) prevê uma queda na germinação de aproximadamente 10\% em sementes de soja com $25 \%$ de sementes rachadas armazenadas sob condições de conservação em ambiente natural (sem controle de temperatura e umidade). COPELAND (1972) também adverte que no ato da colheita e do processamento, o dano mecânico pode causar $10 \%$ de queda na germinação, sendo que o manuseio inadequado pode aumentar a perda para $20 \%$ ou $30 \%$.

Em função da resposta na germinação de sementes de soja com tegumento danificado, os danos nas sementes podem ser classificados em quatro classes, classe 1: sementes que não apresentam danos visíveis, classe 2: sementes com tegumentos rachados, classe 3: sementes quebradas, resultando sementes maiores que a metade da semente original; classe 4: sementes quebradas, resultando sementes menores que a metade da semente original. Quando a quantidade de dano no tegumento aumenta, a porcentagem de germinação decresce, por exemplo; sementes da classe 2 apresentam uma redução de $30 \%$ na porcentagem de germinação quando comparadas à classe 1 ; já as sementes da classe 3 têm o percentual de germinação com valores próximos à metade dos encontrados na classe 2 (STANWAY, 1974).

Em laboratório, a germinação da semente de soja com tegumento rachado, mas com cotilédones intactos, diminuiu para $50 \%$ quando comparada com sementes intactas (83\%). Havendo quebra no cotilédone este percentual caiu para $9 \%$. Em campo, a emergência foi ainda menor que a germinação em laboratório, provavelmente devido à presença de patógenos e adversidades fisicas do solo. Sementes intactas apresentaram $66 \%$ de emergência a campo, contra $10 \%$ nos lotes de semente com tegumento rachado 
mas com cotilédones intactos, e $2 \%$ nos lotes de sementes com tegumento e cotilédones danificados (STANWAY, 1978).

\subsubsection{Relações no processo industrial e consumo humano}

Embora a soja seja naturalmente excelente na qualidade de proteína, ela não é utilizada extensivamente na alimentação em muitos lugares do mundo, porque possui, muitas vezes, um sabor desagradável. No processo industrial dos grãos de soja para alimentação, o primeiro requisito é eliminar os grãos danificados na matéria prima, pois quando as células dos tecidos dos cotilédones de soja são rompidas ou danificadas de algum modo, na presença de baixos teores de umidade, a característica de sabor desagradável é desenvolvida. Este sabor é causado pela reação da enzima lipoxigenase na hidrólise e oxidação dos ácidos graxos livres. Os grãos devem estar intactos e não danificados para o processamento destinado à alimentação, prevenindo que a enzima lipoxigenase possa catalisar o desenvolvimento deste sabor desagradável (RODDA et al., 1972).

Em grãos de soja secos, inteiros e intactos, os sítios das enzimas lipoxigenases e os substratos de ação destas estão localizados separadamente nas células, então os odores e sabores desagradáveis não ocorrem. Quebras e danificações das células dos tecidos expõem a enzima aos sítios do substrato, mas se os tecidos contiverem pouca umidade esta enzima não atua. Entretanto, a adição de água aos tecidos danificados resulta no desenvolvimento do odor e sabor desagradáveis (NELSON et al., 1980).

Deste modo, o tegumento rachado em soja contribui para o aumento de ácidos graxos livres, resultando em menor qualidade do óleo e conseqüente prejuízo a sua industrialização (PAULSEN, 1977). 


\subsubsection{Relações com empresas de sementes e agricultores}

Em nove lotes do cultivar de soja Lee, as sementes não danificadas tiveram porcentagem de germinação superior à fração de sementes danificadas, resultado do efeito imediato de danos mecânicos. Lotes originais de sementes apresentavam em média $91 \%$ de germinação, revelando boa qualidade destes. No entanto, quando estes lotes foram divididos em duas fiações (fração não danificada e fração danificada), a fração com sementes não danificadas apresentou porcentagem de germinação média de $95 \%$. Na fração danificada a porcentagem de germinação média foi de $56 \%$, ficando evidente o efeito depressivo do dano mecânico (COELHO, 1973).

Na safra agrícola de 1980/81, um levantamento realizado em 37 lavouras que se destinavam à produção de sementes de soja nas regiões Norte, Centro-Sul e Oeste do Estado do Paraná, revelou que mais de $70 \%$ das amostras de sementes colhidas mecanicamente apresentaram queda de vigor (metodologia do tetrazólio, classes 1-3). Porém, neste estudo, não foram detectadas muitas diferenças no poder germinativo entre os dois métodos de colheita (manual e mecânico), devido, talvez, a não manifestação de possiveis danos latentes que porventura tenham ocorridos e não foram detectados logo após a coleta das amostras (FRANÇA NETO et al., 1981).

Através do teste de tetrazólio, foram avaliados 493 e 461 lotes de sementes de soja no Estado do Paraná, nas safras de 76/77 e 78/79, respectivamente. Aproximadamente $80 \%$ dos lotes de sementes apresentaram mais que $20 \%$ das sementes com evidências de dano mecânico, sendo estes niveis considerados extremamente altos, visto que os lotes estudados não tinham sido ainda beneficiados, ou seja, foram apenas submetidos ao processo de trilha. O estudo teve prosseguimento nas safras de 79/80, $81 / 82$ e 82/83, havendo um gradual decréscimo nos niveis de dano em relação aos anos anteriores. Acredita-se que isto se deva, pelo menos em parte, à campanha educacional com os agricultores sobre regulagem de colhedoras (COSTA et al., 1986).

$\mathrm{Na}$ avaliação de 43 amostras de sementes comerciais, representando aproximadamente $22 \%$ do total do número de lotes de sementes comerciais de soja produzidas no Estado da Flórida em 1986, verificou-se que o dano mecânico durante a 
colheita foi o fator que mais afetou a qualidade das sementes, seguido de deterioração por umidade e dano por percevejos (FRANÇA NETO et al., 1987).

\subsubsection{Relações com suscetibilidade e resistência da semente}

A semente de soja é muito sensível ao dano mecânico, uma vez que as partes vitais do eixo embrionário (radícula, hipocótilo e plúmula), estão situados sob um tegumento pouco espesso, que praticamente não lhe oferece proteção (ZNN, 1966; FAGUNDES, 1971; COPELAND, 1972; DELOUCHE, 1972; GUPTA et al., 1973; AGRAWAL \& MENON, 1974; COSTA et al., 1979; FRANÇA NETO \& HENNING, 1984; COSTA et al., 1986).

As anormalidades de plântulas mais freqüentes, devidas a danos mecânicos, estão localizadas no hipocótilo. Esta anormalidade na soja é muito comum, devido ao fato do eixo embrionário localizar-se em uma região muito exposta, sendo facilmente atingido por um impacto (JIÓN \& BARROS , 1983).

Altas porcentagens de tegumento rachado contribuem para o aumento do crescimento de fungos, reduzem o período de estocagem, aumentam a suscetibilidade à quebra durante o manuseio da semente (PAULSEN \& NAVE, 1977). Segundo MASON et al. (1982), a ocorrência de fungos em sementes pode predispor as sementes de soja a uma maior suscetibilidade ao dano mecânico.

O dano mecânico é uma das principais causas do baixo vigor em lotes de sementes. Durante o período de armazenamento, este vigor é ainda reduzido pelo aumento da taxa respiratória (consumo de energia) em regiões próximas aos danos na semente. Deste modo, o nível de energia para germinação em amostras de sementes após o armazenamento provavelmente será mais baixo do que o de uma semente com o mesmo tipo de dano no momento da colheita. Cada dano mecânico que afeta a semente, por pequeno que seja, é cumulativo e é parte integral do dano total da plântula, podendo reduzir seu poder germinativo, vigor inicial e rendimentos (BUNCH , 1960; JJÓN \& BARROS , 1983). 
No estudo do dano mecânico causado por várias técnicas de beneficiamento de grãos, encontrou-se que os grãos de soja são mais danificados conforme o aumento de queda livre (1,22 m, 2,17 m e 3,05 m), redução do seu teor de umidade $(12,7 \%, 11,0 \%$ e $10,7 \%)$ e redução do orificio de descarga dos grãos $(30,56$ e $20,37 \mathrm{~cm})$ sob duas diferentes superficies de impacto (concreto e grão de soja). Os tratamentos que apresentaram uma maior média percentual de grãos quebrados foram de 5,72\% (para a umidade de $10,7 \%$ ) e $5,63 \%$ (para a umidade de $11,0 \%$ ), na altura de queda livre de $3,05 \mathrm{~m}$ e $20,37 \mathrm{~cm}$ de abertura do orificio de descarga sobre a superficie de concreto (FISCUS et al., 1971).

O efeito do impacto mecânico sobre sementes de soja, varia conforme a posição de ocorrência do dano provocado, sendo que na região do eixo embrionário, posição oposta ao hilo, posição oposta à região do eixo embrionário, hilo e lado da semente, foram respectivamente, as posições que mais influenciaram para a queda do vigor (BARTSCH et al., 1986).

A queda de sementes de soja de diversas alturas é mais prejudicial para sementes enrugadas do que para sementes não enrugadas, tanto na germinação quanto no vigor, sendo, as primeiras, mais suscetíveis ao dano mecânico. A combinação do aumento da altura de queda, menor porcentagem de umidade dos lotes de sementes, menores temperaturas de armazenamento $\left(6,0 \mathrm{~m}, 8 \%\right.$ umidade e $\left.18^{\circ} \mathrm{C}\right)$ e sementes enrugadas, resultam em menores valores de germinação. Em amostras de sementes que não foram submetidas às quedas, com $13 \%$ de umidade, armazenadas à $21^{\circ} \mathrm{C}$ e não enrugadas, a porcentagem de germinação quase dobra em relação à combinação anterior (BURCHETT et al., 1985).

A relação do teor de umidade da semente e o percentual de dano mecânico tem sido amplamente estudado. Evidências têm mostrado uma correlação negativa entre a porcentagem de injúria e o conteúdo de umidade para Phaseolus vulgaris L., sendo que o menor teor de umidade das sementes aumenta o nível de danos (BARRIGA, 1961).

Lotes de sementes com baixos teores de umidade (8\%) apresentam germinação significativamente reduzida, tornando-os mais suscetiveis ao dano mecânico 'imediato' do que lotes de sementes de soja com maiores teores de umidade (13\%) (FAGUNDES, 1971; COPELAND, 1972; DELOUCHE, 1972; MOORE, 1972; POPINIGIS, 1972; SEDIYAMA et al., 1972; ZAPPIA, 1972; WALTERS \& 
CAVINESS, 1973; BYG, 1974; BURRIS, 1979; COSTA et al., 1979; LUEDDERS \& BURRIS, 1979; COSTA et al., 1982; JIJÓN \& BARROS , 1983; FRANÇA NETO \& HENNING, 1984; BURCHETT et al., 1985).

No entanto, segundo MESQUITA \& HANNA (1993), a eficiência da trilha aumenta com a redução de umidade nas sementes. Os autores reportaram que a umidade de $10 \%$ na vagem, necessita uma energia de 0,013 joules/vagem para provocar a debulha nos grãos. Esta energia é 4, 3 e 3 vezes menor do que a energia limite necessária para provocar danificações em sementes de soja nas posições de impacto na região paralela ao plano dos cotilédones, na região do hilo e na região oposta ao hilo, respectivamente, na umidade de 10,89\% na semente (MOREIRA et al., 1988/1989).

$\mathrm{O}$ efeito de diferentes métodos de trilha sobre a qualidade de sementes de soja, foi estudado durante dois anos (1976 e 1977) e observou-se que com o aumento da velocidade do cilindro de trilha de $300 \mathrm{rpm}$ houve um aumento em média de 5,3\% na porcentagem de dano mecânico na semente; de 400 rpm um aumento médio de 6,3\% e $500 \mathrm{rpm}$ um aumento médio de 8,2\%. Devido à diferença de umidade nas sementes trilhadas nos dois anos, 12,4\% em 1976 e 10,5\% em 1977, houve diferenças na porcentagem de danos nas diferentes velocidades de trilha, sendo a mais pronunciada na velocidade de $500 \mathrm{rpm}$, onde em 1976 apresentou 4,0\% de sementes danificadas em relação a $12,3 \%$ em 1977 , diferença esta devido provavelmente à diferença de umidade (SAINI et al., 1982).

O desenvolvimento de plântulas normais em soja, média de $95 \%$ de germinação, pode ser obtida em trilha manual de plantas nas umidades testadas $(8,12 \mathrm{e}$ $20 \%$ ). Entretanto, para trilha através de 'batida com galhos' e trilhadora, ambos apresentaram reduções na porcentagem de germinação e alta porcentagem de plântulas anormais nas umidades de $8 \%$ ( $84 \%$ de germinação para trilha através de 'batidas com galhos' e 68\% de germinação para trilhadora) e $12 \%(91,3 \%$ de germinação para trilha através de 'batidas com galhos' e $81,3 \%$ de germinação para trilhadora). Com alta umidade nas sementes $(20 \%)$ os diferentes métodos de trilha não afetaram a germinação imediatamente após a trilha (PRAKOBBOON, 1982).

No entanto, o efeito da injúria mecânica durante o processo de armazenamento por 12 semanas foram também quantificados, e os percentuais de plântulas anormais, nos teores de umidade de $8 \%$ e $12 \%$ evoluíram, quando comparados 
aos valores obtidos antes do armazenamento. A $20 \%$ de umidade onde não se tinha detectado o efeito do dano mecânico sobre a germinação antes do armazenamento (96\% de germinação), ocorreu uma redução na viabilidade e um aumento no tipo e número de anormalidades de plântulas durante a estocagem a $20^{\circ} \mathrm{C}$ e $35 \%$ de umidade relativa do ar ( $5 \%$ de plântulas anormais em colheita manual, $12 \%$ em 'batidas com galhos' e $20 \%$ em trilhadora), e especialmente sob condições adversas a $40^{\circ} \mathrm{C}$ e $35 \%$ de umidade relativa do ar (32\% de plântulas anormais em colheita manual, $38 \%$ em 'batidas com galhos' e $41 \%$ em trilhadora) (PRAKOBBOON, 1982). Com o aumento do teor de umidade nas sementes, há uma redução do dano mecânico imediato (visível), influenciando diretamente na germinação inicial, mas ocorre um aumento do dano mecânico latente (invisível) que será uma das causas principais da queda de germinação durante o armazenamento, devido ao progresso do processo de deterioração e conseqüente redução do vigor (ZINK, 1966; FAGUNDES, 1971; COPELAND, 1972; DELOUCHE, 1972; MOORE, 1972; COSTA et al., 1979).

Há uma tendência geral do aumento de sementes de soja rachadas e quebradas com o retardamento da colheita. Sementes deterioradas a campo pela ação de microorganismos e condições climáticas adversas são mais suscetíveis ao dano mecânico, tendo como conseqüência a redução da germinação e do vigor (GREEN et al., 1966; COPELAND, 1972; DELOUCHE, 1972; MOORE, 1972; POPINIGIS, 1972; SEDIYAMA et al., 1972; BYG, 1974; FRANÇA NETO \& POTTS , 1979; WOLF et al., 1981; MASON et al., 1982; BURCHETT et al., 1985).

Todo o organismo vivo menos vigoroso é afetado mais facilmente que aquele mais vigoroso; as sementes com baixo vigor, são mais suscetíveis às danificações mecânicas, sendo que os danos em pontos internos (latentes) são cumulativos até refletirem-se externamente (JJÓN \& BARROS , 1983).

Do mesmo modo, sementes inteiras quando danificadas deterioram-se mais rapidamente durante a armazenagem que sementes não danificadas, pois são mais suscetíveis aos danos por fumigação ou por volatilização de fungicidas e inseticidas. São também mais suscetíveis à entrada de patógenos e ao rápido desenvolvimento de doenças produzidas por esses microrganismos, podendo baixar o seu vigor (BUNCH, 1960).

Sementes de soja com tegumento impermeável são menos suscetíveis ao dano mecânico que as sementes com tegumento permeável, muito embora estas 
diferenças não possam ser atribuídas exclusivamente às diferenças de permeabilidade de tegumento (FRANÇA NETO \& POTTS, 1979).

Há indicações de que a trilha mecânica danifica mais severamente as sementes grandes de soja dentro de cada lote (GREEN et al., 1966; MOORE, 1972). STANWAY (1978) verificou que a germinação de sementes pequenas, tais como as do cultivar Forrest foi menos influenciada pela quebra do que sementes grandes de outros cultivares.

A resistência à compressão também é maior em sementes pequenas. Diferenças significativas entre sementes pequenas e médias foram encontradas a $11 \% \mathrm{e}$ $14 \%$ de umidade em posição horizontal ao hilo. Diferença significativa foi encontrada entre sementes médias e grandes somente a $17 \%$ de umidade em posição horizontal ao hilo. Com $8 \%$ de umidade encontraram-se diferenças entre sementes pequenas e médias tanto em compressão horizontal quanto vertical ao hilo, sendo que em umidades de $14 \%$ e $17 \%$ foram encontradas somente diferenças de resistência entre sementes pequenas e médias em posição vertical ao hilo (PAULSEN, 1978).

\subsubsection{Relações com a estrutura celular da semente}

O tegumento da semente de soja apresenta quatro camadas: cutícula, células paliçádicas ou macroesclerídeos (epiderme), osteoesclerídeos (hipoderme) e células do parênquima. As células da hipoderme, uma camada unicelular, são formadas por células do esclerênquima cuja parede celular tem espessura desuniforme, constituindo uma camada de suporte com considerável espaço intercelular. Este tipo de célula não é observado no hilo; entretanto, os osteoesclerídeos adjacentes ao hilo são maiores que nas áreas mais distanciadas, causando variação na espessura da camada de 30 a 70 microns (PESKE \& PEREIRA, 1983); esta camada de células também é conhecida como células colunares.

O estudo de tegumento de soja dos cultivares Bragg e Davis em microscópio eletrônico, mostra que as células colunares são altamente desenvolvidas na região subhilar, e que nos dois cultivares a espessura desta camada reduz-se 
gradualmente, desaparecendo na região oposta ao hilo. Acredita-se que esta camada de células funciona como uma espécie de 'almofada' na região subhilar, reduzindo a ocorrência do enrugamento causada pela hidratação e desidratação freqüente da semente, comum na região oposta ao hilo (PEREIRA \& ANDREWS, 1985).

O tegumento em soja não é uma barreira perfeita para a entrada de microrganismos na semente, porém, dependendo de sua estruturação, a contaminação pode ser substancialmente reduzida. Dentro de cada cultivar, a característica fisica das sementes é constante, sendo esta característica controlada geneticamente entre os cultivares (PESKE \& PEREIRA, 1983)

A menor espessura do tegumento e a menor porcentagem de lignina nos cultivares Clark-63 e Adelphia, comparadas às maiores espessura e porcentagem de lignina dos cultivares Portage e Merit, podem ser as razões da grande suscetibilidade das primeiras à rachadura do tegumento (AGRAWAL \& MENON, 1974).

Estudos realizados com feijão lima (Phaseolus lunatus L.), demonstram que, diretamente ou indiretamente, tegumento claro oferece menor proteção ao embrião que tegumento colorido. Uma vez que a função da lignina é primeiramente estrutural, sugere-se que o menor teor de lignina ( $1 \%$ do peso do tegumento) em tegumento claro é a causa principal de sua alta suscetibilidade a injúrias. Tegumento colorido possui, aproximadamente, $15 \%$ do peso em lignina. Observa-se também diferenças de espessura entre os tegumentos, sendo que os tegumentos claros são mais finos (KANNENBERG \& ALLARD, 1964). Em Phaseolus vulgaris L. o peso das sementes influencia a porcentagem de rachadura do tegumento (DORREL \& ADAMS, 1969).

Em soja, não há correlação entre espessura de tegumento e resistência ao dano mecânico, visto que Davis apresenta uma alta porcentagem de quebra de sementes e possui uma maior espessura de tegumento dentre os cultivares testados (CAVINESS \& SIMPSON JÚNIOR, 1974). 


\subsection{Variabilidade existente no germoplasma de soja}

A variabilidade no germoplasma de soja tem sido identificada sob os mais variados métodos de observação, número e condições de genótipos avaliados.

Utilizando um 'Impactador Centrífugo' para proporcionar o dano mecânico em sementes de soja nos cultivares Beeson, Corsoy e Williams, observou-se que, o cultivar Beeson possui uma maior suscetibilidade ao dano mecânico provocado, que os outros dois cultivares em todos os níveis de umidade testados. A porcentagem de dano na semente aumenta significativamente com a velocidade de impacto e o decréscimo do teor de umidade da semente (PAULSEN et al., 1981 a).

Em outro estudo, PAULSEN et al. (1981b) observou que a porcentagem de sementes danificadas dos cultivares Beeson e Williams, trilhadas em diferentes velocidades do cilindro batedor, cresceu com o aumento da velocidade; os autores também observaram diferenças na suscetibilidade de quebra entre os cultivares. $\mathrm{O}$ cultivar Beeson foi mais suscetível que o Williams. Outra observação encontrada para os dois cultivares é que em cada velocidade de trilha com a redução da porcentagem de umidade, aumentava a porcentagem de quebra da semente, ocorrendo o fato de dobrar a porcentagem de quebra quando a umidade passou de $16,7 \%$ para $11,5 \%$. O cultivar Beeson teve aproximadamente duas vezes mais tegumento danificado que o cultivar Williams.

$\mathrm{Na}$ avaliação de 18 cultivares de soja nos anos de 1985 e 1986, para a resistência ao dano mecânico observou-se que os cultivares Cristalina, Doko, EMGOPA 301, EMGOPA 302, e Bossier apresentaram menores porcentagens de sementes quebradas, sendo relativamente mais resistentes que os cultivares IAC-8, IAC-2, IAC-6, UFV-1 e Sucupira. O cultivar IAC-2 foi o cultivar mais suscetível ao dano mecânico. Nesta metodologia, plantas foram colhidas na maturação fisiológica e penduradas para secar até atingirem $12 \%$ de umidade nas sementes, quando estas eram trilhadas em uma trilhadora estacionária. A porcentagem de quebra das sementes era então determinada (COSTA et al., 1987).

Sementes de cinco genótipos (Davis, IAS-5, BR83-147, FT-2 e FT-10) foram avaliadas para identificar alguns possíveis mecanismos que determinam a qualidade 
fisiológica de sementes de soja, tendo sido observado que o cultivar IAS-5 é o mais suscetível ao dano mecânico e que o FT-2 é o menos suscetível (índice de semente quebrada e tetrazólio-nivel D.M. 6 a 8). O cultivar FT-10 também apresentou resultados semelhantes ao FT-2 (KRZYZANOWSKI et al., 1989).

\subsection{Melhoramento para qualidade fisiológica de sementes com ênfase no dano mecânico}

Para avaliação de diferenças varietais para qualidade de semente, deve-se ter meios para quantificação do vigor das sementes após sofrerem os estresses de campo e/ou de armazenamento (KUENEMAN, 1989). Métodos de laboratório para provocar os estresses em sementes também são eficientes; no entanto, qualquer que seja a metodologia empregada, o melhorista precisa de uma método rápido, repetitivel e pouco oneroso.

Os estudos envolvendo melhoramento para resistência da semente ao dano mecânico são raros, mas não menos importante que outra característica. São raros porque geralmente os trabalhos sobre dano mecânico são realizados por tecnologistas de sementes, e estes não estão preocupados em avaliar o dano para fins de melhoramento, mas sim para diferenciação de lotes de sementes para comercialização (qualidade do lote); isto ocorre porque os danos mecânicos em sementes de soja são muitas vezes responsáveis pela condenação de lotes de sementes ou redução do poder germinativo e vigor de sementes.

A proposta de COSTA et al. (1987), para seleção de genótipos de soja resistentes ao dano mecânico através do uso de uma trilhadora estacionária para provocar o dano nas sementes, é um método que necessita grandes quantidades de plantas para a trilha e não se tem controle sobre fatores como: nivel de danos de percevejos e umidade no campo, teor de umidade da amostra e tamanho de sementes. Deste modo, o uso para fins de melhoramento e seleção ficam prejudicados.

No estudo da determinação da energia limite exigida para danificar sementes de soja em diferentes umidades e posição de semente, MOREIRA et al. (1988/89) 
reportam uma metodologia eficiente na determinação do dano e suas relações com umidade e posição na semente, através do uso de uma máquina impactadora. No entanto, o uso rotineiro em programas de melhoramento não é considerado prático, mas pode ser utilizada em estudos básicos na identificação de diferenças varietais para fins determinação de padrões de resistência.

KUENEMAN (1989) relata os maleficios do dano mecânico em lotes de sementes de soja, a ocorrência de variabilidade genética e sugere para soja uma metodologia utilizada por indústrias de sementes de feijão (Phaseolus vulgaris $L_{\text {.) }}$ ) para seleção de lotes de sementes resistentes ao dano mecânico. Esta metodologia baseia-se na queda livre de sementes sobre um prato de aço com a inclinação de $12^{\circ}$.

No entanto, esta sugestão de KUENEMAN (1989) para o uso do 'teste de queda' não apresentou resultados satisfatórios, pois não separou os genótipos de soja testados em classes de resistência (CARBONELL et al., 1992). Foi proposto então por CARBONELL \& KRZYZANOWSKI (1995) o 'teste do pêndulo', que através da queda livre de um pêndulo de aço sobre sementes individualizadas em alvéolos de um disco de aço recebe um impacto de força conhecida. Relatam ainda que a melhor separação dos cultivares deu-se com a umidade de $13 \%$ (dentre $9 \%, 11 \%$ e $13 \%$ ) e altura de queda do pêndulo de $13 \mathrm{~cm}$ (dentre 11, 13 e 14,5 cm). Em outro trabalho, determinou-se que a avaliação do dano mecânico provocado poderia ser quantificado através do teste de tetrazólio ou hipoclorito de sódio (CARBONELL et al., 1993). Nestes estudos realizados, os cultivares IAS-5 e Paraná foram os mais resistentes e IAC-2 e Paranagoiana os mais suscetíveis.

A partir destes resultados, ALVAREZ (1994) propõe a metodologia de análise de lignina como alternativa de laboratório para seleção de genótipos resistentes ao dano mecânico em soja. Este trabalho relacionou os teores de lignina com os valores de dano mecânico medidos pelo 'teste do pêndulo', encontrando um coeficiente de determinação de 0,90 .

Todos estes resultados são iniciais na aplicação para o melhoramento. Por isso, há muito a se fazer para o entendimento e aperfeiçoamento destas metodologias de seleção. No entanto, tais resultados já fornecem subsídios aos melhoristas para uso rotineiro destas técnicas, com discriminação satisfatória de padrões de resistência e suscetibilidade. 


\subsection{Genética da qualidade de semente e resistência ao dano mecânico}

A herdabilidade do caráter qualidade de semente tem sido reportada para a soja com base em dados de germinação de plântulas em laboratório e emergência no campo (GREEN \& PINNELL, 1968a). Os autores estudaram seis populações segregantes $\mathrm{F}_{2}$ e $\mathrm{F}_{3}$ e estimaram a herdabilidade no sentido restrito de $3 \%$ a $29 \%$ para emergência no campo e $2 \%$ a $60 \%$ em testes de germinação em laboratório. Relatam ainda que a média de populações $F_{3}$ para o caráter qualidade de semente foi geralmente igual ou superior à média dos valores dos parentais. Em cada cruzamento, 10\% a 20\% das famílias $F_{3}$ excederam o valor do parental superior em dados de emergência no campo.

Com relação à herança de caracteres visuais nas sementes de soja relacionados com baixa germinação de plântulas em laboratório, GREEN \& PINNELL (1968b) estudando as mesmas populações, estimaram a herdabilidade de $6 \%$ a $30 \%$ para cotilédones enrugados, $10 \%$ a $38 \%$ para cotilédones com dobras e falhas, $0 \%$ e $29 \%$ para cotilédones verdes e $7 \%$ a $28 \%$ para notas visuais de aparência geral das sementes.

Estudando estas mesmas populações em gerações avançadas $\left(F_{5}\right.$ e $\left.F_{6}\right)$ para todos os caracteres estudados nas gerações $F_{2}$ e $F_{3}$, GREEN et al. (1971) reportaram baseados em dados de herdabilidade e ganhos na seleção, que entre todos os caracteres, os valores de germinação em laboratório e notas visuais de aparência geral das sementes, são os mais eficientes meios de obter ganhos na qualidade de sementes em programas de melhoramento.

A herança da resistência da semente ao dano mecânico em Phaseolus vulgaris L., foi pesquisada através do cruzamento entre três linhagens com sementes coloridas e duas com sementes brancas obtidas de seleções em populações $F_{7}$ resistentes ao dano mecânico. A herdabilidade no sentido restrito para a resistência ao dano mecânico variou de $22 \%$ a $73 \%$. Estes resultados foram obtidos através de quatro sucessivas quedas livres de amostras de 25 sementes de cada família das populações segregantes, de uma altura de $180 \mathrm{~cm}$ sob um prato de aço inclinado a $26^{\circ} \mathrm{em} 1975 \mathrm{e}$ $12^{\circ} \mathrm{em} 1976$ (DICKSON \& BOETTGER, 1977). 
Sementes de feijão remanescentes de populações segregantes $F_{3}$ provenientes de cruzamentos entre um parental suscetivel e outro resistente, foram submetidas a 16 quedas livres consecutivas. Sementes $F_{4}$ que sobreviveram às quedas livres da população $F_{3}$, germinaram bem melhor que as sementes do parental suscetível não submetido à queda livre de suas sementes. Isto sugere que em feijão, o melhorista pode usar esta técnica de se fazer um cruzamento entre uma linhagem suscetível e outra resistente e avançar as gerações de autofecundação na forma de populações de sementes viáveis, sendo que antes de serem semeados, devem ser analisados para remoção de todas as sementes visualmente danificadas. Após a semeadura, deve-se realizar uma inspeção nas populações para eliminação de plântulas com sinais de danos mecânicos (sem epicótilo). Esta técnica de obtenção de linhagens resistentes ao dano mecânico requer um mínimo de trabalho do melhorista e custo reduzido na operação (DICKSON \& BOETTGER, 1977).

Em soja, não foram encontrados registros em literatura sobre a genética da resistência da semente ao dano mecânico. 


\section{MATERIAL E MÉTODOS}

\subsection{Material genético}

$O$ material genético utilizado nesta pesquisa compreendeu dez linhagens $F_{7: 5}$ e $\mathrm{F}_{8: 5}$ de cada um dos 45 cruzamentos oriundos do dialelo entre dez parentais precoces de soja, totalizando 450 progênies (Apêndice 1). Estas linhagens foram desenvolvidas pelo Setor de Genética Aplicada às Espécies Autógamas, Departamento de Genética, Escola Superior de Agricultura "Luiz de Queiroz", Universidade de São Paulo. Os parentais foram escolhidos segundo os critérios de: precocidade, diversidade analisada pelas genealogias e valor agronômico satisfatório. No Apêndice 2, são apresentadas algumas características desses genótipos parentais.

Os cultivares Paraná, IAC-Foscarin-31, Primavera e IAS-5 foram utilizados como padrões de ciclo e produtividade nos dois anos de avaliação. Os cultivares IAS-5 e IAC-2 (semeado somente no segundo ano de avaliação), foram utilizados como padrões de resistência e suscetibilidade ao dano mecânico, respectivamente, como determinado por CARBONELL (1991).

\subsubsection{Obtenção de sementes $F_{1}$ e gerações segregantes}

Todos os cruzamentos possiveis entre os dez $(\mathrm{n})$ parentais, com exceção dos recíprocos, num total de $[\mathrm{n}(\mathrm{n}-1) / 2]=45$ foram realizados em telado no segundo semestre de 1985, seguindo um esquema de cruzamentos dialélicos (Tabela 1). Os 45 cruzamentos foram avançados pelo método SHDT ("single hill descent thinned") a partir da geração $F_{2}$ e conduzidos na forma de uma planta/cova (VELLO, 1992), no campo experimental do Departamento de Genética, ESALQ/USP, em Piracicaba, SP. 


\subsubsection{Material genético utilizado nos experimentos}

Na safra de 1989/90 foram selecionadas as dez melhores plantas $F_{5}$ de cada cruzamento baseado em dados de acamamento, altura de planta, ciclo, valor agronômico e produção de grãos. As linhagens experimentais $F_{6: 5}$ foram avançadas para $F_{7: 5}$ (semeadura em 03/12/1991), a qual foi utilizada para o primeiro ano de avaliação do dano mecânico. $O$ segundo ano de avaliação foi feito com linhagens experimentais $F_{8: 5}$ semeado em 02/12/1992.

\subsection{Delineamento e características dos experimentos}

Utilizou-se o delineamento experimental de blocos casualizados contendo quatro repetições, onde foram avaliados os 45 cruzamentos (dez linhagens por cruzamento), quatro testemunhas e os dez parentais, totalizando 464 tratamentos. Este delineamento em campo teve o objetivo principal de eliminar qualquer efeito ambiental existente na área de semeadura utilizada, que posteriormente viesse à influenciar na qualidade da semente produzida.

Os experimentos foram semeados em dois anos agrícolas com semeaduras em 03/12/1991 e 02/12/1992 com o mesmo delineamento experimental. No experimento semeado em 02/12/1992 foi acrescentado mais uma testemunha, o cultivar IAC-2, classificado como padrão de suscetibilidade ao dano mecânico por CARBONELL (1991).

A parcela experimental foi representada por uma fileira de $2,0 \times 0,50$ metros

$\left(1 \mathrm{~m}^{2}\right)$. Na semeadura, efetuou-se a adubação na fileira com $25 \mathrm{~g} / \mathrm{m}$ linear da fórmula NPK 0-30-10, bem como a inoculação com Bradyrhizobium japonicum. Irrigações suplementares, capina e tratamentos com inseticidas foram realizados quando necessários. 


\subsection{Caracteres avaliados}

Os caracteres avaliados nas parcelas experimentais foram os seguintes:

APM : altura de planta na maturidade; corresponde à medida em centímetros da base da planta (no solo) até o ápice da haste principal;

PG : produção de grãos; corresponde ao peso, em gramas, dos grãos da parcela $\left(\mathrm{g} / \mathrm{m}^{2}\right)$;

DM : dano mecânico; corresponde ao dano mecânico provocado pela queda do pêndulo sobre as sementes; média ponderada em uma amostra contendo 50 sementes.

\subsection{Testes preliminares}

Devido ao fato do teor de umidade nas sementes ser um fator de extrema importância na determinação dos valores de dano mecânico (CARBONELL, 1991), foram realizados experimentos preliminares para determinação de uma metodologia de acondicionamento e manutenção constante de umidade em todas as amostras a serem danificadas, se possível na umidade de $13 \pm 0,5 \%$ que segundo CARBONELL (1991) melhor separou os genótipos estudados em classes de resistência. Deste modo, amostras de sementes dos cultivares Paraná, Primavera e IAC-Foscarin-31, escolhidos de acordo com a disponibilidade de sementes, foram acondicionadas em sacos de papel e colocadas em câmara seca $\left(26^{\circ} \mathrm{C}\right.$ e $40 \%$ de umidade relativa do ar) por um período de quatro meses aproximadamente, período pelo qual estas sementes obtiveram uniformidade na umidade entre as amostras de 7,0\% (equilíbrio higroscópico).

Este equilibrio higroscópico inicial, que é função fundamentalmente, da espécie, da umidade relativa, da temperatura e do fenômeno conhecido como histerese (SILVA, 1986), é importante de ser obtido para atenuar os efeitos da histerese no momento da hidratação ou secagem das sementes, que não estão em equilíbrio higroscópico. Histerese pode ser definida, simplificadamente, como o fenômeno das 
sementes atingirem graus de umidades diferentes sob uma mesma umidade relativa e temperatura, devido ao fato de possuírem graus de umidades iniciais diferentes.

Após o acondicionamento inicial, as amostras de sementes foram retiradas da câmara seca, deixadas em temperatura e umidade relativa ambiente dentro do laboratório ( $30{ }^{\circ} \mathrm{C}$ e $60 \%$ Urar) por um período de 24 horas, para a absorção lenta de umidade inicial e não provocar danos de embebição rápida à semente. As amostras então foram uniformizadas por espessura $(5 \mathrm{~mm})$ e submetidas à análise visual (olho desarmado) para a retirada de todas as sementes danificadas por percevejo, mecanicamente ou deterioração por umidade.

A seguir, amostras de 100 sementes foram pesadas e colocadas no interior de uma câmara de crescimento com uma temperatura de $25{ }^{\circ} \mathrm{C}$ e umidade relativa de aproximadamente $85 \%$, obtida com o uso de bandejas $(40 \times 30 \times 10 \mathrm{~cm})$ com uma lâmina d'agua de três centímetros no seu interior. Estes valores de temperatura e umidade foram monitorados através de um termohigrógrafo.

Durante quatro dias, a cada 24 horas foram retiradas quatro amostras de cada cultivar; estas amostras foram submetidas à determinação de umidade pelo método de estufa a $105^{\circ} \mathrm{C}$ por 24 horas, segundo as Regras de Análise de Sementes (BRASIl, 1976).

\subsection{Metodologia do 'teste do pêndulo'}

O 'teste do pêndulo', metodologia proposta por CARBONELL (1991), basicamente pode ser dividida em duas partes: a primeira sob o ponto de vista dos procedimentos ao nivel de campo e a segunda ao nivel de laboratório. Para esta pesquisa, alterações foram realizadas na metodologia original, visando sempre, quando possivel, tornar a metodologia mais prática e rápida, devido ao grande número de genótipos avaliados.

A metodologia do 'teste do pêndulo' proposta por CARBONELL (1991) baseia-se resumidamente em: 1. colheita de plantas no estádio de maturação fisiológica $\left(R_{7}\right) ; 2$. trilha manual de suas sementes; 3. secagem destas sementes até 
atingirem a umidade de $13 \%$; 4. uniformização das sementes por tamanho (uso de peneiras); 5. retirada de todas as sementes visualmente danificadas por percevejos, mecanicamente ou deterioração por umidade; 6. amostragem de 100 sementes; 7. provocar o dano mecânico através da queda livre $(13 \mathrm{~cm})$ de um pêndulo metálico (com energia de impacto conhecida) sobre sementes individualizadas em um disco de ferro; 8. avaliação do dano mecânico provocado através do teste de tetrazólio e/ou hipoclorito de sódio e 9. quantificação do dano mecânico através de cálculos baseados no nivel de dano nas sementes avaliadas.

Maiores detalhes desta metodologia, bem como as modificações realizadas neste trabalho, serão descritas à seguir.

\subsubsection{Procedimentos no campo}

Nas parcelas experimentais, foram colhidas aproximadamente cinco plantas nos estádios de maturação fisiológica $\left(\mathrm{R}_{7}\right)$ no experimento com semeadura em 03/12/1991 e de maturação morfológica $\left(R_{8}\right)$ no experimento com na semeadura em $02 / 12 / 1992$.

As plantas provenientes da semeadura de 03/12/1991 $\left(\mathrm{F}_{7: 5}\right)$ por ainda apresentarem folhas e alta umidade nas sementes, foram desfolhadas e colocadas para secar sob esteiras de tela de arame em galpão ventilado para que ocorresse inicialmente uma perda gradual de umidade nas sementes antes das vagens serem debulhadas. Após este período de secagem, as vagens foram debulhadas manualmente, propiciando o menor dano possível às sementes antes do teste.

As plantas provenientes da semeadura de $02 / 12 / 1992\left(\mathrm{~F}_{8: 5}\right)$ foram trilhadas imediatamente após a colheita com o auxílio de uma caixa de madeira para batida das plantas em suas feces internas, tendo-se sempre o cuidado de não causar danos às sementes. Esta modificação tem o objetivo de tornar o método de obtenção de sementes mais rápido e prático. 


\subsubsection{Procedimentos no laboratório}

\subsubsection{Obtenção das amostras}

Após todo o processo de trilha e secagem das sementes, houve a necessidade de uma uniformização da espessura das sementes $(5,0 \mathrm{~mm})$ antes da retirada das amostras de 100 sementes de cada tratamento para serem submetidas ao dano mecânico, pois a massa da semente é uma variável envolvida na absorção da energia cinética resultante da queda livre do pêndulo (BURRIS, 1979).

Esta uniformização deu-se pela passagem das sementes pela peneira de $5,5 \mathrm{~mm}$ e retenção sobre a peneira de $5,0 \mathrm{~mm}$. As sementes remanescentes sobre a peneira de $6,75 \mathrm{~mm}$ constituíram a fonte de sementes para a amostragem, sendo estas submetidas a uma análise visual sem o uso de lentes de aumento (olho desarmado) para retirada de todas as sementes danificadas por percevejo, umidade ou mecanicamente, que podem interferir nos resultados de reação ao dano mecânico. Com isto, pode-se avaliar o efeito isolado do dano provocado pelo 'teste do pêndulo'.

Desta amostra de 100 sementes por tratamento, 50 foram submetidas ao impacto do pêndulo (subamostra 1). As outras 50 sementes foram analisadas em teste de hipoclorito de sódio (subamostra 2), para quantificar os possíveis danos provocados durante o processo de trilha.

Nas amostras dos dez parentais, quatro padrões e linhagens de cinco cruzamentos aleatoriamente amostrados, foram avaliados o potencial de germinação nos dois anos na subamostra 2 em análise pelo método do papel toalha descrito pelas Regras de Análises de Sementes (BRASI, 1976). Esta avaliação, realizada nos dois experimentos (semeaduras em 03/12/1991 e 02/12/1992) e considerando-se a amostra aleatória de cinco cruzamentos, forneceram informações sobre os efeitos da qualidade fisiológica de sementes (expressas em valores percentuais de germinação), sobre a suscetibilidade ao dano mecânico provocado. 


\subsubsection{Dano mecânico}

O dano mecânico provocado, baseia-se na queda livre de um pêndulo metálico sobre sementes de soja distribuídas individualmente em alvéolos de um disco metálico, como está ilustrado na Figura 1. Nesta metodologia é necessário apenas uma queda livre do pêndulo sobre a semente para provocar o dano, no entanto, o local de impacto na semente é considerado um fator não controlável.

A altura de queda deste pêndulo, determinada por CARBONELL (1991), que melhor separou os genótipos estudados em classes de resistência foi a de 13 $\mathrm{cm}$, no entanto, devido às modificações realizadas na metodologia de obtenção de sementes a campo, optou-se pelo uso da altura de $11 \mathrm{~cm}$, que segundo este autor também é eficiente na discriminação de genótipos.

Segundo BURRIS (1979) a força aplicada sobre as sementes é proporcional à energia potencial contida no pêndulo, e logicamente à energia cinética transmitida à semente segundo a equação abaixo.

$$
\mathrm{EP}=\mathrm{EC}=\mathrm{m} \cdot \mathrm{g} \cdot \mathrm{h}
$$

onde:

$E P$ : energia potencial do pêndulo $=0,2695 \mathrm{j}$;

EC : energia cinética do pêndulo aplicada sobre a semente $=0,2695 \mathrm{j}$;

$\mathrm{m}$ : massa do pêndulo $=0,25 \mathrm{~kg}$;

g : aceleração da gravidade $=9,8 \mathrm{~m} / \mathrm{s}^{2} \mathrm{e}$

h : altura de queda livre do pêndulo $=0,11 \mathrm{~m}$.

As energias limites determinadas por MOREIRA et al. (1988/1989) para provocar danificações em sementes de soja com umidade de $12,8 \%$ foram de $0,0525 \mathrm{j}$, 0,0657 j e $0,0657 \mathrm{j}$ para as posições de impacto na região paralela ao plano de separação dos cotilédones, na região do hilo e na região oposta ao hilo, respectivamente. Estes valores são 5,13, 4,10 e 4,10 vezes menores que o utilizado pelo teste do pêndulo que intencionalmente tem o objetivo de provocar danos nas sementes. 
Sendo a capacidade do disco metálico utilizado de 50 sementes, foram necessários em média 2 minutos entre a distribuição da subamostra 1 nos alvéolos do prato metálico e a realização do dano.

$\mathrm{O}$ dano mecânico provocado pelo pêndulo foi avaliado pelo teste de hipoclorito de sódio, por ser um teste rápido, ter custo reduzido e de fácil execução (CARBONELL et al., 1993). Este teste, identifica toda a semente que apresenta ruptura em seu tegumento, pela observação do entumescimento de seus cotilédones causado pela rápida penetração da solução de hipoclorito (5 a 10 minutos) (VAUGHAN, 1982).

$\mathrm{O}$ teste de hipoclorito de sódio apresenta menores valores de danos que os detectados pelos testes de tetrazólio e de acetato de indoxil. Isto se deve talvez, porque sementes com pequenos danos não absorvem solução suficiente para o intumescimento das sementes no período de cinco minutos (PAULSEN \& NAVE, 1979). Por isso, optouse pelo prolongamento deste período para 10 a 15 minutos de embebição das sementes em solução de hipoclorito de sódio com água destilada (solução estoque - 5,25\%). Para o preparo da solução de trabalho, adicionaram-se $25 \mathrm{ml}$ da solução estoque em $975 \mathrm{ml}$ de água destilada.

\subsubsection{Procedimento para quantificar o valor do dano mecânico}

Para a avaliação dos resultados após o dano provocado, foi utilizada a análise visual (olho desarmado) para a separação de todas as sementes trincadas e quebradas, seguido do teste de hipoclorito de sódio.O cálculo ponderado do valor do dano mecânico (DM), foram conferidos índices de suscetibilidade aos tipos de sementes obtidas após a realização do dano, como segue:

Tipo de sementes (classes) Índice de suscetibilidade

Sementes quebradas (SQ) 10

Sementes danificadas (SD) 6

Sementes intumescidas (SI) 2

Sementes não intumescidas (sem dano) (SNI) 0 onde cada classe de semente corresponde a um tipo de dano: 
- Sementes quebradas (SQ)

- Sementes danificadas (SD)

- Sementes intumescidas (SI)
: são sementes visualmente esmagadas, partidas e com danos bem acentuados; : são sementes com danificações que embora visíveis (olho desarmado), não apresentam cotilédones partidos ou parcialmente partidos.

: são sementes que possuem danos não visíveis a olho desarmado, mas que com o uso da solução de hipoclorito de sódio tornam-se visíveis.

- Sementes não intumescidas (SNI) : são sementes submetidas ao hipoclorito de sódio e que não intumescem, indicando não haver danificações visuais significativas.

Com o uso destas classes e índices pode-se determinar um único valor ponderado e expresso em unidades de dano mecânico ( $\mathrm{udm}$ ), variando de zero à dez, sendo o valor zero correspondente à máxima resistência e o valor dez a máxima suscetibilidade.

$$
\mathrm{DM}=\frac{\mathrm{SQ} \times 10+\mathrm{SD} \times 6+\mathrm{SI} \times 2+\mathrm{SNI} \times 0}{\mathrm{SQ}+\mathrm{SD}+\mathrm{SI}+\mathrm{SNI}}
$$

onde:

DM : dano mecânico (udm);

SQ : sementes quebradas;

SD : sementes danificadas;

SI : sementes intumescidas e

SNI : sementes não intumescidas.

\subsection{Análises estatístico-genéticas}

As análises estatístico-genéticas foram realizadas com $o$ auxilio de programas de computador, mais precisamente do pacote estatístico S.A.S., a partir de 
dados obtidos na parcela experimental. Os valores destas observações para as variáveis que envolvem porcentagem (dados de germinação), foram todos transformados utilizando $\operatorname{Arcsen} \sqrt{\%}$ para aproximação à distribuição normal.

As análises referentes ao dano mecânico (DM) no experimento com semeadura em 03/12/1991 foram baseadas em dados dos dez parentais, quatro testemunhas e cinco cruzamentos (aleatoriamente amostrados) contendo dez linhagens por cruzamento. No experimento com semeadura em 02/12/1992, os 45 cruzamentos contendo dez linhagens cada, participaram da análise de DM. Os caracteres altura de planta na maturação (APM) e produção de grãos (PG) foram analisados igualmente nas duas épocas de semeadura, envolvendo as linhagens dos 45 cruzamentos, os parentais e testemunhas.

\subsubsection{Análise de resíduos}

Através da análise de resíduo para cada variável estudada por ano, pode-se verificar a validade do delineamento proposto e dos pré-requisitos para a realização das subseqüentes análises de variâncias. Com este método, verifica-se se existem dados discrepantes, também chamados 'outliers'. Pela distribuição gráfica dos resíduos padronizados pode-se detectar os 'outliers', a falta de homogeneidade de variâncias dos erros e da não normalidade destes, dependência dos erros e a não aditividade do modelo matemático.

No método da análise de resíduos é utilizada a análise gráfica entre os resíduos padronizados e o valor esperado (PARENTE, 1984). Estes resíduos foram determinados segundo a equação abaixo:

$$
\mathrm{d}_{\mathrm{ij}}=\frac{\mathrm{e}_{\mathrm{ij}}}{\sqrt{Q M \operatorname{Re} s}}
$$

onde: 
$\mathrm{d}_{\mathrm{ij}}$ : resíduo padronizado;

$\mathrm{e}_{\mathrm{ij}}$ : é o resíduo obtido através do modelo estatístico escolhido

$$
\begin{gathered}
e_{\mathrm{ij}}=\left[\mathrm{Y}_{\mathrm{ij}}(\text { observado })-\mathrm{Y}_{\mathrm{ij}}(\text { esperado })\right] \\
\mathrm{Y}_{\mathrm{ij}}(\text { esperado })=\hat{m}+\hat{t}_{\mathrm{i}}+\hat{b}_{\mathrm{j}}
\end{gathered}
$$

QMRes. : é o quadrado médio do resíduo obtido através da análise de variância.

As análises de resíduo foram realizadas com o uso de um programa de computador que utiliza o pacote estatístico S.A.S., sendo que na identificação de parcelas 'outliers' estas foram retiradas. Utilizou-se novamente o programa de análise de resíduos e os valores preditos (esperados) para estas parcelas foram utilizados nas análises subseqüentes. Segundo CZERMAINSKI (1986), a substituição do 'outlier' pela correspondente estimativa mostra-se satisfatória nos exemplos discutidos em sua pesquisa.

\subsubsection{Análises de variância}

Foram realizadas duas análises de variância para cada caráter ao nível de médias das parcelas, uma baseada somente nos dados anuais (por semeadura) e outra baseado na análise conjunta dos dois anos agrícolas. Seguiu-se o modelo linear descrito em blocos casualizados nas duas análises, com respectivos desdobramentos de suas fontes de variação pela decomposição dos quadrados médios. Os tratamentos foram divididos em três grupos: parentais, linhagens (cruzamentos) e testemunhas.

As análises de variância (ANAVA) por semeadura e conjunta, foram realizadas com o auxilio de um programa de computador do pacote estatístico S.A.S. para o cálculo das somas de quadrados das fontes de variação e seus respectivos desdobramentos. Para a determinação das esperanças dos quadrados médios das ANAVAS por experimento e conjunta utilizou-se o procedimento VARCOMP (método 
tipo 1) do S.A.S., que utiliza um sistema de equações reportado por GAYLOR et al. (1970).

Nestas análises, o modelo matemático é tido como misto, pois é composto por efeitos fixos nos componentes de observação para parentais e testemunhas e aleatório para repetições, anos e linhagens. Embora tenha sido realizada na geração $F_{5}$ uma seleção das dez linhagens de cada cruzamento, considerou-se as variáveis APM, PG e DM aleatórias para estes caracteres, ou seja, considerou-se a amostra de dez linhagens como representante do potencial máximo de cada cruzamento.

\subsubsection{Análise individual por experimento}

O modelo linear analisado em blocos casualizados por semeadura é descrito a seguir, sendo os esquemas com os devidos quadrados médios, esperanças matemáticas dos quadrados médios e respectivos desdobramentos da soma de quadrados das fontes de variação, detalhados na Tabela 2.

$$
Y_{i(j) k}=\mu+t_{i(j)}+b_{k}+e_{i(j) k}
$$

onde:

$$
\begin{aligned}
& Y_{i(j) k} \text { : valor observado na unidade experimental do bloco } k \text { que recebeu o } \\
& \mu \quad \text { : média geral do experimento; } \\
& t_{i(j)} \text { : efeito do tratamento i dentro do grupo } j \text {, sendo: } \\
& i=i \text { ', efeito fixo dos parentais dentro do grupo j'; } \\
& i=i \text { ", efeito fixo das testemunhas dentro do grupo j"; } \\
& \mathrm{i}=\mathrm{i} \text {, efeito aleatório das linhagens dentro do grupo } \mathrm{j} \text {; } \\
& b_{k} \text { : efeito aleatório do bloco } k \text {; } \\
& e_{i(j) k} \text { : efeito aleatório do erro experimental, associado a } \mathrm{Y}_{\mathrm{i}(\mathrm{j}) \mathrm{k}} \text {, admitido ser normal } \\
& \text { e independentemente distribuído com média zero e variância } \sigma^{2} \text {. }
\end{aligned}
$$




\subsubsection{Análise conjunta dos experimentos}

O modelo linear analisado em blocos casualizados na análise conjunta é descrito a seguir, sendo os esquemas com os devidos quadrados médios, esperanças matemáticas dos quadrados médios e respectivos desdobramentos da soma de quadrados das fontes de variação, detalhados nas Tabelas 3 e 4.

$$
Y_{i(j) k(1)}=\mu+a_{1}+t_{i(j)}+b_{k}+e_{i(j) k(1)}
$$

onde:

$\mathrm{Y}_{\mathrm{i}(\mathrm{j}) \mathbf{k}(1)}$ : valor observado na unidade experimental do bloco $\mathrm{k}$ dentro de 1 que recebeu o tratamento i dentro do grupo $\mathrm{j}$;

$\mu \quad$ : média geral do experimento;

$a_{1}$ : efeito aleatório do ano l;

$t_{i(j)}$ : efeito do tratamento i dentro do grupo $j$, sendo:

$i=i$ ', efeito fixo de parental dentro do grupo j';

$\mathrm{i}=\mathrm{i}$ ", efeito fixo das testemunhas dentro do grupo $\mathrm{j}$ ";

$\mathrm{i}=\mathrm{i}$, efeito aleatório das linhagens dentro do grupo j;

$b_{k(1)}$ : efeito aleatório do bloco $\mathrm{k}$ dentro do ano l;

$\mathrm{e}_{\mathrm{i}(\mathrm{j}) \mathrm{k}(1)}$ : efeito aleatório do erro experimental, associado a $\mathrm{Y}_{\mathrm{i}(\mathrm{j}) \mathbf{k}(\mathbf{l})}$, admitido ser normal e independentemente distribuído com média zero e variância $\sigma^{2}$. 


\subsubsection{Correlação entre caracteres}

\subsubsection{Correlação fenotípica de ordem}

A medida do grau de associação entre duas variáveis foi realizado com o auxílio de um programa de computador que utiliza o pacote estatístico S.A.S., baseado na correlação simples de Spearman. Este estimador, baseado no 'ranks' das variáveis, segue a expressão:

$$
r_{s}=\frac{\sum\left(R_{i}-\bar{R}\right)\left(S_{i}-\bar{S}\right)}{\sqrt{\left[\sum\left(R_{i}-\bar{R}\right)^{2} \sum\left(S_{i}-\bar{S}\right)^{2}\right]}}
$$

onde:

$$
\begin{array}{ll}
\mathrm{R}_{\mathrm{i}} & : \text { é a ordem do i-ésimo valor de } \mathrm{x} ; \\
\mathrm{S}_{\mathrm{i}} & : \text { é a ordem do i-ésimo valor de } \mathrm{y} ; \\
\bar{R} & \text { e } \bar{S}: \text { : são as médias de } \mathrm{R}_{\mathrm{i}} \text { e } \mathrm{S}_{\mathrm{i}} .
\end{array}
$$

Esta correlação foi utilizada para medir o grau de associação na análise de variância conjunta contendo o grupo de parentais, testemunhas e linhagens provenientes de cinco cruzamentos aleatoriamente amostrados, entre as variáveis:

- Dano mecânico (DM) e Germinação de sementes (G);

- Dano mecânico (DM) e Sementes duras (SDu);

- Germinação de sementes (G) e Sementes duras (Sdu); 


\subsubsection{Correlações genotípica, fenotípica e de ambiente}

Os coeficientes de correlação fenotípica $\left(\mathrm{r}_{\mathrm{F}}\right)$, genotípica $\left(\mathrm{r}_{\mathrm{G}}\right)$ e de ambiente $\left(\mathrm{r}_{\mathrm{E}}\right)$ entre os pares de caracteres foram obtidos através das respectivas estimativas da variância e covariância, com base na expressão apresentada por KEMPTHORNE (1969). Todos os cálculos para a obtenção destas estimativas foram obtidos através do uso de um programa de computador do pacote estatístico S.A.S., somente para o grupo de linhagens que apresentam efeitos aleatórios, entre os caracteres DM, APM e PG.

$$
V(X+Y)=V(X)+V(Y)+2 \operatorname{COV}(X+Y)
$$

logo:

$$
\operatorname{COV}(X, Y)=\frac{V(X+Y)-V(X)-V(Y)}{2}
$$

onde:

$\operatorname{COV}(\mathrm{X}, \mathrm{Y}) \quad$ : covariância entre os caracteres $\mathrm{X}$ e $\mathrm{Y}$;

$\mathrm{V}(\mathrm{X})$ e $\mathrm{V}(\mathrm{Y})$ : variância dos caracteres $\mathrm{X}$ e $\mathrm{Y}$, respectivamente;

$\mathrm{V}(\mathrm{X}+\mathrm{Y}) \quad$ : variância da soma dos caracteres $\mathrm{X}$ e $\mathrm{Y}$.

A partir das covariâncias, foram estimados os coeficientes de correlação baseados nas seguintes fórmulas:

a) Coeficiente de correlação fenotípica $\left(\mathrm{r}_{\mathrm{F}}\right)$

$$
r_{F(X, Y)}=\frac{\operatorname{Cov}_{F}(X, Y)}{\sqrt{\overline{V_{F}(X) \cdot V_{F}(Y)}}}
$$

onde:

$\operatorname{COV}_{\mathrm{F}}(\mathrm{X}, \mathrm{Y})$ : estimativa da covariância fenotípica para o par de caracteres $\mathrm{X}$ e $\mathrm{Y}$; $V_{F}(X)$ e $V_{F}(Y)$ : estimativas da variância fenotípica dos caracteres $X$ e $Y$. 
b) Coeficiente de correlação genotípica $\left(\mathrm{r}_{\mathrm{G}}\right)$

$$
r_{G(X, Y)}=\frac{\operatorname{COV}_{G}(X, Y)}{\sqrt{V_{G}(X) \cdot V_{G}(Y)}}
$$

onde;

$$
C O V_{G(X, Y)}=\frac{\operatorname{COV}_{F}(X, Y)-\operatorname{COV}_{E}(X, Y)}{r} .
$$

sendo:

$\operatorname{COV}_{\mathrm{G}}(\mathrm{X}, \mathrm{Y})$ : estimativa da covariância genotípica para o par de caracteres $\mathrm{X}$ e $\mathrm{Y}$; $\operatorname{COV}_{\mathrm{F}}(\mathrm{X}, \mathrm{Y})$ : estimativa da covariância fenotípica para o par de caracteres $\mathrm{X}$ e $\mathrm{Y}$; $\operatorname{COV}_{\mathrm{E}}(\mathrm{X}, \mathrm{Y})$ : estimativa da covariância ambiental para o par de caracteres $\mathrm{X}$ e $\mathrm{Y}$; $\mathrm{V}_{\mathrm{G}}(\mathrm{X})$ e $\mathrm{V}_{\mathrm{G}}(\mathrm{Y})$ : estimativas da variância genotípica dos caracteres $\mathrm{X}$ e $\mathrm{Y}$; $\mathrm{r}$ : número de repetições.

c) Coeficiente de correlação ambiental ( $\left.\mathrm{r}_{\mathrm{E}}\right)$

$$
r_{E}=\frac{\operatorname{COV}_{E}(X, Y)}{\sqrt{V_{E}(X) \cdot V_{E}(Y)}}
$$

onde:

$\operatorname{COV}_{\mathrm{E}}(\mathrm{X}, \mathrm{Y})$ : estimativa da covariância ambiental para o par de caracteres $\mathrm{X}$ e $\mathrm{Y}$; $\mathrm{V}_{\mathrm{E}}(\mathrm{X})$ e $\mathrm{V}_{\mathrm{E}}(\mathrm{Y})$ : estimativas da variância de ambiente dos caracteres $\mathrm{X}$ e $\mathrm{Y}$; 


\subsubsection{Regressão linear múltipla}

À partir dos resultados de DM (dano mecânico=udm) obtidos atravéz das análises laboratoriais do conjunto de observações de SQ (sementes quebradas), SD (sementes danificadas) e SI (sementes intumescidas), estudou-se a possibilidade, através da regressão linear múltipla, de se determinar qual ou quais destas observações estão mais relacionados com os valores de DM obtidos.

Para obtenção destas regressões, utilizou-se um programa estatístico do pacote SAS denominado PROC STEPWISE (SAS Institute, 1982) e procedimento STEPWISE (STRAP) descrito por DRAPER \& SMITH (1966), entre a variável dependente DM e as variáveis independentes SQ, SD e SI, segundo o modelo:

$$
\mathrm{Y}=\mathrm{bX} \mathrm{X}_{\mathrm{o}}+\mathrm{bX_{1 }}+\mathrm{bX_{2 }}+\mathrm{bX}
$$

onde:

Y : variável dependente (DM);

b : coeficiente de regressão estimado em função dos dados;

$X_{0}$ : valor da variável $Y$ quando $X=0$ ('intercept') e

$\mathrm{X}_{1}, \mathrm{X}_{2}$ e $\mathrm{X}_{3}$ : valores das variáveis independentes (SQ, SD e SI).

Para seleção das equações que melhor explicam o efeito das variáveis independentes em estudo, foi utilizado o coeficiente de determinação múltiplo $\left(R^{2}\right)$, onde quanto maior o $\mathrm{R}^{2}$, melhor a equação.

$\mathrm{O}$ valor de $\mathrm{R}^{2}$ é calculado com base na análise de variância do modelo e segundo a equação:

$$
\begin{aligned}
& \text { SQregressão }
\end{aligned}
$$

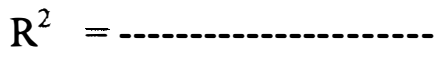

$$
\begin{aligned}
& \text { SQtotal }
\end{aligned}
$$

onde: SQ: soma de quadrados obtido nas ANAVAS. 
Os valores utilizados para esta análise são números absolutos de sementes observadas dentro de cada classe de dano na semente (SQ, SD e SI), avaliadas visualmente (SQ e SD) e através da embebição no hipoclorito de sódio (SI).

\subsubsection{Contribuição relativa de efeitos genéticos vs. efeitos (genéticos + ambientais)}

As contribuições relativas expressas em porcentagem foram realizadas no grupo de linhagens em dados de um ano (experimento com semeadura em 02/12/1992) segundo fórmulas obtidas por FALCONER (1989) que utiliza os valores de herdabilidade dos caracteres $\left(\mathrm{h}^{2}\right)$ para os cálculos. Deste modo, pode-se separar as contribuições genética e ambiental que fazem parte da correlação fenotípica:

$$
r_{F x y}=\sqrt{h_{X}^{2} \cdot h_{Y}^{2}} \cdot r_{G x y}+\sqrt{\left(1-h_{X}^{2}\right) \cdot\left(1-h_{Y}^{2}\right)} \cdot r_{E x y}
$$

onde a primeira parte desta fórmula corresponde à contribuição genética e a segunda parte à ambiental.

\subsubsection{Relação entre os coeficientes de variação genética e experimental (b)}

Segundo VENCOVSKY \& BARRIGA (1992) foi determinada esta relação de acordo com a fórmula:

$$
b=\frac{C V_{G}}{C V_{E}}
$$


onde:

$$
\begin{aligned}
& C V_{G}=\frac{\sqrt{\sigma_{G}^{2}}}{\bar{x}} \cdot 100 \\
& C V_{E}=\frac{\sqrt{\sigma_{E}^{2}}}{-} \cdot 100
\end{aligned}
$$

sendo:

$\mathrm{CV}_{\mathrm{G}}$ : coeficiente de variação genética;

$\mathrm{CV}_{\mathrm{E}}$ : coeficiente de variação ambiental;

$\bar{x} \quad$ : média geral do caráter.

\subsubsection{Progresso esperado na seleção}

Foram determinados os ganhos de seleção $(\hat{G} s)$ para o grupo de linhagens baseado nas fórmulas reportadas por VENCOVSKY \& BARRIGA (1992):

$$
\hat{G} s=i \cdot \frac{\sigma_{G}^{2}}{\sigma_{F}}
$$

onde:

$$
\begin{aligned}
& i \quad: \text { intensidade de seleção; } \\
& \sigma_{\bar{F}}^{2}: \text { variância fenotípica entre tratamentos; } \\
& \sigma_{G}^{2} \text { : variância genética entre tratamentos; }
\end{aligned}
$$

considerando cada cruzamento individualmente e os 45 cruzamentos: 
Por experimento: $\sigma_{F}^{2}=\sigma_{G}^{2}+\frac{\sigma_{E}^{2}}{r}$

Conjunta (dois experimentos): $\sigma_{F}^{2}=\sigma_{G}^{2}+\frac{\sigma_{G x 4}^{2}}{a}+\frac{\sigma_{E}^{2}}{r a}$

onde:

$\sigma_{F}^{2}$ : variância fenotípica entre tratamentos;

$\sigma_{G}^{2}$ : variância genética entre tratamentos;

$\sigma_{E}^{2}$ : variância ambiental;

$\sigma_{G \times 4}^{2}$ : variância genética da interação anos x tratamentos;

r $\quad$ : número de repetições;

a : número de anos.

\subsubsection{Herdabilidade}

As estimativas do coeficiente de herdabilidade $\left(\mathrm{h}^{2}\right)$ ao nivel de médias foram obtidas conforme FALCONER (1989), da seguinte forma:

$$
h^{2}=\frac{\sigma_{G}^{2}}{\sigma_{F}^{2}}
$$

onde:

Por experimento: $\sigma_{F}^{2}=\sigma_{G}^{2}+\frac{\sigma_{E}^{2}}{r}$ 
Conjunta (dois experimentos): $\sigma_{F}^{2}=\sigma_{G}^{2}+\frac{\sigma_{G x 4}^{2}}{a}+\frac{\sigma_{E}^{2}}{r a}$

sendo:

$\sigma_{F}^{2}$ : variância fenotípica entre tratamentos;

$\sigma_{G}^{2}$ : variância genética entre tratamentos;

$\sigma_{E}^{2}$ : variância ambiental;

$\sigma_{G x 4}^{2}$ : variância genética da interação anos x tratamentos;

r : número de repetições;

a : número de anos.

\subsubsection{Resposta correlacionada à seleção}

A resposta correlacionada à seleção (rcs) foi realizada somente com os dados de um ano (semeadura em 02/12/1992), entre os caracteres DM, APM e PG no grupo de linhagens, segundo as fórmulas obtidas em VENCOVSKY \& BARRIGA (1992):

$$
r c s_{(X, Y)}=i \cdot \frac{\operatorname{COV}_{G}(X, Y)}{\sigma_{F}(X)}
$$

onde:

i : intensidade de seleção.

Podendo-se a resposta correlacionada ser expressa em porcentagem:

$$
r c s \%=\frac{r c s_{X}}{\bar{X}} \cdot 100
$$




\subsubsection{Progresso genético observado}

O progresso genético observado $\left(\mathrm{G}_{\mathrm{s}}\right)$ foi calculado para os caracteres $\mathrm{DM}$, APM e PG através das seguinte expressões:

$$
\begin{gathered}
G_{s p}-=\frac{\bar{x}_{\text {populac } \tilde{\tilde{D}}-\bar{x}_{\text {parentais }}}}{\bar{x}_{\text {parentais }}} .100 \\
G_{s p_{s}}=\frac{\bar{x}_{\text {populac } \tilde{\boldsymbol{m}}}-\bar{x}_{p s}}{-100} \bar{x}_{p s}
\end{gathered}
$$

onde:

$$
\begin{array}{ll}
G_{s p}- & \text { progresso genético observado baseado nas médias dos parentais } \\
& \text { envolvidos no(s) cruzamento(s); } \\
G_{s p_{s}}: & \text { progresso genético observado baseado no parental com média superior } \\
& \text { envolvido no(s) cruzamento(s) } \\
\text { ps } \quad \text { parental superior. }
\end{array}
$$




\section{RESULTADOS E DISCUSSÃO}

\subsection{Testes preliminares}

$\mathrm{Na}$ avaliação dos testes preliminares para determinação do período necessário de rehidratação das amostras de sementes de soja para $13 \% \pm 0,5$, que segundo CARBONELL et al. (1993) melhor separa os genótipos em níveis de resistência ao dano mecânico, verificou-se que em câmara de crescimento com temperatura de $25^{\circ} \mathrm{C}$ e umidade relativa de $85 \%$, após 72 horas do início de hidratação foi atingido este teor de umidade nas sementes $(12,74 \% \pm 0,34)$, baseado em valores médios de umidade nas amostras de sementes avaliadas (Tabela 5).

Como observado na Tabela 5, o período de 72 hs não atingiu o equilíbrio higroscópico com base na temperatura e umidade relativa dentro da câmara de crescimento, pois os teores de umidade nas amostras de sementes aumentaram na média dos cultivares para $13,92 \% \pm 1,07$ e $15,00 \% \pm 0,5$ nos períodos de 96 hs e $120 \mathrm{hs}$, respectivamente. Entretanto, devido a pouca variação no teor de umidade entre o período de 72 hs e 96 hs e a própria margem de segurança de 24 hs existente entre estas, optou-se pelo uso como rotina do período de $72 \mathrm{hs,} \mathrm{pois} \mathrm{este} \mathrm{período} \mathrm{além} \mathrm{de} \mathrm{apresentar} \mathrm{menor}$ amplitude de variação $( \pm 0,34 \%)$ da média $(12,74 \%)$, é um período de tempo relativamente curto de acondicionamento de sementes.

Este período curto é importante para programas de melhoramento que avaliam grandes quantidades de linhagens e, também, para fins metodológicos, pois um período maior que 72 hs de exposição das amostras de sementes a altas umidades poderia provocar o aumento de uma possível atividade de microrganísmos (fungos e bactérias) sobre as sementes, que iriam influenciar na avaliação da resistência das sementes ao dano mecânico devido a deterioração destas sementes (DELOUCHE, 1972; FRANÇA NETO \& POTTS, 1979; WOLF et al., 1981; MASON et al., 1982; BURCHETT et al., 1985). Além disso, no período de 72 hs não foram observadas diferenças entre as amostras dos 
cultivares em relação ao teor de umidade (Tabela 5); deste modo, o acondicionamento torna-se homogêneo para as amostras de diferentes linhagens.

\subsection{Análise de resíduos}

Tendo-se a definição de resíduo como a diferença entre o valor observado e o valor predito (estimado) pelo modelo matemático do experimento, ou seja, é o valor observado do erro (PARENTE, 1984), nas Figuras 2 a 7 verifica-se a não ocorrência de dados discrepantes ("outliers"), pois os valores estão entre os limites de dispersão -3 e +3 , considerados adequados na análise gráfica de resíduos em dados de cada experimento. Conseqüentemente ocorre também homogeneidade de variâncias e normalidade dos resíduos (PARENTE, 1984), sendo estes considerados apropriados para as análises estatísticas subseqüentes.

Para a análise dos dados referente a PG, a repetição III de cada experimento foi descartada, devido à ocorrência no campo de um fator fisiológico chamado 'haste verde' no local de plantio (curva de nível) destas repetições. Esta 'haste verde' não afetou a altura da planta, no entanto, reduziu drasticamente a produção em praticamente todas as linhagens da repetição, quando comparadas às outras repetições.

\subsection{Análises de variância}

\subsubsection{Análise individual por experimento}

Nas análises de variância (ANAVA's) individuais para os caracteres estudados nos dois experimentos (Tabelas 6,7 e 8) foram realizados os desdobramentos para as fontes de variação de Tratamentos (T) em Linhagens (L), Parentais (P) e Testemunhas (S). O grupo de Linhagens (L) foi novamente desdobrado em Cruzamentos 
(C) e Linhagens/cruzamento (K). Estes desdobramentos foram realizados conforme o modelo matemático e sua decomposição baseado na soma de quadrados de cada fonte de variação, sendo o teste $F$ de significância obtido através dos respectivas $E(Q M$ 's) decompostas.

\subsubsection{APM (altura de planta na maturação) e PG (produção de grãos)}

Este caráter apresentou segundo a Tabela 6, alta significância do teste $\mathrm{F}$ para a fonte de variação Tratamentos $(T)$ e respectivos desdobramentos nos dois experimentos para o caráter APM. Para PG (Tabela 7), verifica-se alta significância do teste $\mathrm{F}$ para a fonte de variação Tratamentos $(\mathrm{T})$ e respectivos desdobramentos nas duas épocas de semeadura, com exceção de Testemunhas $(S)$. Esses resultados indicam a existência de alta variabilidade nos grupos de linhagens ( $\mathrm{C}$ e $\mathrm{K}$ ), parentais e testemunhas, sendo que no desdobramento da fonte de variação linhagens dentro de cruzamentos $(\mathrm{K})$ verificou-se a ocorrência de vários cruzamentos com alta e outros com baixa variabilidade. Para a fonte de variação testemunha $(S)$, não foi detectada variabilidade para o caráter PG.

As médias do caráter APM foram de $68,4 \mathrm{~cm}$ e $68,2 \mathrm{~cm}$ nos dois experimentos com semeaduras em 03/12/1991 e 02/12/1992, respectivamente (Tabela 6). Estes valores de média são considerados relativamente altos para grupo de genótipos precoces de soja e de interesse para o melhoramento, pois por basear-se em dados de média, indicam ocorrência de linhagens superiores a estes valores. Isto pode ser associado com o hábito de crescimento indeterminado, pois segundo o Apêndice 2, seis dos dez parentais têm hábito de crescimento indeterminado. Os valores de coeficiente de variação de $13,9 \%$ e $14,9 \%$ para os experimentos com semeadura em 03/12/1991 e 02/12/1992, respectivamente, são considerados aceitáveis para o grupo de genótipos avaliados.

As médias do caráter PG foram de $192,4 \mathrm{~g} / \mathrm{m}^{2}$ e $137,7 \mathrm{~g} / \mathrm{m}^{2}$ nos experimentos com semeaduras em 03/12/1991 e 02/12/1992, respectivamente (Tabela 7). Os valores de coeficiente de variação de $24,8 \%$ e $25,8 \%$ para as épocas de semeadura em 
03/12/1991 e 02/12/1992, respectivamente, são considerados aceitáveis para o caráter e grupo de genótipos avaliados, pois baseiam-se em dados de parcelas de uma linha de dois metros lineares/repetição.

\subsubsection{DM (dano mecânico)}

$\mathrm{Na}$ Tabela 8 , verifica-se alta significância do teste $\mathrm{F}$ para a fonte de variação Tratamentos $(\mathrm{T})$ e respectivos desdobramentos nas duas épocas de semeadura, com exceção de testemunhas. Estes resultados indicam a existência de alta variabilidade nos grupos de linhagens ( $\mathrm{C} \mathrm{e} \mathrm{K}$ ) e parentais $(\mathrm{P})$, sendo que no desdobramento da fonte de variação linhagens dentro de cruzamentos $(K)$ verificou-se a ocorrência de vários cruzamentos com alta e outros com baixa variabilidade. Para a fonte de variação testemunha (S), não foi detectada variabilidade para DM. No experimento com semeadura em 02/12/1992 foram realizadas duas análises de variância anteriormente citadas (item 3.6) para posterior discussão sobre o grau de associação entre dano mecânico e potencial de germinação das sementes.

Segundo a Tabela 8 em dados do experimento com semeadura em 02/12/1992 para os 45 cruzamentos, as maiores variabilidades obtidas para o caráter DM foram encontradas nos cruzamentos 26 (Forrest x Primavera), 31 (Forrest x Década) e 41 (FT-81-1835 x Hale-321) segundo a magnitude do QM e significância do teste F. Os menores valores foram obtidos nos cruzamentos 43 (SOC-81-79 x Hale-321), 12 (Década x IAC-Foscarin-31) e 2 (Paraná x Coker-136).

As médias do caráter DM foram de 2,00 udm no experimento com semeadura em 03/12/1991, 3,9 udm e 3,8 udm no experimento com semeadura em 02/12/1992, respectivamente para cinco e 45 cruzamentos. Estes valores médios superiores em 02/12/1992 pode ser devido às mudanças na metodologia empregada que utilizou sementes colhidas no estádio de maturação morfológica $\left(R_{8}\right)$ e trilhadas através da batida de plantas no interior de uma caixa de madeira, enquanto no experimento com semeadura em 03/12/1991 utilizaram-se sementes colhidas no estádio de maturação fisiológica $\left(R_{7}\right)$ e trilhadas manualmente. 
Essas mudanças na metodologia provavelmente acarretaram diferenças na qualidade das sementes, as quais influenciaram na suscetibilidade ao dano mecânico, sendo estes maiores que os efeitos ocasionados pelas diferenças entre anos agrícolas e conseqüentemente, do período de armazenamento. Deste modo, a suscetibilidade ao dano mecânico parece ser mais influenciada por fatores de campo (condições climáticas e fitotécnicas responsáveis pela produção e formação da semente) do que propriamente pela idade das sementes.

$\mathrm{O}$ valor do coeficiente de variação $(\mathrm{C} . \mathrm{V}$.) encontrado para o caráter foi $28,17 \%$ para o experimento com semeadura em 03/12/1991. No experimento com semeadura em 02/12/1992, foram obtidos C.V. de $22,58 \%$ em análise de cinco cruzamentos e $24,60 \%$ em análise dos 45 cruzamentos. Estes valores de C.V. são considerados aceitáveis para o caráter e grupo de genótipos avaliados, pois segundo PAULSEN \& NAVE (1977), valores superiores a $15 \%$ são normalmente obtidos em estudos desta natureza.

\subsubsection{Análise conjunta dos experimentos}

Segundo CAMPOS (1984) o agrupamento de experimentos para uma análise conjunta poderá obedecer a diferentes critérios, dentre os quais, a título de exemplificação, cita:

a) por setores geográficos;

b) por ano agrícola;

c) por afinidade quanto a alguma característica de interesse, exemplificando: "ensaios com rendimentos acima de um valor pré-fixado";

d) pela ordem de grandeza dos quadrados médios dos resíduos das análises individuais. Neste particular recomenda-se o agrupamento de ensaios cujos QMR não difiram além de uma relação de $4: 1$.

Utilizando o critério ' $d$ ', as ANAVA's dos experimentos individuais (Tabelas 6, 7 e 8) apresentam condições para se realizar a análise conjunta dos dois 
experimentos, pois as relações de QMR foram 1,13:1, 1,62:1 e 2,48:1 para os caracteres APM, PG e DM, respectivamente.

Do mesmo modo, utilizando a metodologia de HARTLEY (1950) para teste de homogeneidade de variâncias segundo $F_{\text {maximo, foram considerados como homogêneos }}$ os QM's das interações do desdobramento AxLng/C-1 à 45. Deste modo, para os caracteres APM, PG e DM, os fatores Lng/C-1 à 45 foram testados com a interação global AxLng/C com 405 (APM e PG) e 45 (DM) graus de liberdade.

Nestas ANAVA's, os coeficientes de variação encontrados foram considerados satisfatórios para os caracteres avaliados. As ANAVA's conjuntas para DM foram baseadas em dados de cinco cruzamentos, dez parentais e quatro testemunhas.

\subsubsection{APM (altura de planta na maturação) e PG (produção de grãos)}

Conforme as Tabelas 9 e 11, foram detectadas diferenças significativas pelo teste $\mathrm{F}$ da fonte de variação tratamentos $(\mathrm{T})$ para os caracteres APM e PG, que após o seu desdobramento, somente para o grupo das linhagens $(\mathrm{L})$ e respectivo desdobramento em cruzamentos $(\mathrm{C})$ e linhagens dentro de cruzamentos $(\mathrm{K})$ foram significativos. Deste modo, há variabilidade entre os cruzamentos e dentro dos cruzamentos para os caracteres APM e PG. Os cruzamentos que apresentaram as maiores magnitudes de variabilidade entre suas linhagens em dados de APM foram:

- 1 (Paraná x IAC-Foscarin-31)

- 19 (Coker-136 x Década)

- 15 (IAC-Foscarin-31 x SOC-81-79)

- 3 (Paraná x Primavera)

e para $P G$ :

- 44 (Palmetto x SOC-81-79)

- 23 (Coker-136 x Hale-321)

- 41 (FT-81-1835 x Hale-321)

-28 (SOC-81-79 x Primavera) 
Os menores valores para APM, não apresentando diferenças significativas pelo teste $\mathrm{F}$, foram encontrados nos cruzamentos:

- 8 (Paraná $x$ Hale-321)

- 40 (FT-81-1835 x SOC-81-79)

- 25 (Década $x$ Primavera)

e para PG:

- 36 (Forrest x FT-81-1835)

- 8 (Paraná $x$ Hale-321)

- 32 (Década x FT-81-1835)

$\mathrm{O}$ grupo dos parentais $(\mathrm{P})$ e testemunhas $(\mathrm{S})$ não foram significativamente diferentes, demonstrando pouca variabilidade entre eles para o caráter APM e PG. Também não foram obtidos significância para os contrastes de médias entre linhagens vs parentais (LvsP) e testemunhas vs linhagens e parentais (SvsL,P) e na fonte de variação anos (A) entre os experimentos.

A interação Anos x Tratamentos (AxT) e desdobramento AxL (AxC e AxK) e AxP apresentaram alta significância pelo teste $\mathrm{F}$ em dados de APM, como também o contraste de médias AxLvsP (Tabela 9). Para PG (Tabela 11), a interação Anos x Tratamento (AxT) e desdobramento AxL (AxK) e AxP também apresentou alta significância pelo teste $F$. Deste modo, o desdobramento destas interações deve ser realizado para melhor discussão da interação entre Anos (A) e os demais fatores desdobrados (Tabelas 10 e 12).

A interação AxS em APM e PG e AxL em PG não foram significativas, mesmo assim efetuou-se o desdobramento desta fonte de variação para discutir ao nível de cultivar o efeito de anos sobre APM e PG (Tabelas 10 e 12).

No desdobramento da interação $\mathrm{AxL}$ em $\mathrm{AxC}$, analisando os cruzamentos dentro de anos (C/A), observa-se que o Ano 1 (experimento com semeadura em 03/12/1991) apresenta uma magnitude do QM maior que no Ano 2 (experimento com semeadura em 02/12/1992), indicando uma maior variabilidade dos caracteres neste Ano 1 para cruzamento, embora os dois anos fossem significativos para APM e PG. 
Analisando o efeito dos anos dentro de cruzamento (A/C), observa-se para APM, que os cruzamentos que apresentaram maiores valores de QM e significância pelo teste $\mathrm{F}$ foram:

- 42 (Palmetto x FT81-1835)

- 17 (IAC-Foscarin-31 x Forrest)

- 26 (Forrest x Primavera)

e para PG:

- 45 (Hale-321 x Palmetto)

- 15 (IAC-Foscarin-31 x SOC-81-79)

- 41 (FT-81-1835 x Hale-321)

- 37 (Forrest x SOC-81-79)

demonstrando maior influência de anos agrícolas nestes cruzamentos para estes caracteres. Os cruzamentos que apresentaram maior estabilidade para o caráter em relação ao efeito de anos agricolas para APM foram:

- 34 (Hale-321 x Década)

- 25 (Década x Primavera)

- 1 (Paraná x IAC-Foscarin-31)

e para PG:

- 8 (Paraná x Hale-321)

- 16 (IAC-Foscarin-31 x Hale-321)

- 21 (Coker-136 x FT-81-1835).

A interação Anos $x$ Parentais (AxP) apresentou resultados semelhantes para o fator Parental/Anos (P/A), demonstrando diferenças significativas pelo teste $\mathrm{F}$ nos dois experimentos para APM (Tabela 10). Para PG (Tabela 12) o desdobramento Parentais/Anos (P/A) foi significativo no Ano 1 e não significativo no Ano 2, demonstrando que as diferenças entre os parentais foram observadas significativamente somente no experimento com semeadura em 03/12/1991.

$\mathrm{Na}$ análise do efeito de Anos dentro dos Parentais (A/P) para APM, apenas os cultivares Primavera e Forrest manifestaram influência de anos sobre o caráter APM. No caso do cultivar Primavera, na parcela de testemunhas, o efeito de anos não foi 
significativo. Os demais parentais, bem como as testemunhas, não apresentaram significância pelo teste $\mathrm{F}$ entre os dois experimentos (Tabela 10).

No entanto, na análise do efeito de Anos dentro dos Parentais (A/P) para PG, os cultivares SOC81-79, Palmetto, Hale 321 e Coker 136 manifestaram influência de anos sobre o caráter PG. Os demais parentais, bem como as testemunhas, com exceção do cultivar IAC-Foscarin-31, não apresentaram significância pelo teste $F$ entre os dois experimentos (Tabela 12).

Na análise da interação AxLvsP, somente no Ano 1 para dados de APM e Ano 2 para $P G$, os valores médios das linhagens foram diferentes aos parentais. Isto não implica em falta de variabilidade nas linhagens em relação aos parentais nos anos sem significância, pois são dados de média onde fatores positivos (maiores altura e produção) e negativos (menores altura e produção) contribuem para esta média.

\subsubsection{DM (dano mecânico)}

As análises conjuntas dos dois anos agricolas para o caráter DM foram realizadas somente com um grupo (cinco) de cruzamentos aleatoriamente amostrados dos 45 existentes. Participaram também desta análise o grupo dos parentais e testemunhas.

Nos resultados apresentados na Tabela 13 verifica-se a diferença significativa pelo teste $\mathrm{F}$ da fonte de variação Anos (A), indicando haver um efeito de anos agricola sobre o caráter DM. Esta significância é explicada devido à mudança de metodologia utilizada para a obtenção de sementes nas duas épocas de semeadura, como discutido no item 3.3.1.3, influenciando na médias de DM dos genótipos estudados.

A fonte de variação Tratamentos $(\mathrm{T})$ apresentou significância pelo teste $\mathrm{F}$ e no desdobramento de testemunhas (S). Para o grupo das linhagens (L) e respectivo desdobramento em cruzamentos $(\mathrm{C})$ e linhagens dentro de cruzamentos $(\mathrm{K})$, e grupo dos parentais $(P)$, o teste $F$ não apresentou significância. Estes resultados, embora não significativos, não indicam a falta de variabilidade para o caráter DM, pois analisando as interações com Anos, apenas Anos x Testemunha (AxS) e Anos x Cruzamento (AxC) não foram significativas. Deste modo, há variabilidade entre os parentais e nas linhagens 
dentro dos cruzamentos para o caráter DM quando analisados em cada ano (Tabela 14). $\mathrm{O}$ número restrito de cruzamentos analisados pode ser a causa da não significância da fonte de variação Cruzamentos (C).

$\mathrm{O}$ efeito de anos agrícolas sobre a variabilidade dos genótipos e cruzamentos estudados fica evidenciado em todas as decomposições das interações $(\mathrm{A} / \mathrm{C}$, $\mathrm{A} / \mathrm{P}$ e $\mathrm{A} / \mathrm{S}$ ), deste modo pode-se afirmar que o caráter $\mathrm{DM}$ é muito influenciado pelo ambiente de produção das sementes (Tabela 14).

\subsection{Análise de média e componentes genéticos}

\subsubsection{APM (altura de planta na maturação) e PG (produção de grãos)}

As Tabelas 15 e 16 apresentam os dados de médias dos caracteres APM e $\mathrm{PG}$, respectivamente. Observa-se que dentro do grupo dos parentais, os cultivares Hale-321, Palmetto, IAC-Foscarin-31 e Coker-136 para dados de APM, e os cultivares Coker-136, Primavera, SOC-81-79 e IAC-Foscarin-31 para PG, foram os que apresentaram os maiores valores de médias. No entanto, foram os cultivares Paraná, Década e FT-81-1835 em dados de APM, e os cultivares Forrest, Paraná e Década para PG, que apresentaram os menores valores de variância de tratamento. Isto sugere que cultivares com maior média para estes caracteres estão sujeitos à ocorrência de maior variabilidade devido a efeitos de ambiente, já que são linhagens puras. $\mathrm{O}$ mesmo foi observado para o grupo de testemunhas.

Com relação às médias gerais entre os grupos de linhagens $(68,4 \mathrm{~cm})$, parentais $(66,8 \mathrm{~cm})$ e testemunhas $(65,3 \mathrm{~cm})$ para o caráter APM, observa-se que o grupo de linhagens apresenta a maior média, seguida do grupo de parentais e testemunhas. Para PG, a maior média é dos parentais $\left(163 \mathrm{~g} / \mathrm{m}^{2}\right)$ seguido do grupo das linhagens $\left(160 \mathrm{~g} / \mathrm{m}^{2}\right)$ e testemunhas $\left(154 \mathrm{~g} / \mathrm{m}^{2}\right)$. Pelo fato destes dados serem médios e muito próximos, no grupo de linhagens há grande possibilidade de obtenção de 
cruzamentos e, conseqüentemente, linhagens transgressivas aos parentais para os caracteres de APM e PG.

Deste modo, analisando a média de cada cruzamento, verifica-se para APM que os cruzamentos:

$$
\begin{array}{ll}
\text { - } 39 \text { (Forrest x Palmetto) } & : 85,94 \mathrm{~cm} \\
\text { - } 31 \text { (Forrest x Década) } & : 84,98 \mathrm{~cm} \\
\text { - 40 (FT-81-1835 x SOC-81-79) } & : 82,12 \mathrm{~cm} \\
\text { - 12 (Década x IAC-Foscarin-31) } & : 80,79 \mathrm{~cm} \\
\text { - 17 (IAC-Foscarin-31 x Forrest) } & : 80,20 \mathrm{~cm}
\end{array}
$$

apresentam valores médios entre $80,20 \mathrm{~cm}$ e $85,94 \mathrm{~cm}$, e para PG os cruzamentos:

- 15 (IAC-Foscarin-31 x SOC-81-79) : 195,11 g/m

- 31 (Forrest $x$ Década) $\quad: 188,59 \mathrm{~g} / \mathrm{m}^{2}$

- 20 (Forrest $\times$ Coker-136) : $\quad: 185,96 \mathrm{~g} / \mathrm{m}^{2}$

- 14 (IAC-Foscarin-31 x FT-81-1835) : 184,67 g/m²

- 45 (Hale-321 x Palmetto) : $184,60 \mathrm{~g} / \mathrm{m}^{2}$

apresentam valores médios entre $184,6 \mathrm{~g} / \mathrm{m}^{2}$ e $195,1 \mathrm{~g} / \mathrm{m}^{2}$, dados médios estes bem superiores aos obtidos pelo grupo dos parentais $\left(66,8 \mathrm{~cm} \mathrm{e} 163 \mathrm{~g} / \mathrm{m}^{2}\right)$.

Os menores valores para APM foram para os cruzamentos:

- 36 (Forrest x FT-81-1835) : 53,24 cm

- 23 (Coker-136 x Hale-321) : 54,55 cm

- 8 (Paraná x Hale-321) : $54,81 \mathrm{~cm}$

- 22 (SOC-81-79 x Coker-136) : 55,24 cm

- 20 (Forrest x Coker-136) : 55,40 cm

e para PG:

- 36 (Forrest x FT-81-1835) : 106,37 $\mathrm{g} \mathrm{m}^{2}$

- 35 (Palmetto $x$ Década) $\quad: 117,34 \mathrm{~g} / \mathrm{m}^{2}$

- 43 (SOC-81-79 x Hale-321) : 127,74 g/m

- 42 (Palmetto x FT-81-1835) : 128,62 g/m

- 38 (Hale-321 x Forrest) : : 128,69 g/m 
No estudo do grupo de linhagens dentro de cruzamentos, a ocorrência de maior variância genética/cruz $\left(\mathrm{V}_{\mathrm{g}^{\prime} \text { cruz }}\right)$ é desejada para fins de melhoramento e obtenção de genótipos transgressivos aos parentais. Para APM, foram observados os maiores valores de variância genética nos cruzamentos:

- 1 (Paraná x IAC-Foscarin-31)

- 19 (Coker-136 x Década)

- 15 (IAC-Foscarin-31 x SOC-81-79)

- 3 (Paraná $x$ Primavera)

- 2 (Paraná x Coker-136)

e para PG nos cruzamentos:

- 44 (SOC-81-79 x Palmetto)

- 23 (Coker-136 x Hale-321)

- 41 (FT-81-1835 x Hale-321)

- 28 (SOC-81-79 x Primavera)

- 1 (Paraná x IAC-Foscarin-31)

Os menores valores de $\mathrm{V}_{\text {g/cruz }}$ (Tabelas 15 e 16), com estimação de valores negativos de variâncias, foram encontrados em APM nos cruzamentos:

- 8 (Paraná $x$ Hale-321)

- 40 (FT-81-1835 x SOC-81-79)

- 25 (Década x Primavera)

- 29 (Hale-321 x Primavera)

- 32 (Década x FT-81-1835)

- 28 (SOC-81-79 x Primavera)

e para PG nos cruzamentos:

- 36 (Forrest x FT-81-1835)

- 8 (Paraná $x$ Hale-321)

- 32 (Década x FT-81-1835),

- 40 (FT-81-1835 x SOC-81-79)

- 9 (Paraná x Palmetto) 
- 21 (Coker-136 x FT-81-1835)

- 34 (Hale-321 x Década)

- 16 (IAC-Foscarin-31 x Hale-321)

- 6 (Paraná x FT-81-1835)

- 2 (Paraná x Coker-136)

- 39 (Forrest x Palmetto)

- 30 (Palmetto x Primavera)

- 13 (IAC-Foscarin-31 x Forrest)

- 26 (Forrest x Primavera)

- 45 (Hale-321 x Palmetto)

- 33 (SOC-81-79 x Década)

- 42 (Palmetto x FT-81-1835)

- 12 (Década x IAC-Foscarin-31)

Os valores negativos de variância $\left(\mathrm{V}_{\mathrm{g}^{\prime} \text { cruz }}\right)$ obtidos em dados de APM e PG refletem a pouca variabilidade no cruzamento, chegando a ser inferior a variância ambiental obtida no experimento.

\subsubsection{Relação entre os coeficientes de variação genética e experimental}

A precisão de um ensaio é geralmente medida através do coeficiente de variação experimental. No entanto, não é somente esta estimativa que importa, mas também o quociente entre os coeficientes de variação genética e o experimental, representado por ' $b$ ' e expresso em porcentagem.

Analisando as Tabelas 15 e 16, no grupo de linhagens, observa-se que somente o caráter APM $(b=1,015)$ apresenta condições favoráveis para a seleção, visto que a variação genética é maior que a variação experimental. Para o caráter PG $(b=0,530)$ que apresenta valor $d e b<1$, a seleção deve ser menos eficiente, pois a variação experimental é maior que a variação genética. Maior influência ambiental é explicada pela maior natureza genética complexa (quantitativa) do caráter PG; tal fato pode explicar inclusive os valores negativos de variância genética $\left(\mathrm{V}_{\mathrm{g} / \mathrm{cruz}}\right)$, e conseqüentemente $\mathrm{CVg}$ e $\mathrm{b}$ 
encontrados em alguns cruzamentos citados no item anterior (4.4.1). Certamente, técnicas experimentais mais sofisticadas (p.ex.: parcelas de quatro fileiras com $5 \times 0,6 \mathrm{~m}$, maior número de repetições) devem melhorar a eficiência da seleção para maior PG.

No entanto, para os dois caracteres são observados cruzamentos com valores de $\mathrm{b}>1$, obtidos para APM nos cruzamentos:

- 1 (Paraná x IAC-Foscarin-31) : : 1,38

- 19 (Coker-136 x Década) : : 1,32

- 15 (IAC-Foscarin-31 x SOC-81-79) : 1,12

- 37 (Forrest x SOC-81-79) : :1,11

- 2 (Paraná x Coker-136) : : 1,10

e para PG nos cruzamentos:

- 44 (SOC-81-79 x Palmetto) : : 1,16

- 23 (Coker-136 x Hale-321) : : 1,16

Verifica-se que o número de cruzamentos com $b>1$ é superior em APM quando comparado à $\mathrm{PG}$, indicando que a seleção para o caráter APM é mais eficiente, pois PG é bastante influenciada pelas condições experimentais. Isto fica evidente quando são observados os valores de $\mathrm{CVg}$ do caráter $\mathrm{PG}$ ao nível de cruzamentos, onde grande número de cruzamentos não são estimados devido a ocorrência de variâncias genéticas negativas.

\subsubsection{Progresso esperado na seleção}

Utilizando uma intensidade de seleção (i) de $10 \%$ observa-se nas Tabelas 15 e 16 um progresso esperado na seleção de $12,68 \mathrm{~cm}$ para APM e $16,14 \mathrm{~g} / \mathrm{m}^{2}$ para $P G$ no grupo de linhagens. Em relação à média geral de linhagens, isto representa ganhos de $18 \%$ e $10 \%$ para os caracteres APM e PG, respectivamente. Estes resultados sugerem uma seleção promissora para o aumento destes caracteres, pois são considerados valores altos em um programa de melhoramento de soja. 
Pode-se ainda observar nas Tabelas 15 e 16 diferenças entre os cruzamentos com relação ao progresso esperado na seleção para APM, sendo encontrado os maiores valores nos cruzamentos:

$$
\begin{array}{ll}
-1 \text { (Paraná x IAC-Foscarin-31) } & : 15,54 \mathrm{~cm} \\
-19 \text { (Coker-136 x Década) } & : 15,51 \mathrm{~cm} \\
-15 \text { (IAC-Foscarin-31 x SOC-81-79) } & : 13,32 \mathrm{~cm} \\
-3 \text { (Paraná x Primavera) } & : 12,44 \mathrm{~cm} \\
-2 \text { (Paraná x Coker-136 } & : 11,93 \mathrm{~cm} \\
-37 \text { (Forrest x SOC-81-79) } & : 11,17 \mathrm{~cm} \\
-33 \text { (SOC-81-79 x Década) } & : 10,29 \mathrm{~cm}
\end{array}
$$

e para PG nos cruzamentos:

$$
\begin{array}{ll}
\text { - } 44 \text { (SOC-81-79 x Palmetto) } & : 51,44 \mathrm{~g} / \mathrm{m}^{2} \\
\text { - 23 (Coker-136 x Hale-321) } & : 47,20 \mathrm{~g} / \mathrm{m}^{2} \\
\text { - 41 (FT-81-1835 x Hale-321) } & : 40,04 \mathrm{~g} / \mathrm{m}^{2} \\
\text { - 28 (SOC-81-79 x Primavera) } & : 38,83 \mathrm{~g} / \mathrm{m}^{2} \\
\text { - 1 (Paraná x IAC-Foscarin-31) } & : 36,64 \mathrm{~g} / \mathrm{m}^{2} \\
\text { - } 19 \text { (Coker-136 x Década) } & : 35,60 \mathrm{~g} / \mathrm{m}^{2} \\
\text { - 25 (Década x Primavera) } & : 33,82 \mathrm{~g} / \mathrm{m}^{2} \\
\text { - } 5 \text { (Paraná x Forrest) } & : 32,88 \mathrm{~g} / \mathrm{m}^{2} \\
\text { - } 4 \text { (Paraná x Década) } & : 30,29 \mathrm{~g} / \mathrm{m}^{2}
\end{array}
$$

Para PG os valores destes cruzamentos foram bem superiores $\left(>30 \mathrm{~g} / \mathrm{m}^{2} \equiv 19 \%\right)$ que a média geral das linhagens para o caráter, novamente sugerindo uma grande variabilidade existente entre os cruzamentos e linhagens, com valores altos, médios e baixos para produção de grãos

\subsubsection{Herdabilidade}

A herdabilidade dos caracteres medida no grupo de linhagens foi considerada alta para APM $\left(h^{2}=0,823\right)$ e baixa para PG $\left(h^{2}=0,286\right)$ como observado nas 
Tabelas 15 e 16. Esta diferença entre APM e PG na magnitude da herdabilidade é explicada pela menor e maior complexidade genética (número de genes) dos caracteres. Estes resultados, juntamente com as outras estimativas de parâmetros genéticos já discutidos, indicam que o caráter APM para genótipos do grupo precoce de soja é considerado promissor e de certa facilidade para a obtenção de genótipos transgressivos. Para PG, também se pode obter grandes avanços e sucesso na seleção; no entanto, a escolha dos parentais e da metodologia de condução dos experimentos em campo são muito importantes: parentais contrastantes devem originar grande variabilidade genética nos cruzamentos; técnicas mais elaboradas (maior tamanho da parcela experimental, maior número de repetições) devem melhorar a precisão experimental.

\subsubsection{DM (dano mecânico)}

Observando a Tabela 17, nos dados de média do caráter DM para o grupo dos parentais, verifica-se que os cultivares Paraná, Hale-321, IAC-Foscarin-31 e Primavera para o experimento com semeadura em 02/12/1992 e para os dois experimentos em conjunto, apresentaram os menores valores de médias $\mathrm{e}$, conseqüentemente maior resistência ao dano mecânico. No entanto, os cultivares Palmetto, Coker-136, FT-81-1835 e Forrest foram os que apresentaram os maiores valores de $\mathrm{DM}$ e, conseqüentemente, maior suscetibilidade ao dano mecânico.

No grupo das testemunhas, o cultivar IAS-5 possui nível de resistência ao dano mecânico semelhante aos melhores parentais, sendo este cultivar considerado por CARBONELL (1991) como padrão de resistência ao dano. Neste grupo houve tendência de ocorrer valores de DM superiores para os cultivares Paraná e IAC-Foscarin-31, quando comparados aos valores destes como parentais; isto pode ser devido a possíveis diferenças de umidade nas amostras de sementes não identificadas por ocasião do teste do pêndulo. Observa-se que o cultivar IAC-2 considerado por CARBONELL (1991) como padrão de suscetibilidade, apresentou os maiores valores na análises do experimento semeado em 02/12/1992 e análise conjunta dos dois experimentos (Tabela 17). 
As variâncias dos tratamentos parentais e testemunhas foram consideradas alta, principalmente para os cultivares FT-81-1835, Primavera e IAS-5, sugerindo que nestes cultivares o controle de umidade nas sementes não foi suficientemente eficiente ou fatores como pureza varietal possam ter promovido variabilidade nas amostras.

Com relação a média geral entre os grupos de linhagens ( $3,8 \mathrm{udm}$ na análise do experimento semeado em 02/12/1992 e 3,02 udm na análise conjunta dos dois experimentos), parentais ( $3,89 \mathrm{udm}$ na análise do experimento semeado em 02/12/1992 e 2,82 udm na análise conjunta dos dois experimentos) e testemunhas (3,55 na análise do experimento semeado em 02/12/1992 e 2,58 na análise conjunta dos dois experimentos), observa-se que o grupo de testemunhas apresenta o menor valor médio, seguida do grupo de linhagens e parentais na análise do experimento semeado em 02/12/1992 e parentais e linhagens na análise conjunta dos dois experimentos. Isto se deve ao fato de que no grupo das testemunhas todos os quatro cultivares são consideradas como padrões de resistência. No entanto, pelo fato destes dados serem médios e muito próximos, no grupo de linhagens, há grande possibilidade de obtenção de cruzamentos superiores, e conseqüentemente, linhagens transgressivas aos parentais.

Deste modo, analisando a média de cada cruzamento, verifica-se no experimento semeado em 02/12/1992 que os cruzamentos:

- 30 (Palmetto x Primavera) $\quad: 2,53 \mathrm{udm}$

- 42 (Palmetto x FT-81-1835) : 2,62 udm

- 21 (Coker-136 x FT-81-1835) : 2,87 udm

- 27 (FT-81-1835 x Primavera) : 2,95 udm

- 22 (SOC-81-79 x Coker-136) : 3,07 udm

apresentam valores médios entre 2,53 e 3,07 udm, e na análise conjunta dos dois experimentos o cruzamento 29 (Hale-321 x Primavera), apresenta valor médio de 2,80 udm, dados médios estes inferiores aos obtidos pelo grupo dos parentais $(3,892 \mathrm{udm}$ na análise do experimento semeado em 02/12/1992 e 2,82 udm na análise conjunta dos dois experimentos).

Os maiores valores encontrados no experimento semeado em 02/12/1992 foram para os cruzamentos:

$$
\text { - } 36 \text { (Forrest x FT-81-1835) } \quad: 5,18 \mathrm{udm}
$$


- 16 (IAC-Foscarin-31 x Hale-321) : 5,10 udm

- 1 (Paraná x IAC-Foscarin-31) : 4,67 udm

- 26 (Forrest $x$ Primavera) : : 4,39 udm

- 8 (Paraná x Hale-321) : : 4,37 udm

e na análise conjunta dos dois experimentos o cruzamento 4 (Paraná $\mathrm{x}$ Década) apresentou o maior valor $(3,33 \mathrm{udm})$.

No estudo do grupo de linhagens (cruzamentos) a ocorrência de maior variância genética/cruz $\left(\mathrm{V}_{\mathrm{g} / \mathrm{cruz}}\right)$ é desejada para fins de melhoramento e obtenção de genótipos transgressivos aos parentais. As maiores $\mathrm{V}_{\mathrm{g} / \text { cruz }}$ do experimento semeado em 02/12/1992 foram encontradas nos cruzamentos:

- 26 (Forrest $x$ Primavera)

- 31 (Forrest x Década)

- 41 (FT-81-1835 x Hale-321)

- 37 (Forrest x SOC-81-79)

- 5 (Paraná x Forrest)

e em dados da análise conjunta dos dois experimentos o cruzamento 44 (SOC-81-79 x Palmetto) apresentou o maior valor de variância genética; já os cruzamentos:

- 8 (Paraná x Hale-321)

- 43 (SOC-81-79 x Hale-321)

- 2 (Paraná x Coker-136)

- 12 (Década x IAC-Foscarin-31)

- 20 (Forrest x Coker-136)

em dados da análise do experimento semeado em 02/12/1992 e o cruzamento 13 (IAC-Foscarin-31 x Forrest) na análise conjunta dos dois experimentos, mostram os menores valores de $\mathrm{V}_{\mathrm{g} / \text { rouz }}$ (Tabela 17).

\subsubsection{Relação entre os coeficientes de variação genética e experimental}

Analisando a Tabela 17, no grupo de linhagens, observa-se para o caráter DM $(b=0,84$ na análise do experimento semeado em 02/12/1992 e $b=0,33$ na análise 
conjunta dos dois experimentos) que a variação experimental é maior que a variação genética $(b<1)$; deste modo, a seleção parece ser menos eficiente. No entanto, valores de b> 1 ocorrem no experimento semeado em 02/12/1992 nos cruzamentos:

- 26 (Forrest x Primavera) $\quad: 1,38$

- 31 (Forrest $x$ Década) : : 1,34

- 41 (FT-81-1835 x Hale-321) : 1,17

- 21 (Coker-136 x FT-81-1835) : 1,05

no entanto; em dados da análise conjunta dos dois experimentos não foram observados valores de $b>1$, provavelmente devido ao limitado número de cruzamentos (cinco) avaliados.

\subsubsection{Progresso esperado na seleção}

Utilizando uma intensidade de seleção (i) de $10 \%$ em favor dos indivíduos com menores valores de DM e, conseqüentemente, maior resistência ao dano, observa-se na Tabela 17 um progresso esperado de 0,95 udm na análise do experimento com semeadura em 02/12/1992 e 0,17 udm na análise conjunta dos dois experimentos para o grupo de linhagens. Estes valores foram considerados altos para o caráter DM, particularmente na análise do experimento com semeadura em 02/12/1992, pois representam ganhos de $24,9 \%$ e 5,6\% na média geral de DM, respectivamente, na análise do experimento com semeadura em 02/12/1992 e na análise conjunta dos dois experimentos.

$\mathrm{Na}$ Tabela 17, verifica-se em dados do experimento semeado em 02/12/1992 que os cruzamentos que apresentaram maiores valores de progresso esperado na seleção para resistência ao DM quando utilizado um i $=10 \%$ foram:

- 26 (Forrest x Primavera) : 1,99 udm

- 31 (Forrest x Década) : 1,82 udm

- 41 (FT-81-1835 x Hale-321) : 1,17 udm

- 5 (Paraná x Forrest) : 1,03 udm 
e na análise conjunta dos dois experimentos foi o cruzamento 44 (SOC-81-79 $\mathrm{x}$ Palmetto), com $0,402 \mathrm{udm}$. Os menores valores foram obtidos no experimento semeado em 02/12/1992 nos cruzamentos:

- 12 (Década x IAC-Foscarin-31) : -0,44 udm

- 43 (SOC-81-79 x Hale-321) : -0,44 udm

- 2 (Paraná x Primavera) : :-0,16 udm

- 20 (Forrest x Coker-136) : :0,03 udm

- 13 (IAC-Foscarin-31 x Forrest) : 0,07 udm

e na análise conjunta dos dois experimentos no cruzamento 13 (IAC-Foscarin-31 x Forrest) com 0,04 udm.

\subsubsection{Herdabilidade}

A herdabilidade do caráter DM medido no grupo de linhagens foi considerada alta para o experimento com semeadura em $02 / 12 / 1992\left(h^{2}=0,74\right)$ e baixa para análise conjunta dos dois experimentos $\left(\mathrm{h}^{2}=0,24\right)$ como observado na Tabela 17. Estes resultados indicam, juntamente com as outras estimativas de parâmetros genéticos já discutidos, que o caráter DM para genótipos do grupo precoce de soja é considerado promissor para a obtenção de linhagens transgressivas para resistência ao DM. No entanto, a escolha dos parentais e metodologia de condução dos experimento em campo e laboratório são muito importantes, pois podem detectar pouca variabilidade na população segregante (quando escolhidos parentais semelhantes) e altos valores de variação experimental, respectivamente. As diferenças encontradas na magnitude das herdabilidades das duas análises (experimento semeado em 03/12/1991 e conjunta), pode ser devido ao número reduzido de cruzamentos (cinco) avaliados na análise conjunta ou devido aos cruzamentos 'per se'. 


\subsection{Correlação entre caracteres}

Nas Tabelas 18 e 19 são apresentados os valores de correlações, estimando o grau de associação entre os caracteres estudados.

\subsubsection{Correlações relacionadas a qualidade fisiológica das sementes}

Na Tabela 18, são apresentados os dados de correlação entre DM e G (germinação), DM e SD (sementes duras) e entre G e SD, nos dois anos agrícolas.

Verifica-se nos dados de DMxG que os valores de correlação no experimento com semeadura em 03/12/1991, embora considerados baixos $(<0,2)$ e médios $(0,2<\mathrm{r}<0,8)$, são bem superiores que os valores obtidos no experimento semeado em 02/12/1992, para todos os grupos e cruzamentos analisados. Como os testes do pêndulo foram realizados entre setembro-dezembro de 1993 para as duas épocas de semeadura, a germinação das amostras do experimento semeado em 03/12/1991 foram naturalmente menores que as do experimento semeado em 02/12/1992 e, conseqüentemente, apresentaram maiores correlações negativas com DM. Estes resultados mostram a importância da qualidade fisiológica das sementes, expressas em dados de germinação, na suscetibilidade da sementes ao dano mecânico e a possibilidade de seleção de genótipos com características para resistência ao dano mecânico ou maior germinação quando $r<0,2$, ou até mesmo os dois $(r>0,2)$.

As correlações entre DMxSD e GxSD, conforme a Tabela 18, têm baixos valores. No entanto, não se pode afirmar com certeza que estas variáveis não são correlacionadas, pois as amostras de sementes analisadas neste estudo apresentaram baixos valores de $\mathrm{SD}$, sendo então pouco representativas para fins de discussão e conclusão. O cruzamento 13 (IAC-Foscarin-31 x Forrest) não apresentou sementes duras na semeadura de 03/12/1991 e por isso não permitiu a estimação das correlações entre DMxSD e GxSD. 


\subsubsection{Correlações genotípica, fenotípica e de ambiente}

Na Tabela 19, para o grupo de linhagens do experimento com semeadura em 02/12/1992, os dados de correlação apresentados são considerados baixos, com valores de ' $r$ ' menores ou próximos a 0,2. No entanto, analisando somente os sinais das correlações, especialmente para as correlações genéticas, observa-se que são negativos entre DMxAPM e DMxPG e positivo entre APMxPG, caracteres importantes (APM e PG) em programas de melhoramento de soja d o ciclo precoce.

As correlações fenotípicas baixas observadas na Tabela 19, foram estudadas através da quantificação da contribuição relativa de efeitos genéticos vs. (genéticos + ambientais), verificando-se que os fatores genéticos contribuem com 99\%, 97\% e 71\% do valor da correlação fenotípica obtida em DMxAPM, DMxPG e APMxPG, respectivamente. Como as herdabilidades destes caracteres são consideradas médias para altas e a contribuição dos fatores genéticos altos nos valores de correlação fenotípica, poder-se-ia, se os valores de ' $r$ ' fossem maiores que 0,8 , seguramente selecionar genótipos superiores para qualquer caráter (DM, APM e PG), baseando-se em dados de correlação fenotípica.

No entanto, devido estas correlações serem consideradas baixas, os caracteres DM, APM, e PG podem ser considerados independentemente na seleção. Deste modo, pode-se reunir em um mesmo genótipo todas as combinações possíveis para estes caracteres, sendo o mais interessante para soja de ciclo precoce maior altura e produção e menor dano mecânico.

\subsection{Resposta correlacionada à seleção}

Embora a Tabela 19 identifique valores baixos de correlação entre os caracteres DM, APM e PG para dados de linhagens do experimento com semeadura em 02/12/1992, efetuou-se os cálculos para o obtenção da resposta correlacionada ( $\mathrm{i}=10 \%$ ), ao nível de médias de linhagens e cruzamentos. Deste modo, quantificou-se em valores 
absolutos e porcentagem da média, as possíveis diferenças em relação as médias dos cruzamentos (Tabela 20).

Os dados do grupo de linhagens apresentaram valores de resposta correlacionada à seleção (rcs) considerados altos para todos os caracteres correlacionados, variando de 3,2\% para PG:APM ate $-7,2 \%$ para DM:PG. Realmente, tais valores são relativamente altos quando se considera a base genética estreita da soja (HIROMOTO \& VELLO, 1986) e o grupo relativamente restrito de parentais precoces.

Na seleção visando uma maior resistência ao DM, segundo a Tabela 20, os cruzamentos que apresentaram maiores valores em porcentagem de rcs em altura (APM>-9,37\%) foram:

$$
\begin{array}{ll}
-24 \text { (Palmetto x Coker-136) } & :-12,15 \% \\
-37 \text { (Forrest x SOC-81-79) } & :-11,36 \% \\
-44 \text { (SOC-81-79 x Palmetto) } & :-11,14 \% \\
\text { - } 29 \text { (Hale-321x Primavera) } & :-9,50 \% \\
\text { - } 33 \text { (SOC-81-79 x Década) } & :-9,37 \%
\end{array}
$$

e para PG com produção maior que $-21,19 \%$ foram:

$$
\begin{array}{lr}
-25 \text { (Década } x \text { Primavera) } & :-37,26 \% \\
-29 \text { (Hale-321 x Primavera) } & :-32,68 \% \\
-41 \text { (FT-81-1835 x Hale-321) } & :-32,61 \% \\
-33 \text { (SOC-81-79 x Década) } & :-24,07 \% \\
-44 \text { (SOC-81-79 x Palmetto) } & :-21,19 \%
\end{array}
$$

Na seleção visando maior altura de planta (APM), segundo a Tabela 20, os cruzamentos que apresentaram maiores valores em porcentagem de rcs para resistência ao dano mecânico (DM<-15,58\%) foram:

$$
\begin{array}{lr}
-29 \text { (Hale-321 x Primavera) } & :-30,57 \% \\
-44 \text { (SOC-81-79 x Palmetto) } & :-23,28 \% \\
-30 \text { (Palmetto x Primavera) } & :-21,61 \% \\
-14 \text { (IAC-Foscarin-31 x FT-81-1835) : }-18,62 \% \\
-37 \text { (Forrest x SOC-81-79) } & :-15,58 \%
\end{array}
$$


e para PG com produção maior que $30,15 \%$, foram:

- 17 (IAC-Foscarin-31 x Forrest) $: 35,35 \%$

- 25 (Década $x$ Primavera) : $\quad 34,00 \%$

- 29 (Hale-321 x Primavera) : : 31,99\%

- 44 (SOC-81-79 x Palmetto) : : 30,15\%

Na seleção visando maior produção (PG), segundo a Tabela 20, os cruzamentos que apresentaram maiores valores em porcentagem de rcs para resistência ao dano mecânico (DM<-19,45\%) foram:

$\begin{array}{ll}-41 \text { (FT-81-1835 x Hale-321) } & :-35,19 \% \\ -31 \text { (Forrest } \times \text { Década) } & :-26,53 \% \\ -29 \text { (Hale-321 x Primavera) } & :-26,23 \% \\ \text { - } 4 \text { (Paraná x Década) } & :-23,53 \% \\ \text { - 25 (Década x Primavera) } & :-19,45 \%\end{array}$

e para APM com altura de planta maior que $0,32 \%$, foram:

- 26 (Forrest x Primavera) : : 0,49\%

- 16 (IAC-Foscarin-31 x Hale-321) : 0,37\%

- 3 (Paraná $x$ Coker-136) : : $\quad 32 \%$

\subsection{Regressão linear múltipla aplicada ao valor de DM}

Considerando o total de observações nos experimentos de 1991/92 e 1992/93 (Tabela 21), verifica-se que as variáveis SQ e SD foram as que mais contribuiram na composição do $R^{2}$ do modelo geral $\left(D M=b_{1} S Q+b_{2} S D+b_{3} S I\right)$. Em 1991/92 a variável SQ contribuiu com 0,59, a SD com 0,11 e a SI com 0,04 do modelo

geral com $\mathrm{R}^{2}=0,74$. Em 1992/93 a variável SQ contribuiu com 0,51 , a SD com 0,27 e a SI com 0,01 do modelo geral com $R^{2}=0,79$.

Os valores de $\mathrm{R}_{\text {parcial }}^{2}$ para SI foram considerados baixos, pois contribuem muito pouco para o modelo geral, sugerindo que apenas uma análise visual com ou sem 
lentes de aumento, é suficiente para quantificar a suscetibilidade de um genótipo em relação ao dano mecânico.

Analisando os cruzamentos individualmente nos dois experimentos avaliados (1991/92 e 1992/93), observa-se que em todos os cruzamentos, testemunhas e parentais, os valores de $\mathrm{R}_{\text {parcial }}^{2}$ para SI é muito baixo, contribuindo muito pouco para o $\mathrm{R}^{2}$ do modelo geral. Lembrando que esta análise de regressão foi realizada com o número absoluto de sementes classificadas conforme o tipo de dano (SQ, SD e SI), sem os indices de resistência, observa-se que para $\mathrm{R}^{2}$ do modelo por cruzamento (Tabela 21),

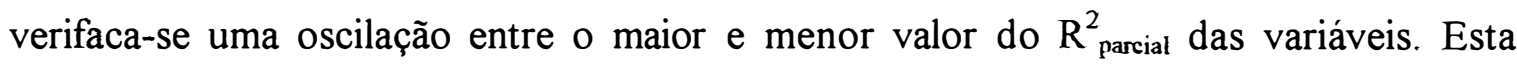
observação sugere que as duas variáveis não devem ser tomadas individualmente para quantificar o DM, e sim juntamente com o uso de índices de resistência ao dano para formar o valor de DM.

O uso destes índices de dano são importantes para diferenciar dois genótipos que apresentem na soma de SQ e SD o mesmo valor. Deste modo, quando avaliados com o auxilio destes índices, os dois genótipos terão valores diferentes de DM, pois o que apresentar maior número de SQ terá o maior valor de DM, logo será o mais suscetivel.

\subsection{Progresso genético observado $\left(G_{s}\right)$}

\subsection{1. $\mathrm{G}_{\mathrm{s}}$ - baseado em número de linhagens}

O progresso genético observado (Tabelas 22, 23 e 24), permite observar as diferenças entre os 45 cruzamentos em relação ao número de linhagens com médias superiores ao melhor dos dez parentais do dialelo (LSP), à melhor testemunha (LST), à média dos dez parentais (LMP), à média das testemunhas (LMT), à média das linhagens (LML), ao melhor parental dentro do cruzamento (LSPC), à média dos parentais dentro de cada cruzamento (LMPC). 


\subsubsection{1. $G_{s}$ - APM (altura de planta na maturação) e PG (produção de grãos)}

Verificando-se as Tabelas 22 e 23 em dados de APM e PG, observa-se que somente para dados de APM foram obtidas linhagens superiores ao melhor parental utilizado no dialelo (Hale-321 com 78,562 cm). Estas linhagens (total=84), estão distribuídas em 23 (51\%) dos 45 cruzamentos, sendo que os cruzamentos 39 (Forrest $\mathrm{x}$ Palmetto), 40 (FT-81-1835 x SOC-81-79) e 31 (Forrest x Década) apresentaram o maior número destas linhagens, com 10,9 e 7 linhagens entre 10 avaliadas, respectivamente (Tabela 22). Estes resultados, indicam a possibilidade de obtenção de linhagens transgressivas para APM. Não foram obtidas linhagens mais produtivas que o melhor parental do dialelo (Coker-136) provavelmente em razão da média alta apresentada por este parental $\left(266,87 \mathrm{~g} / \mathrm{m}^{2}\right)$.

Analisando a média da melhor testemunha para o caráter APM $($ IAC-Foscarin-31 $=74,12 \mathrm{~cm})$ e PG $\left(\right.$ Paraná $\left.=163,25 \mathrm{~g} / \mathrm{m}^{2}\right)$ verifica-se que $33(73 \%)$ e $41(91 \%)$ dos cruzamentos apresentam linhagens superiores à melhor testemunha, respectivamente. Nestes cruzamentos, foram observadas 142 (31,5\%) linhagens com APM e 216 (48\%) linhagens com PG, superiores à melhor testemunha IAC-Foscarin-31. Os cruzamentos que apresentaram maior número de linhagens superiores para APM $(\mathrm{LST} \geq 9)$ foram:

$$
\begin{aligned}
& -39 \text { (Forrest x Palmetto) } \\
& -40 \text { (FT-81-1835 x SOC-81-79) } \\
& -31 \text { (Forrest x Década) } \\
& -17 \text { (IAC-Foscarin-31 x Forrest) } \\
& -41 \text { (FT-81-1835 x Hale-321) }
\end{aligned}
$$

e para PG (LST $\geq 8$ ) foram os cruzamentos:

- 10 (IAC-Foscarin-31 x Coker-136)

- 20 (Forrest x Coker-136)

- 32 (Década x FT-81-1835)

- 45 (Hale-321 x Palmetto) 
- 39 (Forrest x Palmetto)

- 30 (Palmetto x Primavera)

- 15 (IAC-Foscarin-31 x SOC-81-79)

Em relação ao número de linhagens superiores à média dos parentais (LMP), à média das testemunhas (LMT) e à média das linhagens (LML), foram observados 41 (91\%), $40(89 \%)$ e $39(86 \%)$ cruzamentos com LMP, LMT e LML para APM, apresentando 255 (56\%), 277 (61\%) e 234 (52\%) linhagens distribuídas nestes cruzamentos, respectivamente. Para PG foram observados $40(89 \%), 44(98 \%)$ e 43 (95\%) cruzamentos com LMP, LMT e LML, apresentando 206 (46\%), 251 (56\%) e $232(51 \%)$ linhagens distribuídas nestes cruzamentos, respectivamente. Nas Tabelas 22 e 23 , pode-se verificar a distribuição destas linhagens nos cruzamentos.

Analisando o número de linhagens superiores ao melhor parental (LSPC) e à média dos parentais (LMPC) em cada cruzamento, foram observados $32(71 \%)$ e 38 (84\%) cruzamentos com LSPC e LMPC para APM, apresentando 175 (39\%) e 246 (54\%) linhagens distribuídas nestes cruzamentos, respectivamente. Estes resultados indicam a possibilidade de obtenção de linhagens transgressivas para APM. Os melhores cruzamentos foram para LSPC:

- 12 (Década x IAC-Foscarin-31)

- 25 (Década $x$ Primavera)

- 31 (Forrest $x$ Década)

- 32 (Década x FT-81-1835)

- 39 (Forrest x Palmetto)

- 40 (FT-81-1835 x SOC-81-79)

e para LMPC foram:

- 12 (Década x IAC-Foscarin-31)

- 14 (IAC-Foscarin-31 x FT-81-1835)

- 25 (Década x Primavera)

- 27 (FT-81-1835 x Primavera)

- 31 (Forrest $x$ Década)

- 32 (Década x FT-81-1835) 
- 39 (Forrest x Palmetto)

- 40 (FT-81-1835 x SOC-81-79)

- 41 (FT-81-1835 x Hale-321)

- 42 (Palmetto x FT-81-1835)

todos apresentando dez linhagens superiores entre dez linhagens avaliadas.

Em dados de PG, foram observados 33 (73\%) e 39 (86\%) cruzamentos com LSPC e LMPC, apresentando 152 (34\%) e 203 (45\%) linhagens distribuídas nestes cruzamentos, respectivamente. Estes resultados também indicam a possibilidade de obtenção de linhagens transgressivas para PG. Os melhores cruzamentos para LSPC foram:

- 32 (Década x FT-81-1835)

- 39 (Forrest x Palmetto)

- 45 (Hale-321 x Palmetto)

- 15 (IAC-Foscarin-31 x SOC-81-79)

e para LMPC foram:

- 30 (Palmetto x Primavera)

- 45 (Hale-321 x Palmetto)

- 32 (Década x FT-81-1835)

- 39 (Forrest x Palmetto)

- 9 (Paraná x Palmetto)

- 12 (Década x IAC-Foscarin-31)

- 17 (IAC-Foscarin-31 x Forrest)

- 15 (IAC-Foscarin-31 x SOC-81-79)

- 31 (Forrest x Década)

- 44 (SOC-81-79 x Palmetto)

todos apresentando pelo menos oito linhagens superiores entre 10 linhagens avaliadas. 


\subsubsection{2. $\mathrm{G}_{\mathrm{s}}$ - DM (dano mecânico)}

Verificando-se a Tabela 24 em dados de DM, observa-se que no experimento com semeadura em 02/12/1992 foram obtidas linhagens superiores ao melhor parental utilizado no dialelo (Paraná com 1,757 udm). Estas linhagens (total=4), foram distribuídas em quatro dos 45 cruzamentos (1\%), sendo estes os cruzamentos:

- 9 (Paraná x Palmetto)

- 22 (SOC-81-79 x Coker-136)

- 30 (Palmetto x Primavera)

- 42 (Palmetto x FT-81-1835)

Estes resultados, nos indicam a possibilidade de obtenção de linhagens transgressivas para o caráter.

Analisando a média da melhor testemunha para o caráter DM no experimento com semeadura em 02/12/1992 (Primavera $=3,215 \mathrm{udm}$ ), verifica-se que 35 (78\%) dos cruzamentos apresentaram linhagens superiores à melhor testemunha. Nestes cruzamentos, foram observados 110 (24\%) linhagens superiores à melhor testemunha Primavera. Os cruzamentos que apresentaram maior número de linhagens superiores (LST $\geq 6$ ) foram:

- 30 (Palmetto x Primavera)

- 42 (Palmetto x FT-81-1835)

- 21 (Coker-136 x FT-81-1835)

- 27 (FT-81-1835 x Primavera)

Em relação ao número de linhagens superiores à média dos parentais (LMP), à média das testemunhas (LMT) e à média das linhagens (LML) do experimento com semeadura em 02/12/1992, um total de 43 (95\%), 41 (91\%) e 42 (93\%) cruzamentos com LMP, LMT e LML para dados de DM, apresentando 255 (56\%), 180 $(40 \%)$ e 234 (52\%) linhagens distribuídas nestes cruzamentos, respectivamente. $\mathrm{Na}$ Tabela 24 pode-se verificar a distribuição destas linhagens dentro dos cruzamentos do experimento com semeadura em 02/12/1992 e na análise conjunta dos dois experimentos. 
Analisando o número de linhagens superiores ao melhor parental (LSPC) e à média dos parentais (LMPC) em cada cruzamento, foram observados $30(66 \%)$ e $40(89 \%)$ cruzamentos com LSPC e LMPC, apresentando $142(31 \%)$ e $239(53 \%)$ linhagens distribuídas nestes cruzamentos, respectivamente. Estes resultados indicam a possibilidade de obtenção de linhagens transgressivas para DM. Os melhores cruzamentos foram para LSPC:

- 21 (Coker-136 x FT-81-1835)

- 22 (SOC-81-79 x Coker-136)

- 39 (Forrest x Palmetto)

- 40 (FT-81-1835 x SOC-81-79)

e para LMPC foram:

- 21 (Coker-136 x FT-81-1835)

- 22 (SOC-81-79 x Coker-136)

- 27 (FT-81-1835 x Primavera)

- 30 (Palmetto x Primavera)

- 39 (Forrest x Palmetto)

- 40 (FT-81-1835 x SOC-81-79)

- 42 (Palmetto x FT-81-1835)

todos apresentando dez linhagens superiores entre dez linhagens avaliadas.

\subsection{2. $G_{s}$ - baseado na média das linhagens}

O progresso genético observado com base na média das linhagens (Tabelas 25, 26 e 27), permite a análise mais detalhada das diferenças entre os 45 cruzamentos em relação ao melhor parental dentro do cruzamento (PS) e à média dos parentais de cada cruzamento (MP), fornecendo o ganho real em $\mathrm{cm}, \mathrm{g} / \mathrm{m}^{2}$ e udm. 


\subsubsection{1. $G_{\mathrm{s}}$ - APM (altura de planta na maturação) e PG (produção de grãos)}

Na Tabela 25 verifica-se em dados de APM, que os cruzamentos que apresentaram maiores valores percentuais de progresso genético observado em relação à média dos parentais no cruzamento (MP) foram:

$$
\begin{array}{ll}
-40 \text { (FT-81-1835 x SOC-81-79) } & : 42,03 \% \\
-27 \text { (FT-81-1835 x Primavera) } & : 34,08 \% \\
-31 \text { (Forrest x Década) } & : 33,07 \% \\
-32 \text { (Década x FT-81-1835) } & : 28,89 \% \\
-14 \text { (IAC-Foscarin-31 x FT-81-1835) : 28,13\% }
\end{array}
$$

Estes valores percentuais para o caráter APM nos 45 cruzamentos ficaram entre $-27 \%$ e $42 \%$, mostrando a grande variabilidade do caráter nos diferentes cruzamentos e a possibilidade de obtenção de linhagens superiores.

Analisando os dados percentuais do progresso genético observado em relação ao parental superior no cruzamento (PS) em dados de APM, observa-se que os cruzamentos:

$$
\begin{array}{ll}
-31 \text { (Forrest x Década) } & : 30,53 \% \\
\text { - } 40 \text { (FT-81-1835 x SOC-81-79) } & : 18,80 \% \\
\text { - } 27 \text { (FT-81-1835 x Primavera) } & : 15,93 \% \\
\text { - } 39 \text { (Forrest x Palmetto) } & : 13,72 \% \\
\text { - } 25 \text { (Década x Primavera) } & : 13,24 \%
\end{array}
$$

foram os que apresentaram os maiores valores percentuais, indicando a ocorrência de linhagens transgressivas para o caráter. Os valores de PS nos 45 cruzamentos ficaram entre $-30,5 \%$ e $30,5 \%$.

Na Tabela 26 verifica-se em dados de PG, que os cruzamentos que apresentaram os maiores valores percentuais de progresso genético observado em relação à média dos parentais no cruzamento (MP) foram:

$$
\text { - } 45 \text { (Hale-321 x Palmetto) : : 49, 14\% }
$$


- 17 (IAC-Foscarin-31 x Forrest) : 42,82\%

- 39 (Forrest x Palmetto) : : 37,95\%

- 30 (Palmetto x Primavera) : :36,71\%

- 31 (Forrest $x$ Década) : : $31,17 \%$

Estes valores percentuais para o caráter PG nos 45 cruzamentos ficaram entre $-34 \%$ e $49 \%$, revelando a grande variabilidade do caráter nos diferentes cruzamentos e a possibilidade de obtenção de linhagens superiores.

Analisando os dados percentuais do progresso genético observado em relação ao parental superior no cruzamento (PS) em dados de PG, observa-se que os cruzamentos que apresentaram os maiores valores percentuais, indicando a ocorrência de linhagens transgressivas para o caráter foram:

- 31 (Forrest x Década) $: 17,24 \%$

- 15 (IAC-Foscarin-31 x SOC-81-79) : 17,18\%

- 45 (Hale-321 x Palmetto) : : 15,86\%

- 10 (IAC-Foscarin-31 x Coker-136) : 11,60\%

- 14 (IAC-Foscarin-31 x FT-81-1835) : 11,52\%

Os valores de PS nos 45 cruzamentos ficaram entre $-44 \%$ e $17 \%$.

\subsubsection{2. $\mathrm{G}_{\mathrm{s}}$ - DM (dano mecânico)}

Na Tabela 27 verifica-se em dados de DM no experimento com semeadura em 02/12/1992, que os cruzamentos que apresentaram os maiores valores percentuais de progresso genético observado em relação à média dos parentais no cruzamento (MP) foram:

$$
\begin{array}{ll}
-21 \text { (Coker-136 x FT-81-1835) : }-40,66 \% \\
-30 \text { (Palmetto x Primavera) } & :-40,26 \% \\
-24 \text { (Palmetto x Coker-136) } & :-35,54 \% \\
-22 \text { (SOC-81-79 x Coker-136) } & :-34,86 \% \\
-39 \text { (Forrest x Palmetto) } & :-34,77 \%
\end{array}
$$


Estes valores percentuais para o caráter PG nos 45 cruzamentos ficaram entre $-40 \%$ e $96 \%$, mostrando a grande variabilidade do caráter nos diferentes cruzamentos e a possibilidade de obtenção de linhagens superiores.

Analisando os dados percentuais do progresso genético observado em relação ao parental superior no cruzamento (PS) em dados de PG, observa-se que os cruzamentos que apresentaram os maiores valores percentuais, indicando a ocorrência de linhagens transgressivas para o caráter foram:

$$
\begin{aligned}
& \text { - } 21 \text { (Coker-136 x FT-81-1835) : -39,85\% } \\
& \text { - } 24 \text { (Palmetto x Coker-136) : :-33,24\% } \\
& \text { - } 22 \text { (SOC-81-79 x Coker-136) : -31,97\% } \\
& \text { - } 39 \text { (Forrest x Palmetto) : : }-30,49 \% \\
& \text { - } 30 \text { (Palmetto x Primavera) : : -21,06\% }
\end{aligned}
$$

Os valores de PS nos 45 cruzamentos ficaram entre $-40 \%$ e $165 \%$. 


\section{CONCLUSÕES}

As conclusões obtidas com esta pesquisa para o grupo de soja precoce foram as seguintes:

a. $\mathrm{O}$ acondicionamento das amostras de sementes em B.O.D. com temperatura de $25{ }^{\circ} \mathrm{C}$ e umidade de $85 \%$ por um período de $72 \mathrm{hs,} \mathrm{elevou} \mathrm{o} \mathrm{teor} \mathrm{de} \mathrm{umidade} \mathrm{inicial} \mathrm{de} 7 \%$ para $12,74 \% \pm 0,34$, ideais para a realização do 'teste do pêndulo';

b. A suscetibilidade da semente ao dano mecânico parece ser mais influenciada por fatores de campo (condições climáticas e fitotécnicas responsáveis pela produção e formação da semente) do que propriamente pela idade da semente;

c. Existe na população, variabilidade suficiente para se obter ganhos com seleção para altura de plantas, produção de grãos e resistência da semente ao dano mecânico;

d. Os cultivares Paraná, Hale-321, IAC-Foscarin-31 e Primavera, foram considerados com o mesmo nível de resistência ao dano mecânico do cultivar IAS-5, utilizado como padrão de resistência; os cultivares Palmetto, Coker-136, FT-81-1835 e Forrest foram considerados como cultivares suscetíveis, embora superiores ao padrão de suscetibilidade IAC-2;

e. O caráter DM apresenta herdabilidade considerada média para alta $\left(\mathrm{h}^{2}=0,739\right)$; indicando ser promissora a obtenção de linhagens transgressivas para resistência da semente ao dano mecânico;

f. O valor numérico de DM pode ser composto somente pelo número de sementes quebradas (SQ) e danificadas (SD), combinados em um índices de resistência; o valor de sementes intumescidas (SI) obtidas com o auxílio de hipoclorito de sódio não é importante para a determinação do nível de resistência ao dano mecânico de um genótipo; 
g. A qualidade fisiológica da semente, expressa em germinação, é importante na suscetibilidade da semente ao dano mecânico; a correlação entre germinação $(G)$ e DM embora considerada baixa a média, foi negativa;

h. Os caracteres APM, PG e DM apresentaram baixos valores de correlação genética, deste modo, pode-se reunir em um mesmo genótipo todas as combinações possíveis para estes caracteres;

i. Do mesmo modo, a resposta correlacionada à seleção pode apresentar valores altos para os três caracteres estudados em todas as combinações; no entanto, é extremamente dependente dos parentais envolvidos no cruzamento;

j. Para os três caracteres avaliados foram obtidas linhagens transgressivas, sendo que $39 \%$ em APM, 34\% em PG e 31\% em DM do total de linhagens, foram superiores ao melhor parental no cruzamento;

k. O progresso genético observado na média das linhagens, apresenta superioridade em relação ao parental superior no cruzamento em até $30,5 \%$ para altura de planta $(\mathrm{cm})$, $18 \%$ para produção de grãos $\left(\mathrm{g} / \mathrm{m}^{2}\right)$ e $40 \%$ para resistência ao dano mecânico (udm). 


\section{REFERÊNCIAS BIBLIOGRÁFICAS}

AGRAWAL, P.K. \& MENON, S.K. Lignin content and seedcoat thickness in relation to seedcoat cracking in soybean. Seed Research, New Delhi, 2:64-6, 1974.

ALVAREZ, P.J. Releção entre o conteúdo de lignina no tegumento de semente de soja e sua reação ao dano mecânico. Londrina, 1994. 43p. (MestradoUniversidade Estadual de Londrina).

BARRIGA, C. Effect of mechanical abuse of Navy beans seed at various moisture levels. Agronomy Journal, Madison, 53(4):250-1, 1961.

BARTSCH, J.A.; HAUGH, C.G.; ATHOW, K.L.; PEART, R.M. Impact damage to soybean seed. Transactions of the ASAE, Michigan, 29(2):582-6, 1986.

BONETTI, L.P. Distribuição da Soja no Mundo; origem, história e distribuição. In: MIYASAKA, S. \& MEDINA, J.C., ed.. A Soja no Brasil. Campinas, ITAL, 1981. p. 01-06.

BRASI, Ministério da Agricultura. Regras para Análise de Sementes. Brasília, DISEM/DNPV, 1976. 188p. (Portaria do M. A. n532, de 28/07/76).

BUNCH, H.D. Relationship between moisture content of seed and mechanical damage in seed conveying. Seed World, Lynn Whittmore, 86(5):14-6,7, 1960.

BURCHETT, C.A.; SCHAPAUGH JUNIOR, W.T.; OVERLEY, C.B.; WALTER, T.L. Influence of etched seedcoats and environmental conditions on soybean seed quality. Crop Science, Madison, 25(4):655-60, 1985.

BURRIS, J.S. Effect of conditioning environment on seed quality and field performance of soybeans. In: SOYBEAN SEED RESEARCH CONFERENCE, 9, 1979. Proccedings.,American Seed Trade Association, 1979. p.79-85.

BYG, D.B. Minimizing harvest losses and mechanical damage of soybean seed. In: PROCEEDINGS SOUTHEASTERN SOYBEAN SEED SEMINAR, Mississippi, 1974. Proceedings. Starkville, Mississippi State University, 1974. p.53-78.

CAMPOS, H. Estatística aplicada à experimentação com cana-de-açucar. Piracicaba, 1984. FEALQ, Piracicaba, 1984. 292p.

CARBONELL, S.A.M. Metodologia para seleção de genótipos de soja com semente resistente ao dano mecânico. Londrina, 1991. 103p. (Mestrado-Universidade Estadual de Londrina).

CARBONELL, S.A.M. \& KRZYZANOWSKI, F.C. The pendulum test for screening soybean genotypes for seeds resistant to mechanical damage. Seed Science \& Technology. Zürich, 23(2):331-9.1995. 
CARBONELL, S.A.M.; KRZYZANOWSKI, F.C.; KASTER, M. Avaliação do 'teste de queda' para seleção de genótipos de soja com sementes resistentes ao dano mecânico. Revista Brasileira de Sementes. Brasília, 14(2):215-9. 1992.

CARBONELL, S.A.M.; KRZYZANOWSKI, F.C.; OLIVEIRA, M.C.N.de.; FONSECA JUNIOR, N. da S. Teor de umidade das sementes de soja e métodos de avaliação do dano mecânico provocado no teste do pêndulo. Pesquisa Agropecuária Brasileira. Brasilia, 28(11):1277-85. 1993.

CAVINESS, C.E. \& SIMPSON JUNIOR, A.M. Influence of variety and location on seedcoat thickness of mature soybean seed. Proceedings of the Association of Official Seed Analysts, Springfield, 64: 102-8, 1974.

COELHO, R.C. Efeito imediato de danos mecânicos em sementes de soja (Glycine max (L.) Merril). Semente, Brasília, 0:8-9, 1973.

COPELAND, L.O. How seed damage affects germination. Crops \& Soils Magazine, Madison, 24(9):9-12, 1972.

COSTA, A.B.; KUENEMAN, E.A.; MONTEIRO, P.M.F.D. Varietal differences in soybeans for resistance to physical damage of seed. Soybean Genetics Newsletter, Ames, 14:73-6, 1987.

COSTA, N.P.; FRANÇA NETO, J. de B.; PEREIRA, L.A.G.; HENNING, A.A. Avaliação da qualidade da semente de soja produzida no estado do Paraná. Londrina, 1986. EMBRAPA-CNPSo, 1986. 13p. (EMBRAPA-CNPSo, Comunicado Técnico, 36).

COSTA, N.P.; PEREIRA, L.A.G.; FRANÇA NETO, J. de B.; HENNING, A.A.; YAMASHITA, J.A. Avaliação da qualidade da semente de soja produzida nas safras agrícolas de 1976/77 e 1978/79, no Estado do Paraná. In: SEMINÁRIO NACIONAL DE PESQUISA DE SOJA, 2, BRASÍLIA, 1981. Anais. Londrina, EMBRAPA-CNPSo, 1982. v. 1, p.557-73.

COSTA, N.P.; MESQUITA, C.M.; HENNING, A.A. Avaliação das perdas e dos efeitos da colheita mecânica sobre a qualidade fisiológica e a incidência de patógenos em sementes de soja. Revista Brasileira de Sementes, Brasília, 1(3):59-70, 1979.

CZERMAINSKI, A.B.C. Análise exploratória de dados: Identificação de um único “outlier" em dados de experimentos delineados em blocos casualizados. Piracicaba, 1986. 134p. (Mestrado-Escola Superior de Agricultura "Luiz de Queiroz"/USP).

DASSOU, S. \& KUENEMAN, E.A. Screening methodology for resistance to field weathering of soybean seed. Crop Science, Madison, 24(4):774-9, 1984.

DELOUCHE, J.C. Harvesting, handling and storage of soybean seed. SHORT COURSE FOR SEEDSMEN, 15, Starkville, 1972. Mississippi State University, 1972. p. 17-22. 
DICKSON, M.H. \& BOETTGER, M.A. Inheritance of resistance to mechanical damage and transverse cotyledon cracking in Snap Beans (Phaseolus vulgaris L.). Journal American Society for Horticulture Science, Homesterd, 102(4):498-501, 1977.

DORREL, D.G. \& ADAMS, M.W. Effect of some seed characteristics on mechanically induced seedcoat damage in Navy Beans (Phaseolus vulgaris L.). Agronomy Journal, Madison, 61(5):672-3, 1969.

DRAPER, N.R. \& SMITH, H. Applied Regression Analysis. New York. Jonh Wiley \& Sons, Inc. 2 ed. 1966. p. 294-379.

FAGUNDES, S.R.F. Latent effects of mechanical injury on soybean seed (Glycine $m a x$ (L.) Merr.). Starkville, 1971. 80p. (MsC-Mississippi State University).

FALCONER, D.S. Introduction to quantitative genetics. 3.ed. Harlow, Longman, 1989. $438 \mathrm{p}$.

FISCUS, D.E.; FOSTER,G.H.; KAUFMANN, H.H. Physical damage of grain caused by various handling techniques. Transactions of the ASAE, Michigan, 14(3):480-5, 1971.

FRANÇA NETO, J. de B.; COSTA, N.P.; HENNING; A.A.; MESQUITA, C.M. Descarte de lotes de sementes de soja em decorrência de danos mecânicos no processo de colheita. In: EMBRAPA-Centro Nacional de Pesquisa de Soja. Londrina, 1981. Resultados de Pesquisa de Soja 1980/81. Londrina, 1981. p.27580.

FRANÇA NETO, J. de B. \& HENNING, A.A. Qualidade fisiológica e sanitária de sementes de soja. Londrina, 1984. EMBRAPA-CNPSo, 1984. 39p. (EMBRAPACNPSo, Circular Técnica, 09).

FRANÇA NETO, J. DE B. \& POTTS, H.C. Efeitos da colheita mecânica e da secagem artificial sobre a qualidade da semente dura em soja. Revista Brasileira de Sementes, Brasilia, 1(2):64-77, 1979.

FRANÇA NETO, J. de B.; WEST, S.H.; VAUGHAN, W.R. Multiple quality evaluation of soybean seed produced in Florida in 1986. Soil and Crop Science Society of Florida Proc., Gainesville, 47:20-2, 1987.

GAYLOR, D.W.; LUCAS, H.L.; ANDERSON, R.L. Calculation of expected mean squares by the abbreviated doolitle and square root methods. Biometrics, Whashington, 26(4):641-55. 1970.

GREEN, D.E.; CAVANAH, L.E.; PINNELL, E.L. Effect of seed moisture content, field weathering and combine cylinder speed on Soybean seed quality. Crop Science, Madison, 6(1):7-10, 1966.

GREEN, D.E.; LUEDDERS, V.D.; MORAGHAN, B.J. Heritability and advance from selection for six soybean seed-quality characters. Crop Science, Madison, 11(4):531-3, 1971. 
GREEN, D.E. \& PINNELL, E.L. Inheritance of soybean seed quality. I. Heritability of laboratory germination and field emergence. Crop Science, Madison, 8(1):5-11, 1968

GREEN, D.E. \& PINNELL, E.L. Inheritance of soybean seed quality. II. Heritability of visual ratings of soybean seed quality. Crop Science, Madison, 8(1):11-5, 1968.

GUPTA, P.C.; MILLER, D.A.; HITTLE, C.N. Note on the effect of threshing on seed damage, seed vigour and germinability in two soybean varieties. Indian Journal Agricultural Science, Delhi, 43(6):617-8, 1973.

HARTLEY, H.O. The maximum F-Ratio as a short-cut test for heterogeity of variance. Biometrika 37:308-12. 1950.

HIROMOTO, D.M. \& VELLO, N.A. The genetic base of Brazilian soybean (Glycine $\max ($ L.) Merrill) cultivars. Revista Brasileira de Genética. Ribeirão Preto, 9(2):295-306, 1986.

HYMOWITZ, T. On the Domestication of the Soybean. Economic Botany, New York, 24(4):408-21, 1970.

HYMOWITZ, T. \& SINGH, R.J. Taxonomy and Speciation. In: Soybean: Improvement, Production, and Uses. Ed. J.R. Wilcox. 2 ed. Madison, USA. p. 2348. 1987

JIJÓN, A.V. \& BARROS, A.C.S.A. Efeito dos danos mecânicos na semeadura sobre a qualidade de sementes de soja (Glycine max (L.) Merrill). Tecnologia de Sementes, Pelotas, 6(1/2):3-21, 1983.

KANNENBERG, L.W. \& ALLARD, R.W. An association between pigment and lignin formation in the seed coat of the Lima Bean. Crop Science, Madison, 4(6):621-2, 1964.

KEMPTHORNE, O. An introduction to genetic statistics. Ames, Iowa State University Press, 1969. 545p.

KRZYZANOWSKI, F.C.; COSTA, N.P.; MIRANDA, Z.F.S.; KIIHL, R.A.S.; KASTER, M.; SOUZA, P.I. Caracterização de genótipos de soja de ciclos precoce e médio quanto a qualidade fisiológica e suas inter-relações com aspectos morfológicos. IN: EMBRAPA-Centro Nacional de Pesquisa de Soja. Londrina, 1989. Resultados de Pesquisa de Soja 1988/89. Londrina, 1989. p.315-24.

KUENEMAN, E.A. Breeding for resistance to physical damage to soybean seed. In: PASCALE, A. ed. WORLD SOYBEAN RESEARCH CONFERENCE, 4. Buenos Aires, 1989. Proceedings. Buenos Aires, Asociacion Argentina de la Soja, 1989. v.2, p. 1086-90.

LUEDDERS, V.D. \& BURRIS, J.S. Effects of broken seedcoats on field emergence of soybeans. Agronomy Journal, Madison, 71(5):877-9, 1979. 
MAEDA, J.A.; MIRANDA, M.A.C.; ARKCOLL, D.; ZINK, E. Influência de diversos fatores externos sobre a qualidade de sementes de soja. Bragantia, Campinas, 36(1):179-86, 1977.

MASON, S.C.; VORST,.J.J.; HANKINS, B.J.; HOLT, D.A. Standard, cold, and tetrazolium germination test as estimators of field emergence of mecanically damaged soybeans seed. Agronomy Journal, Madison, 74(3):546-50, 1982.

MESQUITA, C.M. \& HANNA, M.A. Soybean threshing mechanics: II. Impact. Transactions of the ASAE, Michigan, 36(2):281-4, 1993.

MOORE, R.P. Effects of mechanical injuries on viability. In: Roberts, E. H. ed. Viability of seeds. s.1., Syracuse University, 1972. Cap. 4. p.94-113.

MOREIRA, S.M.C.; SILVA, A.A.da; ALVARENGA, L.C.da Resistência de sementes de soja a impactos - energia limite. Revista Brasileira de Armazanamento, Viçosa, 13 e 14(1,2):22-4. 1988/1989.

MULLER, L. Taxionomia e Morfologia. In: MIYASAKA, S. \& MEDINA, J.C. (ed.). A Soja no Brasil. Campinas, ITAL, 1981, p. 65-72.

NAVE, W.R.; COOPER, R.L.; WAX, L.M. Tillage-plante interations in narrow-row soybeans. Transactions of the ASAE, Michigan, 20(1):9-17, 1977.

NAVE, W.R. \& PAULSEN, M.R. Soybean seed quality as afected by planter meters. Transactions of the ASAE, Michigan, 22(4):739-45, 1979.

NELSON, A.I.; WEI, L.S.; STEINBERG, M.P. Foods from whole soybean. In: WORLD SOYBEAN RESEARCH CONFERENCE, 2, Raluger, 1979. Proceedings. Bouddes, Westview Press, 1980. p. 745-761.

PARENTE, R.C.P. Aspectos da análise de resíduos. Piracicaba, 1984. 139p. (Mestrado-Escola Superior de Agricultura "Luiz de Queiroz"/USP).

PAULSEN, M.R. Soybean's suscetibility to damage during normal handling conditions. (Univers. of Illinois) Agricultural Experimental Station, Illinois, 19(3):18-9, 1977.

PAULSEN, M.R. Fracture resistance of soybean to compresive loading. Transactions of the ASAE, Michigan, 21(6): 1210-6, 1978.

PAULSEN, M.R. \& NAVE, W.R. Soybean seedcoat damage detection methods. Transaction of the ASAE, Michigan, 1977. 14p. (ASAE . Paper, 77-3503).

PAULSEN, M.R. \& NAVE, W.R. Improved indoxyl acetate test for detecting soybeans seedcoat damage. Transactions of the ASAE, Michigan, 22(6): 1475-9, 1979.

PAULSEN, M.R.; NAVE, W.R.; GRAY, L.E. Soybean seed quality as affected by impact damage. Transactions of the ASAE, Michigan, 24(6):1577-82/89, 1981a.

PAULSEN, M.R.; NAVE, W.R.; MOUNTS, T.L.; GRAY, L.E. Storability of harvestdamaged soybean. Transactions of the ASAE, Michigan, 24(6): 1583-9, 1981b. 
PEREIRA, L.A.G. \& ANDREWS, C.H. Comparison of non-wrinkled and wrinkled soybean seedcoats by scanning electron microscopy. Seed Science \& Technology, Zürich, 13(3):853-9, 1985.

PESKE, S. \& PEREIRA, L.A.S. Tegumento da semente de soja. Tecnologia de Semente, Pelotas, 6(1/2):23-34, 1983.

POPINIGIS, F. Immediate effects of mechanical injury on soybean (Glycine max (L.) Merr.) seed. Starkville, 1972. 72p. (MsC-Mississippi State University).

PRAKOBBOON, N. A study of abnormal seedling development in soybean as affected by threshing injury. Seed Science and Technology, Zürich, 10(3):495-501, 1982.

RODDA, E.D.; STEINBERG, M.P.; WEI, L.S. Soybean damage detection and evaluation for food use. Trasactions of the ASAE, Michigan, 1972. 7p. (ASAE. Paper $\mathrm{n}^{\circ}$ 72-380).

SAINI, S.K.; SINGH, J.N.; GUPTA, P.C. Effect of thresing method on seed quality of soybean. Seed Research, New Delhi, 10(2):133-8, 1982.

SAS, Institute Inc. SAS User's guide: statistics. Edition 1982. Cary, 1982. 684p.

SEDIYAMA, C.S.; VIEIRA, C.; SEDIYAMA, T.; CARDOSO, A.A.; ESTEVÃO, M.M. Influência do retardamento da colheita sobre a deiscência das vagens e sobre a qualidade e poder germinativo das sementes de soja. Experimentiae, Viçosa, 14(5):117-41, 1972.

SILVA, W.R.de Secagem das sementes. In: I semana de Atualização e Produção de Sementes. Piracicaba, 1986. Fundação Cargill, 1986. p.155-82. 1986.

STANWAY, V.M. Germination response of soybean seed with damaged seed coats. Proceedings Association of Official Seed Analysts North American, 64:97-101, 1974.

STANWAY, V.M. Evaluation of 'Forrest' soybean with damaged seed coat and cotyledons. Journal of Seed Technology, Springfield, 3(1):19-26, 1978.

VAUGHAN, C.E. The chlorox test (soybean). In: Quality Assurance techniques. (Emphasis: Mechanical damage). In: SHORT COURSE FOR SEEDSMEN, 1982. Procededings. 1982. Seed Technology Laboratory, 1982. p.117-8.

VELLO, N.A. Efeitos da introdução de germoplasma exótico sobre a produtividade e relações com a base genética dos cultivares de soja (Glycine max (L.) Merrill). Piracicaba, 1985. 91p. (Livre Docência-Escola Superior de Agricultura "Luiz de Queiroz"/USP).

VELLO, N.A. Métodos de melhoramento da soja. In: Simpósio sobre a cultura e produtividade da soja. Piracicaba, 1991. Anais. Piracicaba, FEALQ, 1992. p.41-59.

VENCOVSKY, R. \& BARRIGA, P. Genética biométrica no fitomelhoramento. Ribeirão Preto, SBG, 1992. 486p. 
VIEIRA, C.P.; VIEIRA, R.D; PASCHOALICK, J.H.N. Efects of mechanical damage during soybean seed processing on physiological seed quality and storage potential. Seed Sience \& Technology, Zürich, 22(3):581-9, 1994.

WALTERS, H.J. \& CAVINESS, C.E. Breeding for improved soybean seed quality. Arkansas Farm Reserch, Fayeteville, 22(5):5, 1973.

WOLF, W.J.; BAKER, F.L.; BERNARD, R.L. Soybean seedcoat structural features: pits, deposits and cracks. Scanning Electron Microscopy, Chicago, 3:531-44, 1981.

ZAPPIA, E.S. Ação da rachadura do tegumento sobre a germinação de sementes de soja. Arquivos de Biologia eTecnologia, Curitiba, 15:64-9, 1972.

ZINK, E. Immediate and latent effects of mechanical abuse on the germination of soybean seed. Starkville, 1966. 55p. (MsC-Mississippi State University). 
FIGURAS 


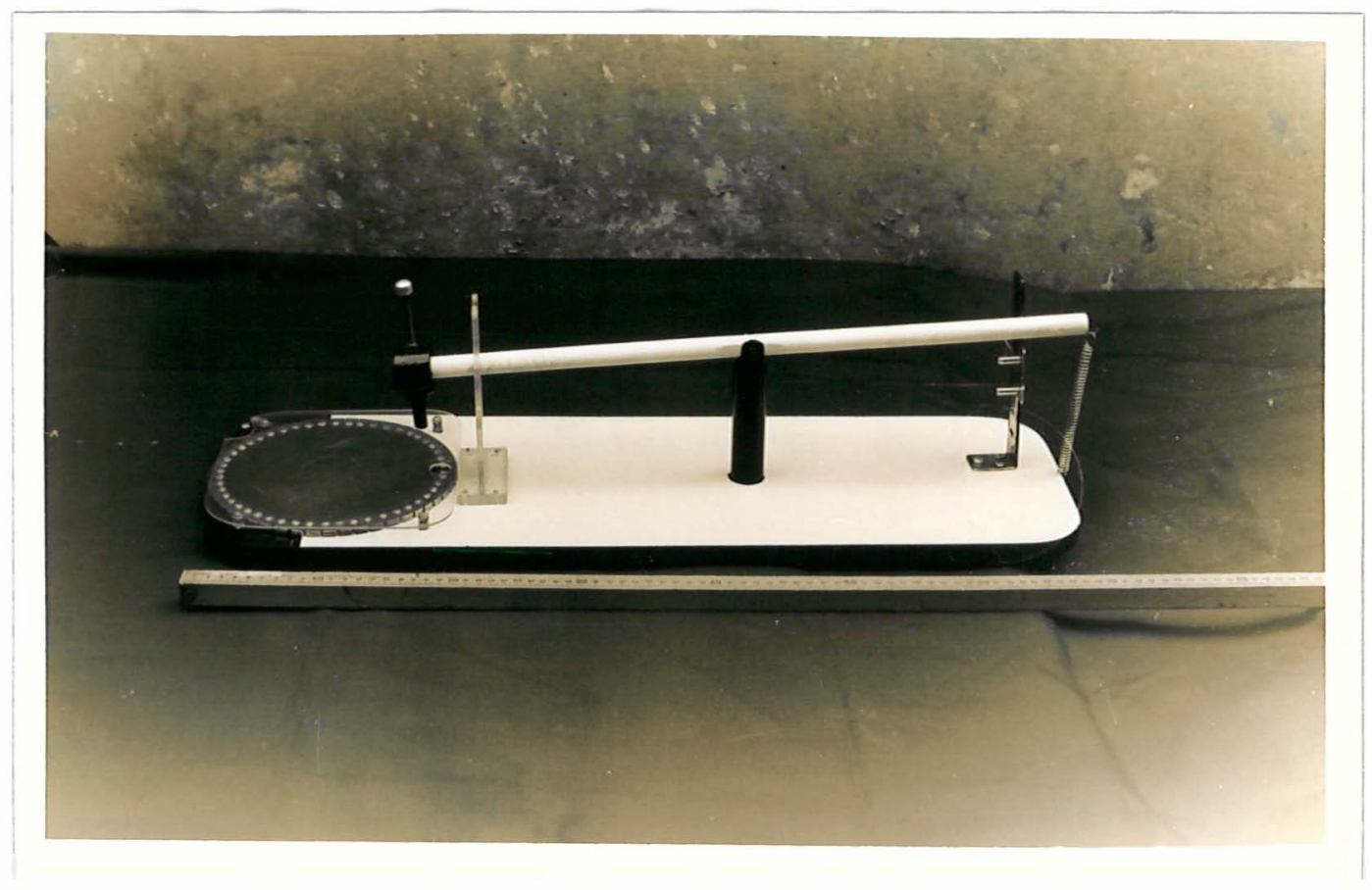

Figura 1 Danificador mecânico utilizado na realização do teste do pêndulo. Soja Precoce.
Piracicaba, ESALQ/USP. 


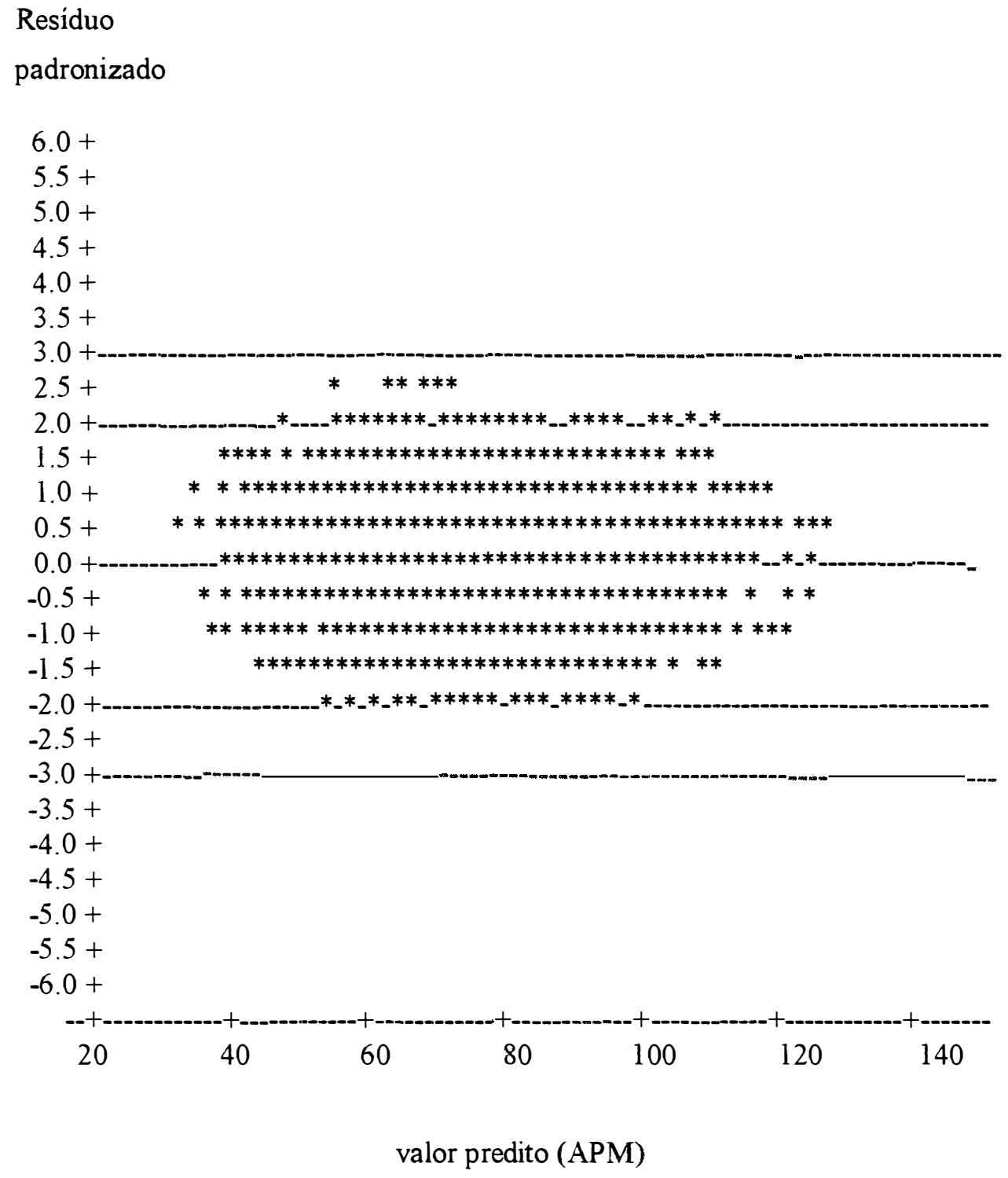

Obs.: 1535 observações sobrepostas.

Figura 2 APM: altura de planta na maturação. Representação gráfica dos residuos padronizados e valores preditos. Soja precoce, Piracicaba, experimento com semeadura em 03/12/91. 


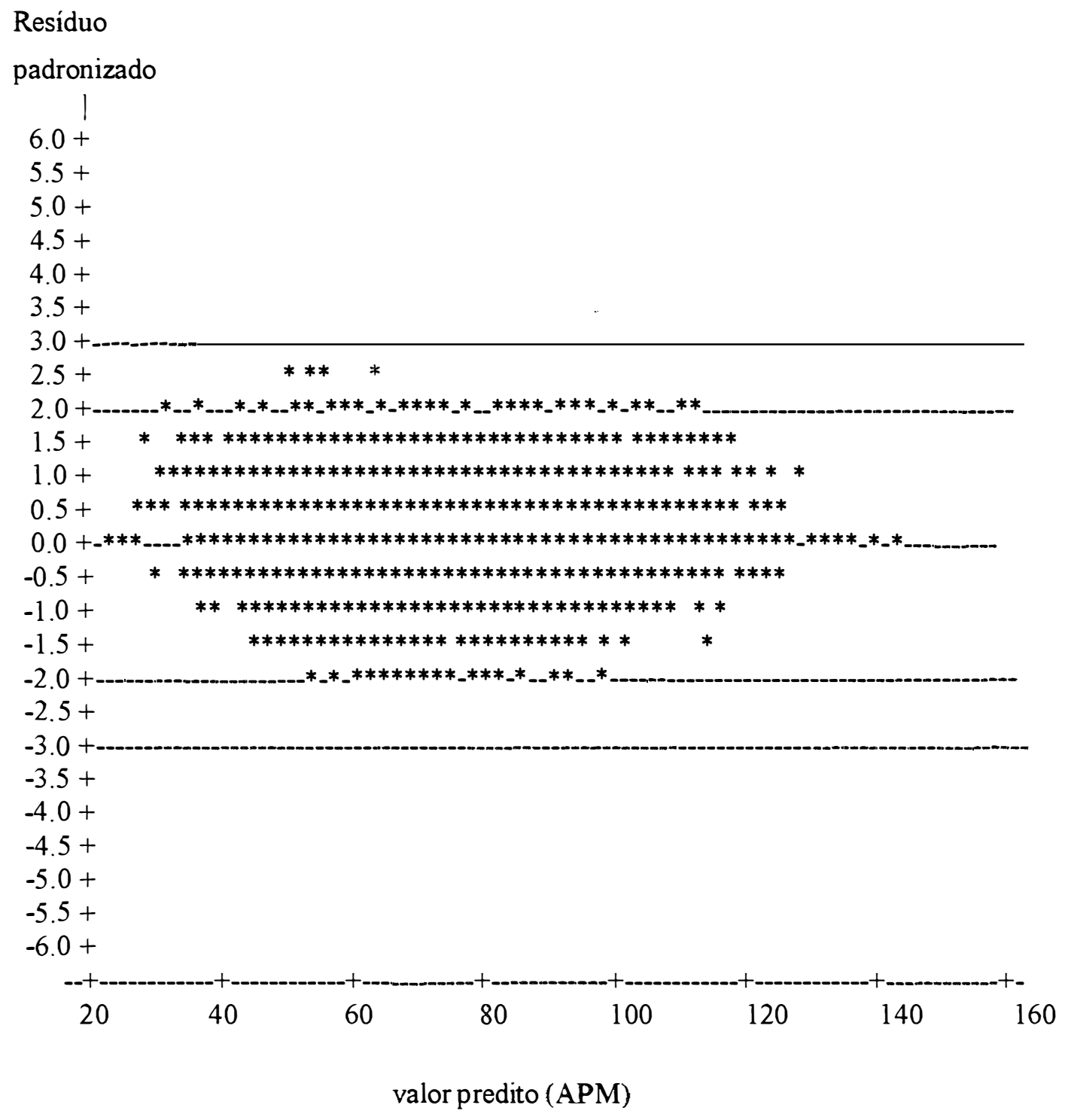

Obs.: 1510 observações sobrepostas

Figura 3 APM: altura de planta na maturação. Representação gráfica dos resíduos padronizados e valores preditos. Soja precoce, Piracicaba, experimento com semeadura em 02/12/92. 


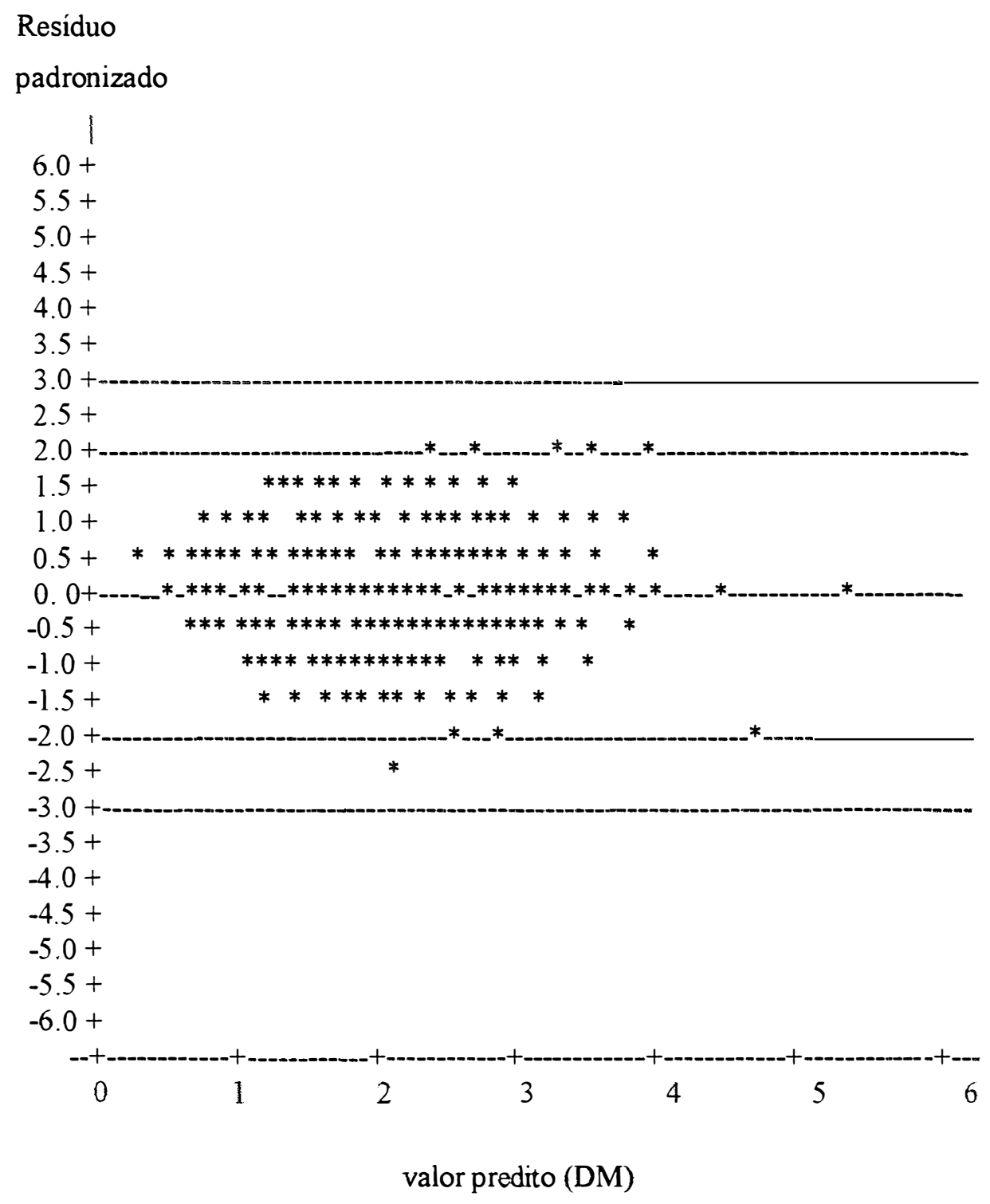

Obs.: 99 observações sobrepostas.

Figura 4 DM: dano mecânico. Representação gráfica dos resíduos padronizados e valores preditos. Soja precoce, Piracicaba, experimento com semeadura em 03/12/91. 


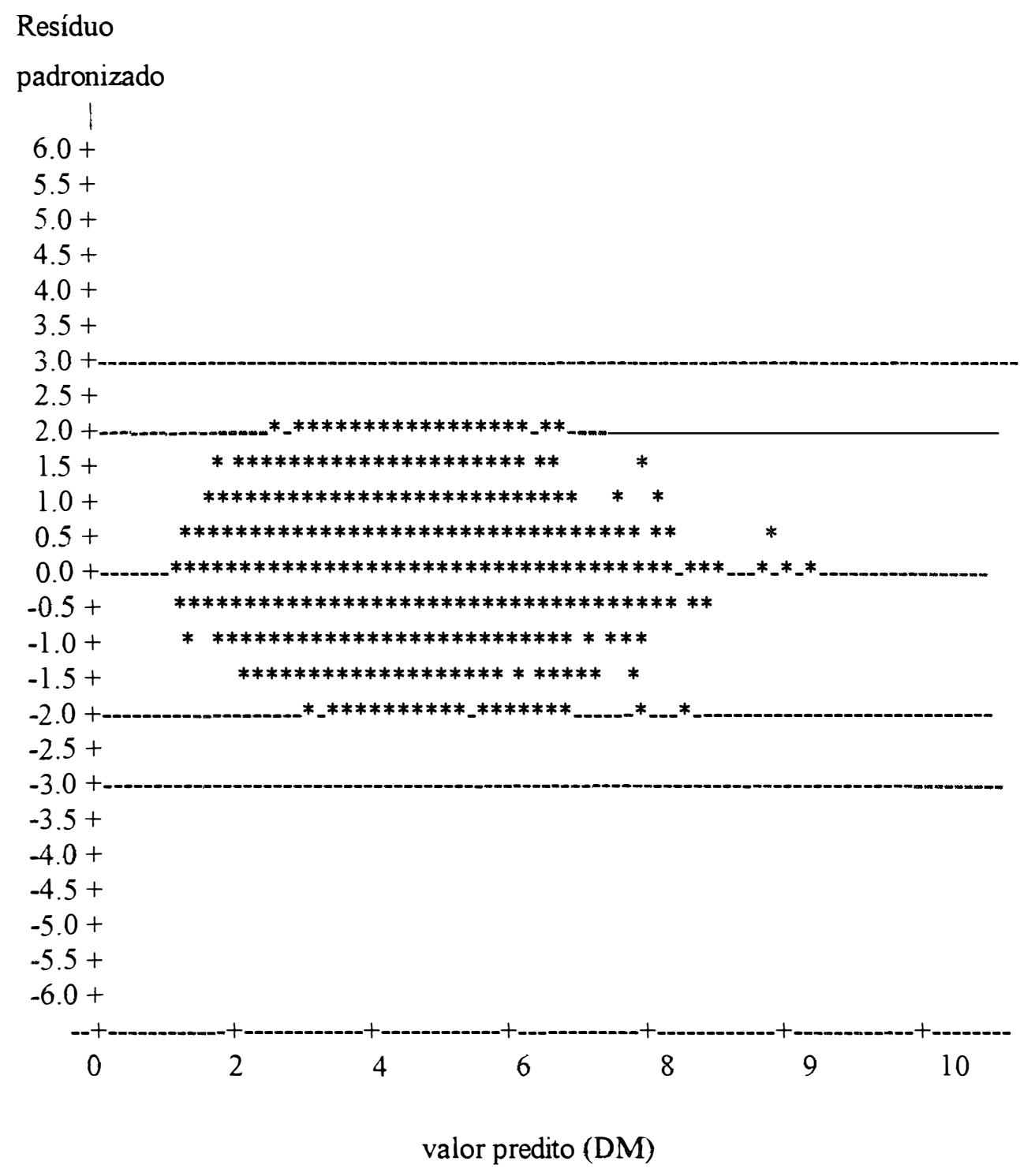

Obs.: 1593 observações sobrepostas.

Figura 5 DM: dano mecânico. Representação gráfica dos resíduos padronizados e valores preditos. Soja precoce, Piracicaba, experimento com semeadura em 02/12/92. 


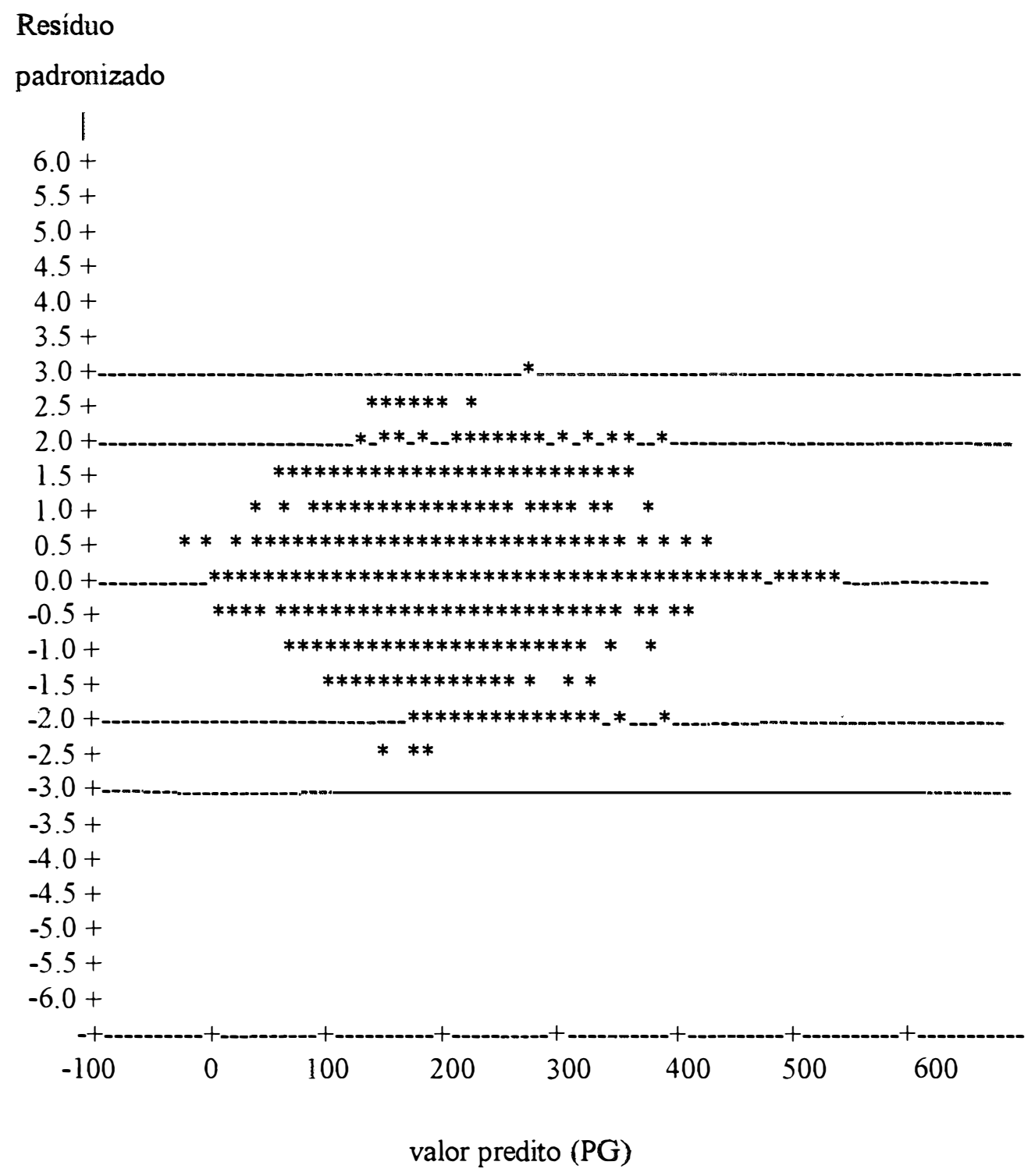

Obs.: 1146 observações sobrepostas.

Figura 6 PG: produção de grãos. Representação gráfica dos resíduos padroni zados e valores preditos. Soja precoce, Piracicaba, experimento com semeadura em 03/12/91. 


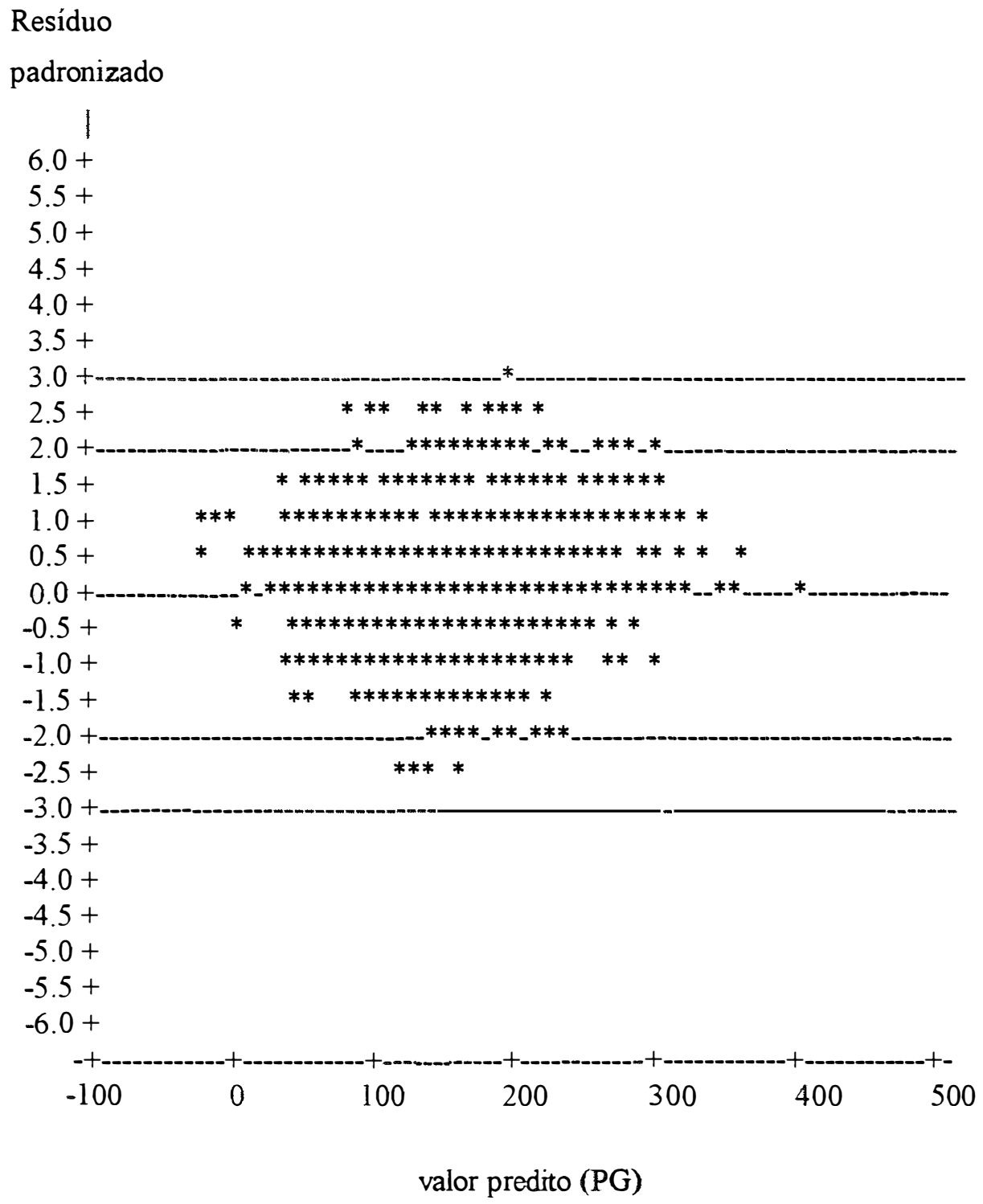

Obs.: 1166 observações sobrepostas

Figura 7 PG: produção de grãos. Representação gráfica dos resíduos padronizados e valores preditos. Soja precoce, Piracicaba, experimento com semeadura em 02/12/92. 


\section{TABELAS}


Tabela 1 Cruzamentos dialélicos (sem recíprocos; meia tabela) acima da diagonal e parentais na diagonal. Soja precoce. Piracicaba.

\begin{tabular}{|c|c|c|c|c|c|c|c|c|c|c|}
\hline Parental ${ }^{\text {a }}$ & 1 & 2 & 3 & 4 & 5 & 6 & 7 & 8 & 9 & 10 \\
\hline 1 & Y1.1 & Y1.2 & Y1.3 & Y1.4 & Y1.5 & Y1.6 & Y1.7 & Y1.8 & Y1.9 & Y1.10 \\
\hline 2 & & Y2.2 & Y2.3 & Y 2.4 & Y2.5 & Y2.6 & Y2.7 & Y 2.8 & Y2.9 & Y 2.10 \\
\hline 3 & & & Y3.3 & Y 3.4 & Y3.5 & Y3.6 & Y3.7 & Y3.8 & Y3.9 & Y3.10 \\
\hline 4 & & & & Y4.4 & Y4.5 & Y4.6 & Y4.7 & Y 4.8 & Y4.9 & Y4.10 \\
\hline 5 & & & & & Y5.5 & Y5.6 & Y5.7 & Y5.8 & Y5.9 & Y5.10 \\
\hline 6 & & & & & & Y6.6 & Y6.7 & Y6.8 & Y6.9 & Y6.10 \\
\hline 7 & & & & & & & Y7.7 & Y7.8 & Y7.9 & Y7.10 \\
\hline 8 & & & & & & & & Y8.8 & Y8.9 & Y8.10 \\
\hline 9 & & & & & & & & & Y9.9 & Y9.10 \\
\hline 10 & & & & & & & & & & Y 10.10 \\
\hline
\end{tabular}

${ }^{\text {a }}$ Parental: $\quad$ 1: Paraná

2: IAC-Foscarin-31

3: Coker-136

4: Primavera

5: Década

6: Forrest

7: FT-81-1835

8: SOC-81-79

9: Hale-321

10: Palmetto 


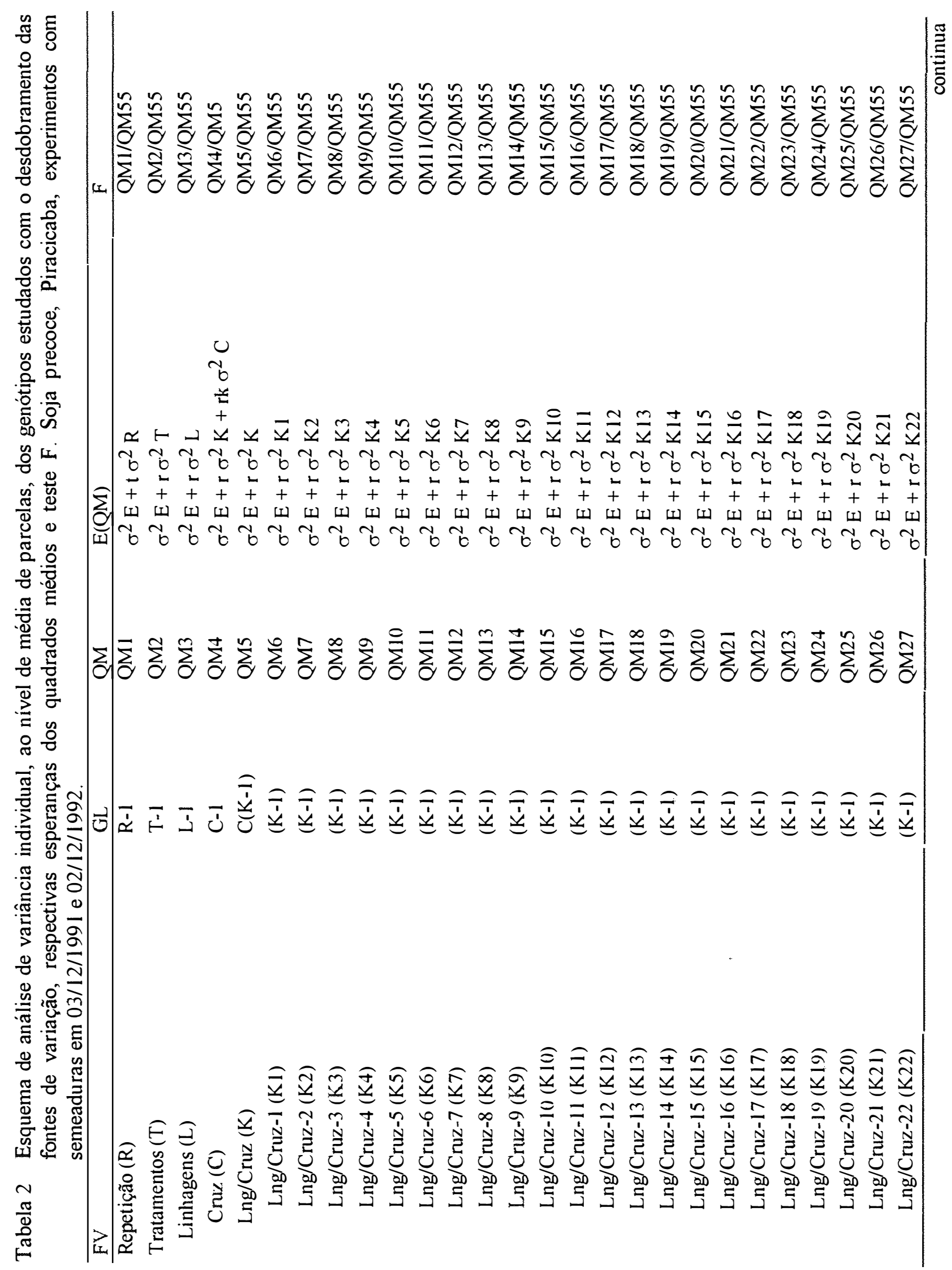




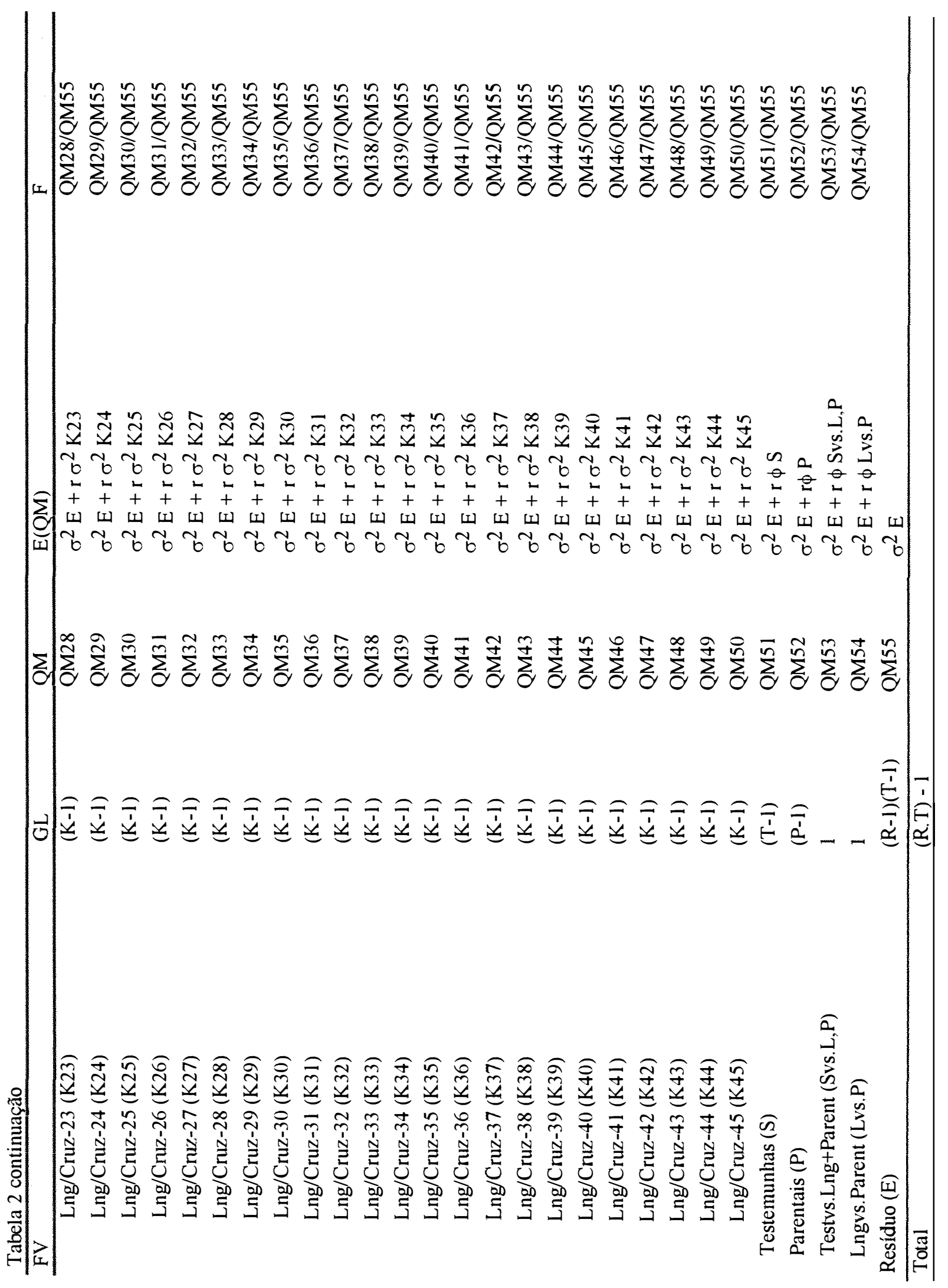




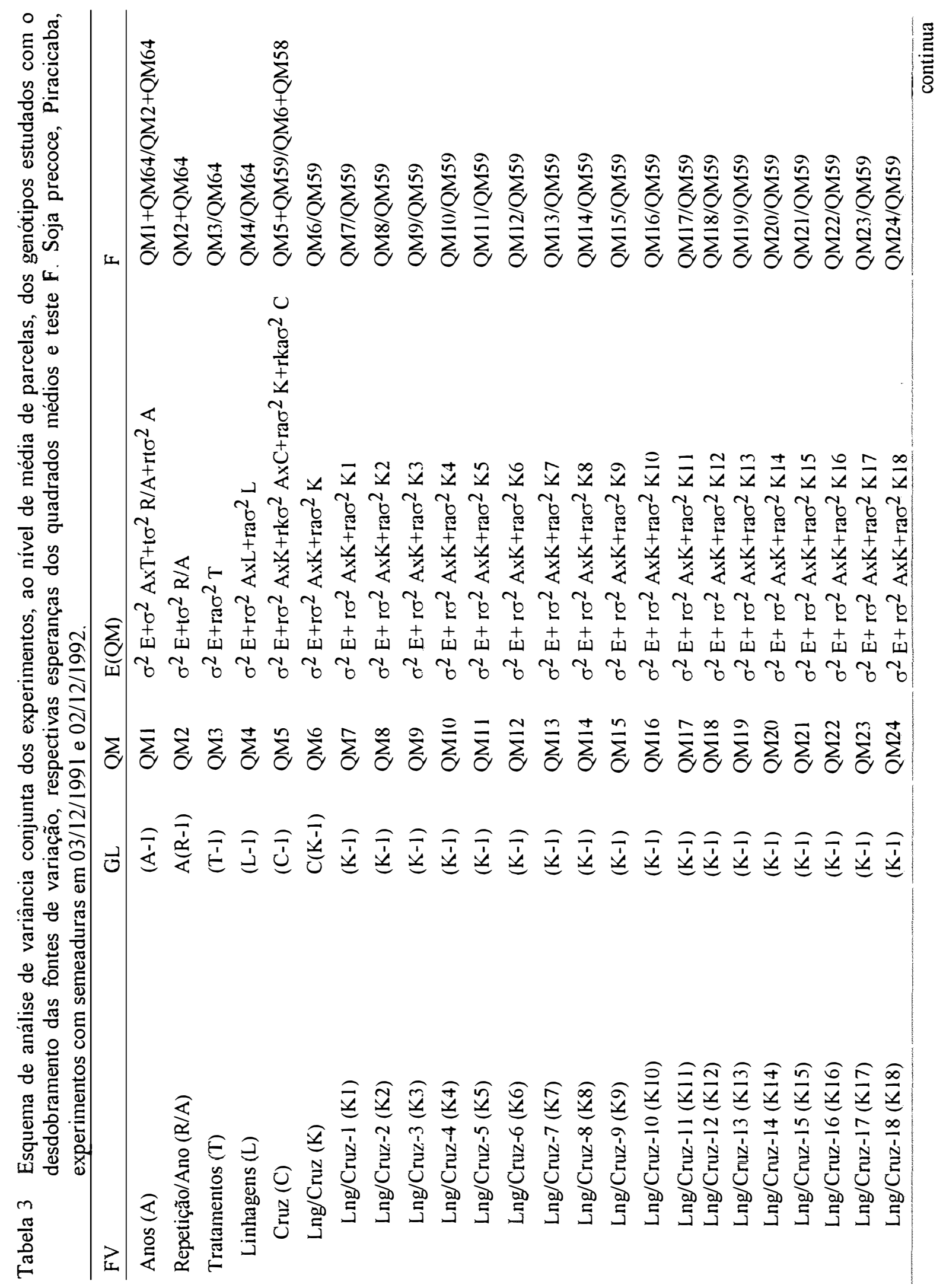




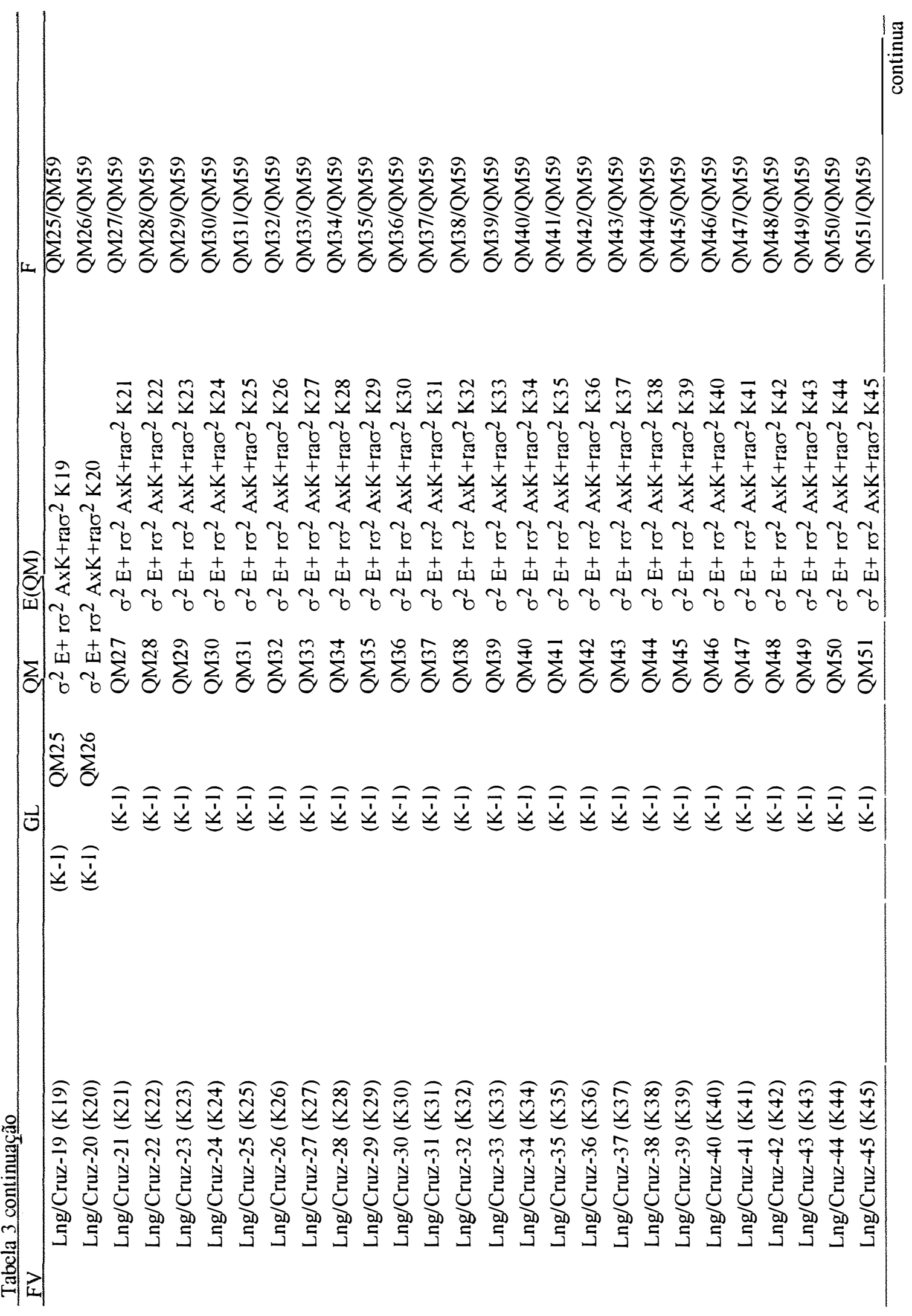




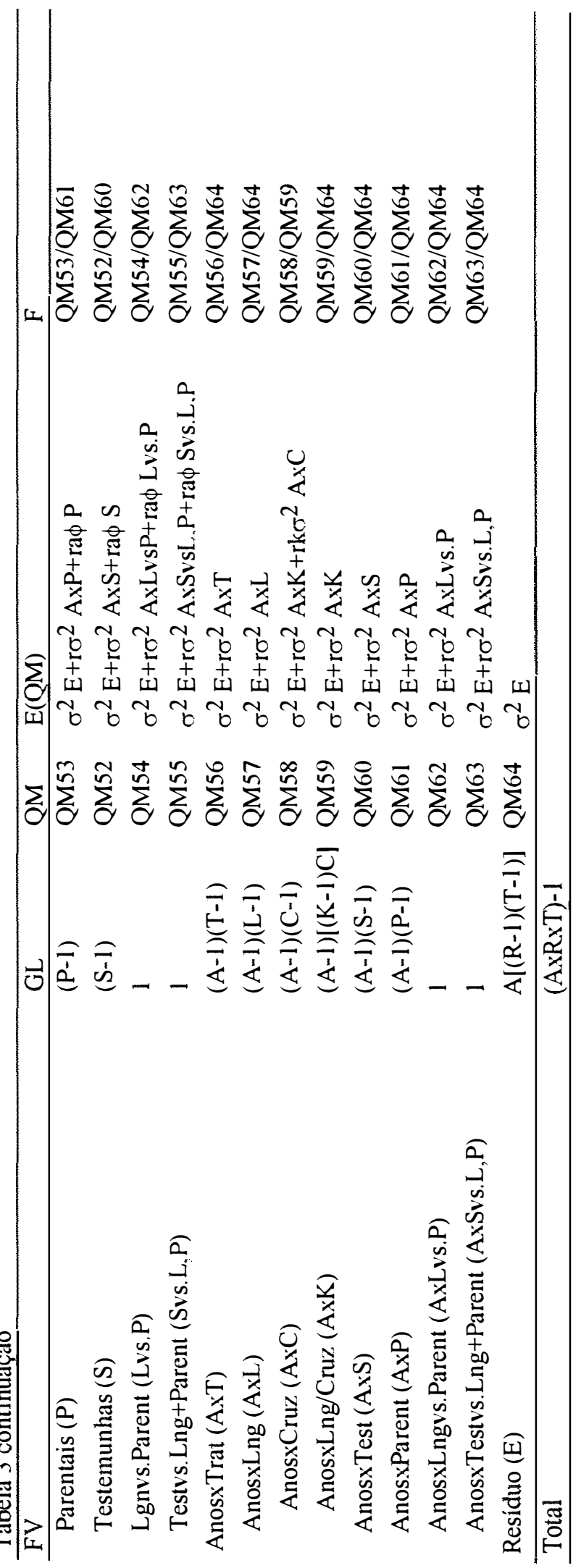




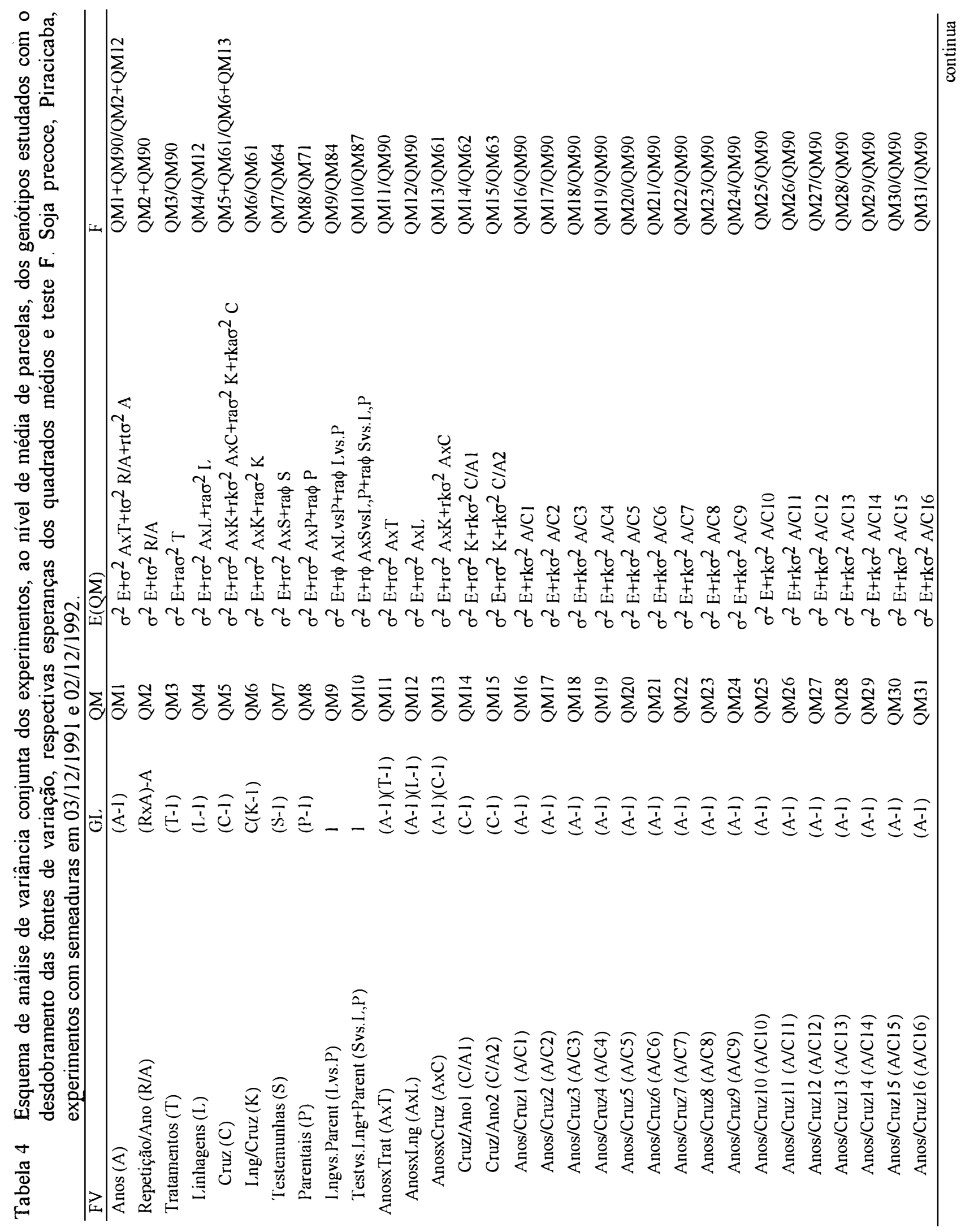




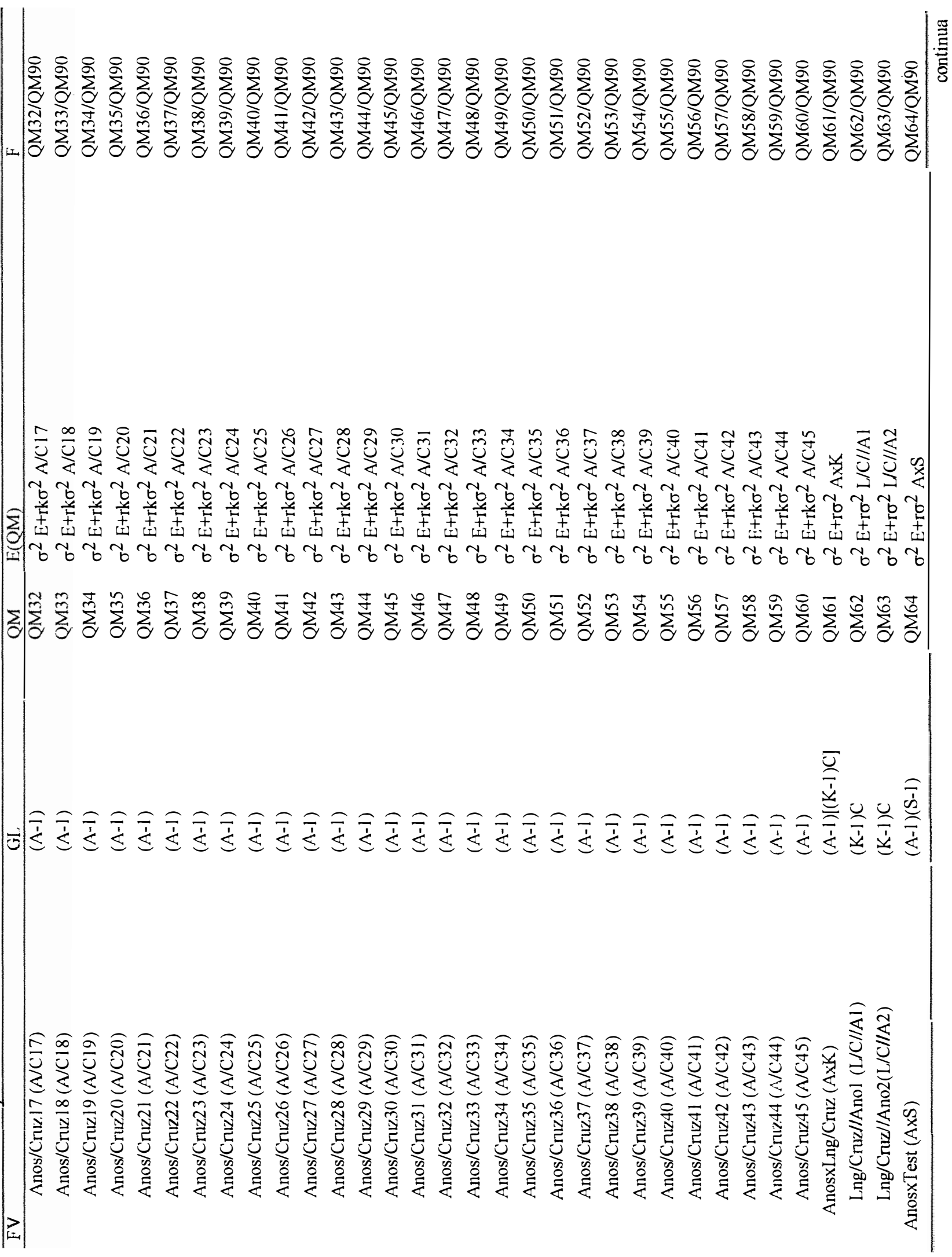




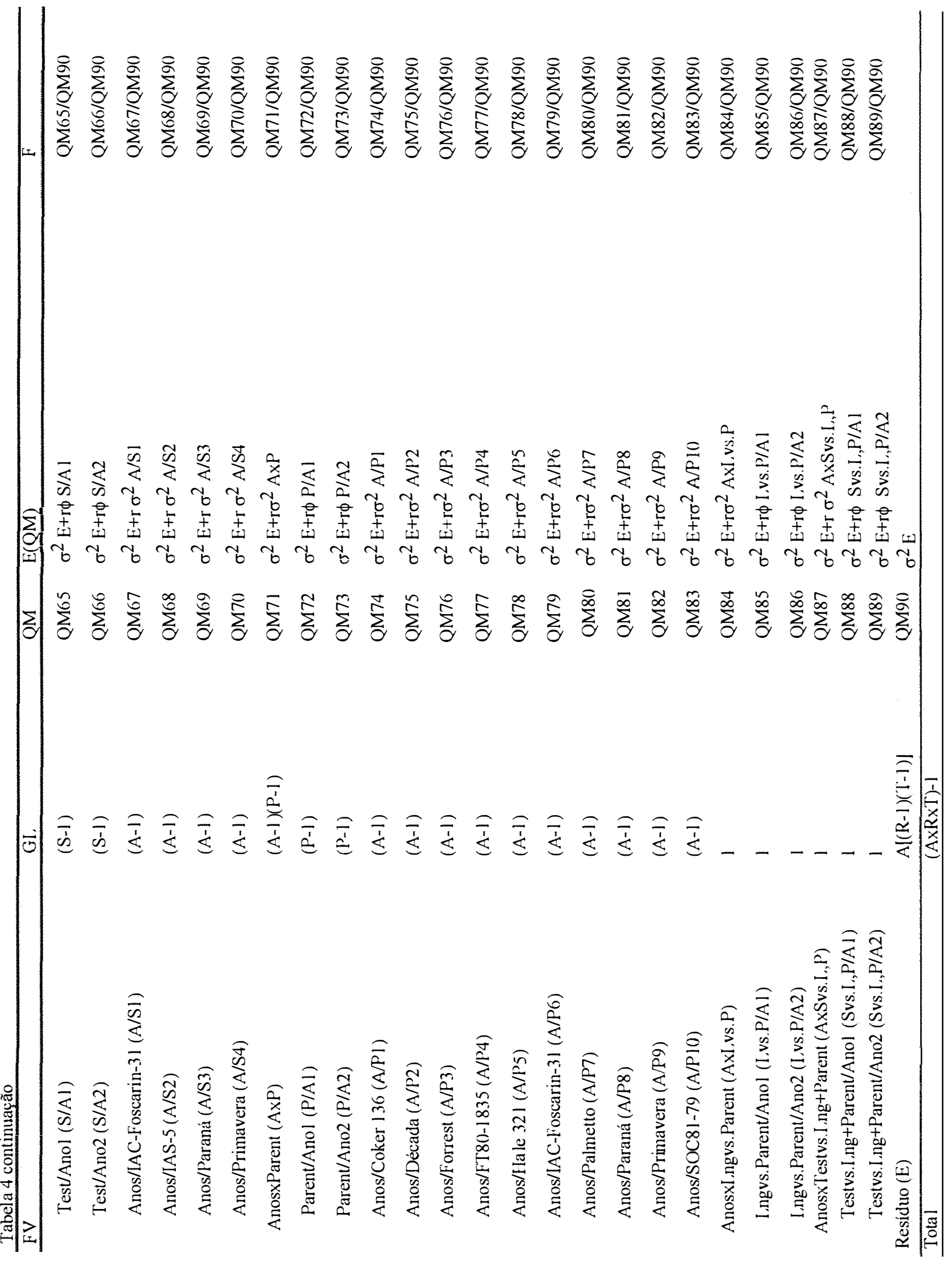


Tabela 5 Teor médio de umidade nas sementes (\%) e amplitude média de variação (AMV), realizado em testes preliminares para determinação do período ideal de acondicionamento de amostras de sementes que serão submetidas ao teste do pêndulo na avaliação da resistência ao dano mecânico. Soja precoce. Piracicaba, 1992.

\begin{tabular}{lcccc}
\hline & \multicolumn{3}{c}{ Cultivares } & \\
\cline { 2 - 3 } Período $^{\mathrm{a}}$ & Paraná & Primavera & IAC-Foscarin-31 & Média \pm AMV $^{\mathrm{b}}$ \\
\hline 48 & 11,58 & 11,73 & 11,43 & $11,58 \pm 0,67$ \\
72 & 12,76 & 12.77 & 12.69 & $12,74 \pm 0,34$ \\
96 & 13,09 & 14,17 & 14,51 & $13,92 \pm 1,07$ \\
120 & 14,92 & 14,69 & 15,41 & $15,00 \pm 0,50$ \\
\hline
\end{tabular}

${ }^{\text {a} P e r i ́ o d o ~: ~ h o r a s ~ d e ~ a c o n d i c i o n a m e n t o ~ e m ~ u m a ~ B . O . D . ~ c o m ~ t e m p e r a t u r a ~ d e ~} 25{ }^{\circ} \mathrm{C}$ e umidade relativa de $85 \%$;

Média \pm AMV: média $(\bar{x})$ dos períodos de acondicionamentos das amostras de sementes baseado em dados de quatro repetições por cultivar e amplitude média de variação (AMV) segundo a fórmula:

$$
A M V=\frac{(\text { Vmi nimo }-\bar{x})+(\text { V maximo }-\bar{x})}{2}
$$

onde: Vmímino e Vmáximo corresponde a dados das repetições. 
Tabela 6 APM: altura da planta na maturacão. Resumo da análise de variância com os valores e significância dos quadrados médios. Soja precoce. Piracicaba, experimentos com semeaduras em $03 / 12 / 1991$ e $02 / 12 / 1992$.

\begin{tabular}{|c|c|c|c|}
\hline \multirow[t]{2}{*}{ FV } & \multirow[t]{2}{*}{ GL } & \multicolumn{2}{|c|}{ QM } \\
\hline & & $03 / 12 / 1991$ & $02 / 12 / 1992$ \\
\hline Repetição (R) & 3 & $17692,974^{-*}$ & $63960,665^{* \pi}$ \\
\hline Tratamentos $(\mathrm{T})$ & 463 & $601,903^{x=}$ & $529,264^{=}$ \\
\hline Linhagens (L) & 449 & $605,741^{=}$ & $532,719^{*=}$ \\
\hline Cruz (C) & 44 & $3550,462^{x=}$ & $2832,567^{=\prime}$ \\
\hline Lng/Cruz (K) & 405 & $285,820=$ & $282,859^{\prime \prime}$ \\
\hline Lng/Cruz-1 (Kl) & 9 & $828,148^{*=}$ & $603,235^{* *}$ \\
\hline Lng/Cruz-2 (K2) & 9 & $424,695^{\prime \prime}$ & $527,085^{*=}$ \\
\hline Lng/Cruz-3 (K3) & 9 & $611,598^{*=}$ & $370,225^{*=}$ \\
\hline Lng/Cruz-4 (K4) & 9 & $530,485^{* *}$ & $208,581^{*}$ \\
\hline Lng/Cruz-5 (K5) & 9 & $159,883^{\text {n.s. }}$ & $64,438^{\text {n.s. }}$ \\
\hline Lng/Cruz-6 (K6) & 9 & $334,045^{* *}$ & $123,613^{\text {n.S }}$ \\
\hline Lng/Cruz-7 (K7) & 9 & $757,537^{*=}$ & $190,191^{\text {n.s. }}$ \\
\hline Lng/Cruz-8 (K8) & 9 & $55,211^{\text {n.s }}$ & $47,619^{\text {n.s. }}$ \\
\hline Lng/Cruz-9 (K9) & 9 & $335,730^{x *}$ & $569,197^{=*}$ \\
\hline Lng/Cruz-10 (K10) & 9 & $158,118^{\text {ns. }}$ & $210,111^{*}$ \\
\hline Lng/Cruz-11 (K11) & 9 & $297,302^{x *}$ & $566,239^{\text {** }}$ \\
\hline Lng/Cruz-12 (K12) & 9 & $86,673^{\text {n.s. }}$ & $194,336^{\circ}$ \\
\hline Lng/Cruz-13 (K13) & 9 & $461,925^{* *}$ & $290,065^{* *}$ \\
\hline Lng/Cruz-14 (K14) & 9 & $243,959^{=:}$ & $228,486^{*}$ \\
\hline Lng/Cruz-15 (K15) & 9 & $564,976^{\prime *}$ & $575,122^{\prime \prime}$ \\
\hline Lng/Cruz-16 (K16) & 9 & $127,710^{\mathrm{ns} .}$ & $144,691^{\text {n.s. }}$ \\
\hline Lng/Cruz-17 (K17) & 9 & $179,585^{\circ}$ & $127,936^{\text {n.s }}$ \\
\hline Lng/Cruz-18 (K18) & 9 & $491,277^{*=}$ & $265,277^{=}$ \\
\hline Lng/Cruz-19 (K19) & 9 & $641,949^{x=}$ & $814,339^{=\prime}$ \\
\hline Lng/Cruz-20 (K20) & 9 & $27,481^{\text {n.s. }}$ & $258,873^{=\prime}$ \\
\hline Lng/Cruz-21 (K21) & 9 & $152,560^{\text {n.s. }}$ & $222,324^{*}$ \\
\hline Lng/Cruz-22 (K22) & 9 & $321,987^{*}$ & $388,547^{=1}$ \\
\hline Lng/Cruz-23 (K23) & 9 & $149,842^{\mathrm{ns}}$ & $270,469^{=\prime}$ \\
\hline Lng/Cruz-24 (K24) & 9 & $504,783^{=}$ & $422,193^{="}$ \\
\hline Lng/Cruz-25 (K25) & 9 & $39,947^{\mathrm{ns}}$ & $91,891^{\text {ns. }}$ \\
\hline Lng/Cruz-26 (K26) & 9 & $165,847^{\mathrm{ns}}$ & $419,362^{=}$ \\
\hline Lng/Cruz-27 (K27) & 9 & $335,725^{* *}$ & $263,144^{\prime \prime}$ \\
\hline Lng/Cruz-28 (K28) & 9 & $123,011^{\text {n.s. }}$ & $149,413^{\text {ns }}$ \\
\hline Lng/Cruz-29 (K29) & 9 & $99,225^{\mathrm{ns}}$ & $102,333^{\text {ns. }}$ \\
\hline Lng/Cruz-30 (K30) & 9 & $311,050^{\text {** }}$ & $258,455^{*=}$ \\
\hline Lng/Cruz-31 (K31) & 9 & $228,876^{* *}$ & $278,901^{* *}$ \\
\hline Lng/Cruz-32 (K32) & 9 & $126,247^{\mathrm{ns}}$ & $41,377^{\text {n.s. }}$ \\
\hline Lng/Cruz-33 (K33) & 9 & $215,642^{\circ}$ & $646,333^{*=}$ \\
\hline Lng/Cruz-34 (K34) & 9 & $408,797^{* *}$ & $377,355^{=1}$ \\
\hline Lng/Cruz-35 (K35) & 9 & $268,555^{\star *}$ & $161,909^{\text {ns }}$ \\
\hline Lng/Cruz-36 (K36) & 9 & $110,231^{\text {n.s }}$ & $392,195^{\prime \prime}$ \\
\hline Lng/Cruz-37 (K37) & 9 & $489,036^{* *}$ & $490,012^{=}$ \\
\hline Lng/Cruz-38 (K38) & 9 & $317,821^{n=}$ & $303,835^{=1}$ \\
\hline Lng/Cruz-39 (K39) & 9 & $220,347^{* *}$ & $149,288^{\text {n.s. }}$ \\
\hline Lng/Cruz-40 (K40) & 9 & $91,680^{\text {n.s. }}$ & $31,277^{\text {ns. }}$ \\
\hline Lng/Cruz-4l (K41) & 9 & $91,548^{\mathrm{ns}}$ & $67,148^{\mathrm{ns}}$ \\
\hline Lng/Cruz-42 (K42) & 9 & $116,733^{\text {n.s }}$ & $123,225^{\text {n.s. }}$ \\
\hline Lng/Cruz-43 (K43) & 9 & $196,791^{\times}$ & $137,669^{\text {ns }}$ \\
\hline Lng/Cruz-44 (K44) & 9 & $235,850^{* x=}$ & $266,413^{=*}$ \\
\hline Lng/Cruz-45 (K45) & 9 & $221,501^{* *}$ & $293,915^{* \prime}$ \\
\hline Testemunhas (S) & 3 & $339,007^{=*}$ & $312,723^{\circ}$ \\
\hline Parentais $(\mathrm{P})$ & 9 & $486,616^{\prime \prime=}$ & $478,989=$ \\
\hline TestvsLng+Parent (Svs.L,P) & 1 & $31,029^{\mathrm{ns}}$ & $333,134^{\text {ns. }}$ \\
\hline LngvsParent (Lvs.P) & 1 & $1276,055^{* *}$ & $276,507^{\text {n.s. }}$ \\
\hline Resíduo (E) & 1389 & 90,705 & 102,779 \\
\hline Total & 1855 & & \\
\hline Média $(\mathrm{cm})$ & & 68,422 & 68,199 \\
\hline C.V. $(\%)$ & & 13,919 & 14,865 \\
\hline
\end{tabular}


Tabela 7 PG: producão de grãos. Resumo da análise de variância com os valores e significância dos quadrados médios. Soja precoce. Piracicaba, experimentos com semeaduras em 03/12/1991 e $02 / 12 / 1992$.

\begin{tabular}{|c|c|c|c|}
\hline \multirow[t]{2}{*}{ FV } & \multirow[t]{2}{*}{ GL } & \multicolumn{2}{|c|}{ QM } \\
\hline & & $03 / 12 / 1991$ & $02 / 12 / 1992$ \\
\hline Repetição (R) & 2 & $236257,612^{* \pi}$ & $776504,598^{\text {*7* }}$ \\
\hline Tratamentos ( T) & 463 & $11378,912^{* *}$ & $5273,644^{* *}$ \\
\hline Linhagens (L) & 449 & $11309,817^{* *}$ & $5357,461^{* *}$ \\
\hline Cruz (C) & 44 & $27155,497^{* *}$ & $12575,376^{* *}$ \\
\hline Lng/Cruz (K) & 405 & $9588,311=$ & $4573,293^{* *}$ \\
\hline Lng/Cruz-1 (K1) & 9 & $22428,351^{* *}$ & $6462,511^{m *}$ \\
\hline Lng/Cruz-2 (K2) & 9 & $6439,613^{* *}$ & $1255,262^{\text {n.s. }}$ \\
\hline Lng/Cruz-3 (K3) & 9 & $10655,060^{* *}$ & $2806,367^{x}$ \\
\hline Lng/Cruz-4 (K4) & 9 & $17849,165^{* *}$ & $2129,257^{\text {ins. }}$ \\
\hline Lng/Cruz-5 (K5) & 9 & $12478,603^{* *}$ & $4377,844^{\prime \prime}$ \\
\hline Lng/Cruz-6 (K6) & 9 & $8327,921^{* *}$ & $4373,538^{* *}$ \\
\hline Lng/Cruz-7 (K7) & 9 & $7211,433^{* *}$ & $4754,117^{* *}$ \\
\hline Lng/Cruz-8 (K8) & 9 & $3548,132^{\text {n.s. }}$ & $1818,453^{\text {ns. }}$ \\
\hline Lng/Cruz-9(K9) & 9 & $1643,861^{\text {n.s. }}$ & $2427,943^{*}$ \\
\hline Lng/Cruz-10 (K10) & 9 & $9471,994^{* *}$ & $4330,518^{* *}$ \\
\hline Lng/Cruz-1 l (K11) & 9 & $4585,931^{\circ}$ & $5233,682^{*=}$ \\
\hline Lng/Cruz-12 (K12) & 9 & $7184,585^{* *}$ & $2858,550^{*}$ \\
\hline Lng/Cruz-13 (K13) & 9 & $2652,622^{\text {n.s. }}$ & $5490,493^{* *}$ \\
\hline Lng/Cruz-14 (K14) & 9 & $13724,987^{* *}$ & $10821,710^{* *}$ \\
\hline Lng/Cruz-15 (K15) & 9 & $11327.294^{* *}$ & $3533,886^{\pi=}$ \\
\hline Lng/Cruz-16 (K 16) & 9 & $4887,018^{*}$ & $933,700^{\text {n.s. }}$ \\
\hline Lng/Cruz-17 (K17) & 9 & $6277,101^{* *}$ & $8047,501^{* *}$ \\
\hline Lng/Cruz-18 (K18) & 9 & $11380,308^{* *}$ & $2799,276^{*}$ \\
\hline Lng/Cruz-19 (K19) & 9 & $17515,439^{* x}$ & $3982,290^{* *}$ \\
\hline Lng/Cruz-20 (K20) & 9 & $6106,929^{* *}$ & $3370,882^{* *}$ \\
\hline Lng/Cruz-21 (K21) & 9 & $3322,456^{\text {n.s. }}$ & $1952,570^{\text {n.s. }}$ \\
\hline Lng/Cruz-22 (K22) & 9 & $18967,577^{* *}$ & $4844,542^{* *}$ \\
\hline Lng/Cruz-23 (K23) & 9 & $28891,303^{\prime *}$ & $11615,656^{* *}$ \\
\hline Lng/Cruz-24 (K24) & 9 & $13725,130 "$ & $1586,408^{\text {n.s. }}$ \\
\hline Lng/Cruz-25 (K25) & 9 & $9205,323^{* *}$ & $8700,555^{* *}$ \\
\hline Lng/Cruz-26 (K26) & 9 & $3248,774^{\text {n.s. }}$ & $2636,679^{*}$ \\
\hline Lng/Cruz-27 (K27) & 9 & $7685,789^{* *}$ & 3310,936 " \\
\hline Lng/Cruz-28 (K28) & 9 & $10785,809^{* *}$ & $7694.137^{\prime \prime}$ \\
\hline Lng/Cruz-29 (K29) & 9 & $12952,413^{\pi *}$ & $4922,273^{=*}$ \\
\hline Lng/Cruz-30 (K30) & 9 & $6528,321^{=*}$ & $2755,519^{*}$ \\
\hline Lng/Cruz-31 (K31) & 9 & $5110,039^{* *}$ & $7286,436^{\prime \prime}$ \\
\hline Lng/Cruz-32 (K32) & 9 & $2250,331^{\text {n.s. }}$ & $3901,150=$ \\
\hline Lng/Cruz-33 (K33) & 9 & $4995,568^{* *}$ & $4429.178^{* "}$ \\
\hline Lng/Cruz-34 (K34) & 9 & $5281,205^{* *}$ & $9787.963^{* *}$ \\
\hline Lng/Cruz-35.(K35) & 9 & $15159,453^{x *}$ & $3881,955^{* *}$ \\
\hline Lng/Cruz-36 (K36) & 9 & $1024,669^{\mathrm{ns}}$ & $4044,958^{* *}$ \\
\hline Lng/Cruz-37 (K37) & 9 & $16599,500^{* *}$ & $7496,723=$ \\
\hline Lng/Cruz-38(K38) & 9 & $10660,339^{=*}$ & $3239.722^{* *}$ \\
\hline Lng/Cruz-39 (K39) & 9 & $3463,959^{\text {n.s. }}$ & $3371,469^{* *}$ \\
\hline Lng/Cruz-40 (K40) & 9 & $1518,464^{\text {n.s. }}$ & $1544,663^{\mathrm{n} . \mathrm{s}}$ \\
\hline Lng/Cruz-4l (K41) & 9 & $25694,825^{* *}$ & $5230,055^{* *}$ \\
\hline Lng/Cruz-42 (K42) & 9 & $4927,928^{*}$ & $6100,596^{* *}$ \\
\hline Lng/Cruz-43 (K43) & 9 & $6931,505^{* *}$ & $5028,742^{* *}$ \\
\hline Lng/Cruz-44 (K44) & 9 & $20957,474^{\pi *}$ & $6629,089^{* *}$ \\
\hline Lng/Cruz-45 (K45) & 9 & $5889,488^{* *}$ & $1998,415^{\text {n.s. }}$ \\
\hline Testemunhas (S) & 3 & $562,666^{\mathrm{ns}}$ & $653,078^{\text {n.s }}$ \\
\hline Parentais $(\mathrm{P})$ & 9 & $20566,214^{* *}$ & $2562,625^{*}$ \\
\hline TestvsLng+Parent (Svs.L,P) & 1 & $22,371^{\text {n.s. }}$ & $1248,102^{\text {n.s. }}$ \\
\hline LngusParent (Lvs.P) & 1 & $3522,173^{\text {n.s }}$ & $9935.224^{* *}$ \\
\hline Resíduo (E) & 926 & 2040,185 & 1261,825 \\
\hline Total & 1391 & & \\
\hline Média (gramas/parcela) & & 192,359 & 137,681 \\
\hline C.V. (\%) & & 24,769 & 25,800 \\
\hline
\end{tabular}


Tabela 8 DM: dano mecânico. Resumo da análise de variância com os valores e significância dos quadrados médios. Soja precoce. Piracicaba, experimentos com semeaduras em 03/12/1991 e $02 / 12 / 1992$.

\begin{tabular}{|c|c|c|c|c|c|c|}
\hline \multirow[t]{2}{*}{$\overline{\text { FV }}$} & \multicolumn{2}{|c|}{$03 / 12 / 1991$} & \multicolumn{4}{|c|}{$02 / 12 / 1992$} \\
\hline & GL & $\mathrm{QM}$ & GL & $\mathrm{QM}$ & GL & $\mathrm{QM}$ \\
\hline Repetição (R) & 3 & $26,337^{-1}$ & 3 & 24,832 & 3 & $170,008^{-1+}$ \\
\hline Tratamentos $(\mathrm{T})$ & 63 & $1,396^{2 *}$ & 63 & $2,540^{*=}$ & 463 & $3,362^{*=}$ \\
\hline Linhagens (L) & 49 & $1,398^{* *}$ & 49 & $2,179^{* *}$ & 449 & $3,351^{=*}$ \\
\hline Cruz (C) & 4 & $4,350^{=*}$ & 4 & $0,711^{\text {n.s. }}$ & 44 & $12,657^{* *}$ \\
\hline Lng/Cruz (K) & 45 & $1,135^{* *}$ & 45 & $2,309^{*}$ & 405 & $2,340=$ \\
\hline Lng/Cruz-1 (Kl) & & & & & 9 & $1,408^{\text {n.s. }}$ \\
\hline Lng/Cruz-2 (K2) & & & & & 9 & $0,687^{\text {ns. }}$ \\
\hline Lng/Cruz-3 (K3) & & & & & 9 & $1,882^{\circ}$ \\
\hline Lng/Cruz-4 (K4) & 9 & $2,000^{* *}$ & 9 & $2,583^{* *}$ & 9 & $2,583^{-*}$ \\
\hline Lng/Cruz-5 (K5) & & & & & 9 & $3,724^{* *}$ \\
\hline Lng/Cruz-6 (K6) & & & & & 9 & $1,162^{\text {ns. }}$ \\
\hline Lng/Cruz-7 (K7) & & & & & 9 & $1,937^{*}$ \\
\hline Lng/Cruz-8 (K8) & & & & & 9 & $0,751^{\text {fls. }}$ \\
\hline Lng/Cruz-9 (K9) & & & & & 9 & $3,138^{* *}$ \\
\hline Lng/Cruz-10 (K10) & & & & & 9 & $2,055^{x}$ \\
\hline Lng/Cruz-11 (K11) & & & & & 9 & $1,815^{*}$ \\
\hline Lng/Cruz-12 (K12) & & & & & 9 & $0,453^{\text {ns. }}$ \\
\hline Lng/Cruz-13 (K13) & 9 & $0,824^{* *}$ & 9 & $0,966^{\text {n.s. }}$ & 9 & $0,966^{\mathrm{ns}}$ \\
\hline Lng/Cruz-14 (K14) & & & & & 9 & $1,674^{*}$ \\
\hline Lng/Cruz-15 (K15) & & & & & 9 & $2,392=$ \\
\hline Lng/Cruz-16 (K16) & & & & & 9 & $3,139^{* *}$ \\
\hline Lng/Cruz-17 (K17) & & & & & 9 & $1,827^{\circ}$ \\
\hline Lng/Cruz-18 (K18) & 9 & $0,613^{*}$ & 9 & $2,104^{=*}$ & 9 & $2,104^{=*}$ \\
\hline Lng/Cruz-19 (K19) & & & & & 9 & $2,826^{* *}$ \\
\hline Lng/Cruz-20 (K20) & & & & & 9 & $0,917^{\text {ns. }}$ \\
\hline Lng/Cruz-21 (K21) & & & & & 9 & $3,089^{* *}$ \\
\hline Lng/Cruz-22 (K22) & & & & & 9 & $2,180^{* *}$ \\
\hline Lng/Cruz-23 (K23) & & & & & 9 & $1,282^{\text {n.s. }}$ \\
\hline Lng/Cruz-24 (K24) & & & & & 9 & $1,255^{\text {n.s. }}$ \\
\hline Lng/Cruz-25 (K25) & & & & & 9 & $1,585^{\text {n.s. }}$ \\
\hline Lng/Cruz-26 (K26) & & & & & 9 & $9,794^{* *}$ \\
\hline Lng/Cruz-27 (K27) & & & & & 9 & $1,916^{*}$ \\
\hline Lng/Cruz-28 (K28) & & & & & 9 & $1,900^{*}$ \\
\hline Lng/Cruz-29 (K29) & 9 & $0,954^{-x}$ & 9 & $2,989^{* *}$ & 9 & $2,989^{* *}$ \\
\hline Lng/Cruz-30 (K30) & & & & & 9 & $1,254^{\text {n.s. }}$ \\
\hline Lng/Cruz-31 (K31) & & & & & 9 & $8,429^{* *}$ \\
\hline Lng/Cruz-32 (K32) & & & & &. .9 & $2,025^{*}$ \\
\hline Lng/Cruz-33 (K33) & & & & & 9 & $1,619^{\text {nts. }}$ \\
\hline Lng/Cruz-34 (K34) & & & & & 9 & $1,935^{*}$ \\
\hline Lng/Cruz-35 (K35) & & & & & 9 & $2,730^{* *}$ \\
\hline Lng/Cruz-36 (K36) & & & & & 9 & $1,666^{\text {n.s. }}$ \\
\hline Lng/Cruz-37 (K37) & & & & & 9 & $4,763^{* *}$ \\
\hline Lng/Cruz-38 (K38) & & & & & 9 & $1,672^{*}$ \\
\hline Lng/Cruz-39 (K39) & & & & & 9 & $1,331^{\text {n.s. }}$ \\
\hline Lng/Cruz-40 (K40) & & & & & 9 & $1,176^{\text {n.s }}$ \\
\hline Lng/Cruz-4l (K4l) & & & & & 9 & $6,417^{\prime *}$ \\
\hline Lng/Cruz-42 (K42) & & & & & 9 & $1,592^{\text {n.s }}$ \\
\hline Lng/Cruz-43 (K43) & & & & & 9 & $0,45^{\mathrm{ns} .}$ \\
\hline Lng/Cruz-44 (K44) & 9 & $1,286^{* *}$ & 9 & $2,903^{* *}$ & 9 & $2,903^{*=}$ \\
\hline Lng/Cruz-45 (K45) & & & & & 9 & $2,411^{\prime \prime}$ \\
\hline Testemunhas (S) & 3 & $0,677^{\text {ns. }}$ & 3 & $1,640^{\text {n.s. }}$ & 3 & $1,640^{\text {n.s. }}$ \\
\hline Parentais $(\mathrm{P})$ & 9 & $1,206^{* *}$ & 9 & $5,081^{* *}$ & 9 & $5,081^{* *}$ \\
\hline TestvsLng+Parent (Svs.L,P) & 1 & $3,909^{* *}$ & 1 & $0,168^{\text {n.s. }}$ & 1 & $1,018^{\mathrm{n} . \mathrm{s}}$ \\
\hline LngvsParent (Lvs.P) & 1 & $2,641^{* *}$ & 1 & $2,450^{\text {n.s. }}$ & 1 & $0,342^{\text {n.s. }}$ \\
\hline Residuo (E) & 189 & 0,317 & 189 & 0,786 & 1389 & 0,873 \\
\hline Total & 255 & & 255 & & 1855 & \\
\hline Média (udm) & & 2,000 & & 3,926 & & 3,798 \\
\hline C.V. $(\%)$ & & 28,174 & & 22,584 & & 24,599 \\
\hline
\end{tabular}


Tabela 9 APM: altura da planta na maturacão. Resumo da análise de variância conjunta dos experimentos, e respectivos desdobramentos, com os valores e significância dos quadrados médios. Soja precoce. Piracicaba. experimentos com semeaduras em 03/12/1991 e 02/12/1992.

\begin{tabular}{|c|c|c|}
\hline FV & GL & QM \\
\hline $\operatorname{Anos}(\mathrm{A})$ & 1 & $45,761^{\text {n.s. }}$ \\
\hline Repetição/Ano (R/A) & 6 & $40826,820^{=*}$ \\
\hline Tratamentos $(\mathrm{T})$ & 463 & $955,177^{* *}$ \\
\hline Linhagens (L) & 449 & $967,609^{* *}$ \\
\hline Cruz $(C)$ & 44 & $5859,472^{* *}$ \\
\hline Lng/Cruz (K) & 405 & $436,148^{\prime *}$ \\
\hline Lng/Cruz-l (Kl) & 9 & $1309,954^{* *}$ \\
\hline Lng/Cruz-2 (K2) & 9 & $889,229^{* *}$ \\
\hline Lng/Cruz-3 (K3) & 9 & $942,629^{* *}$ \\
\hline Lng/Cruz-4 (K4) & 9 & $416,673^{x *}$ \\
\hline Lng/Cruz-5 (K5) & 9 & $184,036^{\text {n.s. }}$ \\
\hline Lng/Cruz-6 (K6) & 9 & $316,408^{*}$ \\
\hline Lng/Cruz-7 (K7) & 9 & $606,916^{* *}$ \\
\hline Lng/Cruz-8(K8) & 9 & $71,574^{\text {n.s. }}$ \\
\hline Lng/Cruz-9 (K9) & 9 & $588,280^{* *}$ \\
\hline Lng/Cruz-10 (K10) & 9 & $181,101^{\text {n.s. }}$ \\
\hline Lng/Cruz-11 (K11) & 9 & $687,145^{* *}$ \\
\hline Lng/Cruz-12 (K12) & 9 & $227,217^{\text {ns. }}$ \\
\hline Lng/Cruz-13 (K13) & 9 & $521,847^{* *}$ \\
\hline Lng/Cruz-14 (K14) & 9 & $378,332^{* *}$ \\
\hline Lng/Cruz-15 (K15) & 9 & $1040,073^{\mathrm{x*}}$ \\
\hline Lng/Cruz-16 (K16) & 9 & $234,259^{\text {n.s. }}$ \\
\hline Lng/Cruz-17 (K17) & 9 & $175,153^{\text {ns. }}$ \\
\hline Lng/Cruz-18 (K18) & 9 & $697,472^{* *}$ \\
\hline Lng/Cruz-19 (K19) & 9 & $1307,072^{* *}$ \\
\hline Lng/Cruz-20 (K20) & 9 & $158,822^{\text {ns }}$ \\
\hline Lng/Cruz-21 (K21) & 9 & $253,789^{*}$ \\
\hline Lng/Cruz-22 (K22) & 9 & $497,844^{-*}$ \\
\hline Lng/Cruz-23 (K23) & 9 & $291,449^{*}$ \\
\hline Lng/Cruz-24 (K24) & 9 & $668,536^{* x}$ \\
\hline Lng/Cruz-25 (K25) & 9 & $96,015^{\text {n.s. }}$ \\
\hline Lng/Cruz-26 (K26) & 9 & $448,764^{* x}$ \\
\hline Lng/Cruz-27 (K27) & 9 & $521,955^{* *}$ \\
\hline Lng/Cruz-28 (K28) & 9 & $126,952^{\text {n.s }}$ \\
\hline Lng/Cruz-29 (K29) & 9 & $101,594^{\text {ns }}$ \\
\hline Lng/Cruz-30 (K30) & 9 & $515,153^{* *}$ \\
\hline Lng/Cruz-31 (K31) & 9 & $420,596^{* *}$ \\
\hline Lng/Cruz-32 (K32) & 9 & $112,195^{\mathrm{ns}}$ \\
\hline Lng/Cruz-33 (K33) & 9 & $730,856^{2 *}$ \\
\hline Lng/Cruz-34 (K34) & 9 & $425,865^{2 *}$ \\
\hline Lng/Cruz-35 (K35) & 9 & $147,220^{\text {ns }}$ \\
\hline Lng/Cruz-36 (K36) & 9 & $243,457^{\text {n.s. }}$ \\
\hline Lng/Cruz-37 (K37) & 9 & $813,739^{-*}$ \\
\hline Lng/Cruz-38 (K38) & 9 & $474,089^{* *}$ \\
\hline Lng/Cruz-39 (K39) & 9 & $223,501^{\text {n.s }}$ \\
\hline Lng/Cruz-40 (K40) & 9 & $92,816^{\text {ns }}$ \\
\hline Lng/Cruz-4l (K41) & 9 & $132,994^{\text {n.s. }}$ \\
\hline Lng/Cruz-42 (K42) & 9 & $136,306^{\text {ns }}$ \\
\hline Lng/Cruz-43 (K43) & 9 & $259,339^{*}$ \\
\hline Lng/Cruz-44 (K44) & 9 & $459,531^{* *}$ \\
\hline Lng/Cruz-45 (K45) & 9 & $497,896^{* *}$ \\
\hline Testemunhas (S) & 3 & $487,638^{\text {n.s. }}$ \\
\hline Parentais $(\mathrm{P})$ & 9 & $651,291^{\text {ns. }}$ \\
\hline LngvsParent (Lvs.P) & 1 & $283,753^{\text {n.s. }}$ \\
\hline TestvsLng+Parent (Svs.L,P) & 1 & $182,279^{\text {n.s. }}$ \\
\hline AnosxTrat (AxT) & 463 & 175,990 "* \\
\hline AnosxLng (AxL) & 449 & $170,850^{* *}$ \\
\hline AnosxCruz (AxC) & 44 & $523,557^{* *}$ \\
\hline
\end{tabular}




\begin{tabular}{lcc} 
Tabela 9 continuação & & \\
\hline FV & QL & $132,531^{* *}$ \\
\hline AnosxLng/Cruz (AxK) & 405 & $164,093^{\text {n.s. }}$ \\
AnosxTest (AxS) & 3 & $314,314^{* *}$ \\
AnosxParent (AxP) & 9 & $1370,088^{* *}$ \\
AnosxLngvsParent (AxLvs.P) & 1 & $80,606^{\text {n.s. }}$ \\
AnosxTestvsLng+Parent (AxSvs.L,P) & 1 & 96,742 \\
Resíduo (E) & 2778 & \\
\hline Total & 3711 & 68,31 \\
\hline Média (cm) & & 14,40 \\
\hline C.V. $\%)$ & & \\
\hline
\end{tabular}


Tabela 10 APM: altura da planta na maturação. Resumo da análise de variância conjunta dos experimentos, e respectivos desdobramentos/ano, os valores e significância dos quadrados médios. Soja precoce. Piracicaba, experimentos com semeaduras em 03/12/1991 e $02 / 12 / 1992$.

\begin{tabular}{|c|c|c|}
\hline FV & $\mathrm{GL}$ & $\mathrm{QM}$ \\
\hline $\operatorname{Anos}(\mathrm{A})$ & 1 & $45,761^{\mathrm{ns}}$ \\
\hline Repetição/Ano (R/A) & 6 & $40826,820^{* * *}$ \\
\hline Tratamentos $(\mathrm{T})$ & 463 & $955,177^{* *}$ \\
\hline Linhagens (L) & 449 & $967,609 " *$ \\
\hline Cruz $(\mathrm{C})$ & 44 & $5859,472^{* *}$ \\
\hline Lng/Cruz (K) & 405 & $436,148^{* *}$ \\
\hline Testemunhas (S) & 3 & $487,638^{\text {n.s. }}$ \\
\hline Parentais $(\mathrm{P})$ & 9 & $651,291^{\text {n.s. }}$ \\
\hline LngvsParent (Lvs.P) & 1 & $283,753^{\text {n.s. }}$ \\
\hline TestvsLng+Parent (Svs.L,P) & 1 & $182,279^{\text {n.s. }}$ \\
\hline AnosxTrat $(\mathrm{AxT})$ & 463 & $175,990^{* *}$ \\
\hline AnosxLng (AxL) & 449 & $170,850^{* *}$ \\
\hline AnosxCruz (AxC) & 44 & $523,557^{* *}$ \\
\hline Cruz/Anol (C/Al) & 44 & $3550,462^{\prime *}$ \\
\hline Cruz/Ano2 (C/A2) & 44 & $2832,567^{* *}$ \\
\hline Anos/Cruzl (A/Cl) & 1 & $4,753^{\mathrm{ns}}$ \\
\hline Anos/Cruz2 (A/C2) & 1 & $452,343^{\circ}$ \\
\hline Anos/Cruz3 (A/C3) & 1 & $171,434^{\mathrm{ns}}$ \\
\hline Anos/Cruz4 (A/C4) & 1 & $504.058^{*}$ \\
\hline Anos/Cruz5 (A/C5) & 1 & $279,527^{\text {n.s }}$ \\
\hline Anos/Cruz6 (A/C6) & 1 & $42,296^{\text {n.s. }}$ \\
\hline Anos/Cruz7 (A/C7) & 1 & $977,202^{\star \star}$ \\
\hline Anos/Cruz8 (A/C8) & 1 & $59,616^{\mathrm{ns}}$ \\
\hline Anos/Cruz9 (A/C9) & 1 & $74,074^{\text {n.s. }}$ \\
\hline Anos/Cruzl0 (A/C10) & 1 & $8,166^{\mathrm{ns}}$ \\
\hline Anos/Cruzll (A/Cl1) & 1 & $10,188^{\mathrm{n.s}}$ \\
\hline Anos/Cruzl2 (A/C12) & 1 & $658,091^{n *}$ \\
\hline Anos/Cruzl3 (A/C13) & 1 & $412,050^{*}$ \\
\hline Anos/Cruzl4 (A/Cl4) & 1 & $185,623^{\text {n.s. }}$ \\
\hline Anos/Cruzl5 (A/C15) & 1 & $878,806^{n *}$ \\
\hline Anos/Cruzl6 (A/C16) & 1 & $1539,749^{* * *}$ \\
\hline Anos/Cruz17 (A/C 17) & 1 & $1985,028^{\prime "}$ \\
\hline Anos/Cruz18 (A/C18) & 1 & $1361,250^{-"}$ \\
\hline Anos/Cruz19 (A/C19) & 1 & $82,418^{\text {n.s }}$ \\
\hline Anos/Cruz20 (A/C20) & 1 & $196,188^{\mathrm{ns}}$ \\
\hline Anos/Cruz21 (A/C21) & 1 & $7,982^{\mathrm{ns}}$ \\
\hline Anos/Cruz22 (A/C22) & 1 & $444,765^{\circ}$ \\
\hline Anos/Cruz23 (A/C23) & 1 & $660,157^{* *}$ \\
\hline Anos/Cruz24 (A/C24) & 1 & $89,570^{\mathrm{ns}}$ \\
\hline Anos/Cruz25 (A/C25) & 1 & $1,978^{\mathrm{n} \cdot \mathrm{s}}$ \\
\hline Anos/Cruz26 (A/C26) & 1 & $1730,823^{* *}$ \\
\hline Anos/Cruz27 (A/C27) & 1 & $1049,365^{* *}$ \\
\hline Anos/Cruz28 (A/C28) & 1 & $55,444^{\text {n.s. }}$ \\
\hline Anos/Cruz29 (A/C29) & 1 & $1160,602^{\times x}$ \\
\hline Anos/Cruz30 (A/C30) & 1 & $8,951^{\text {n.s. }}$ \\
\hline Anos/Cruz31 (A/C31) & 1 & $1209,712^{x \times}$ \\
\hline Anos/Cruz32 (A/C32) & 1 & $154,012^{\mathrm{ns}}$ \\
\hline Anos/Cruz33 (A/C33) & 1 & $132,895^{\text {n.s. }}$ \\
\hline Anos/Cruz34 (A/C34) & 1 & $0,635^{\text {n.s. }}$ \\
\hline Anos/Cruz35 (A/C35) & 1 & $155.849^{\mathrm{ns}}$ \\
\hline Anos/Cruz36 (A/C36) & 1 & $58,294^{\mathrm{ns}}$ \\
\hline Anos/Cruz37 (A/C37) & 1 & $493,819^{*}$ \\
\hline Anos/Cruz38 (A/C38) & 1 & $158,371^{\text {n.s }}$ \\
\hline Anos/Cruz39 (A/C39) & 1 & $16,955^{\text {n.s }}$ \\
\hline Anos/Cruz40 (A/C40) & 1 & $1120,205^{* \pi}$ \\
\hline Anos/Cruz41 (A/C41) & 1 & $237,877^{\text {n.s. }}$ \\
\hline Anos/Cruz42 (A/C42) & 1 & $2656,512^{* *}$ \\
\hline
\end{tabular}


Tabel a 10 continuação

\begin{tabular}{|c|c|c|}
\hline FV & GL & $\mathrm{QM}$ \\
\hline Anos/Cruz43 (A/C43) & 1 & $987,082^{* 2 *}$ \\
\hline Anos/Cruz44 (A/C44) & 1 & $22,791^{\text {n.s. }}$ \\
\hline Anos/Cruz45 (A/C45) & 1 & $666,608^{* *}$ \\
\hline AnosxLng/Cruz (AxK) & 405 & $132,531^{\approx=}$ \\
\hline Lng/Cruz/Anol (L/C//Al) & 405 & $285,820^{* *}$ \\
\hline Lng/Cruz/Ano2(L/C//A2) & 405 & $282,859^{\prime \prime}$ \\
\hline AnosxTest $(\mathrm{AxS})$ & 3 & $164,093^{\mathrm{ns}}$ \\
\hline Test/Anol (S/Al) & 3 & $339,007^{-}$ \\
\hline Test/Ano2 (S/A2) & 3 & $312,723^{*}$ \\
\hline Anos/IAC-Foscarin-31 (A/SI) & 1 & $325,125^{\text {n.s. }}$ \\
\hline Anos/IAS-5 (A/S2) & 1 & $98,420^{\text {n.s }}$ \\
\hline Anos/Paraná (A/S3) & 1 & $11,281^{\text {n.s. }}$ \\
\hline Anos/Primavera (A/S4) & 1 & $148,781^{\text {n.s. }}$ \\
\hline AnosxParent $(\mathrm{AxP})$ & 9 & $314,314^{x=}$ \\
\hline Parent/Anol (P/Al) & 9 & $486,616^{* *}$ \\
\hline Parent/Ano2 (P/A2) & 9 & $478,989^{x=}$ \\
\hline Anos/Coker $136(\mathrm{~A} / \mathrm{P} 1)$ & 1 & $81,281^{\text {n.s. }}$ \\
\hline Anos/Década (A/P2) & 1 & $276,125^{\text {n.s. }}$ \\
\hline Anos/Forrest (A/P3) & 1 & $743,822^{* *}$ \\
\hline Anos/FT80-1835 (A/P4) & 1 & $65,665^{\text {n.s. }}$ \\
\hline Anos/Hale 321 (A/P5) & 1 & $16,531^{\text {ins. }}$ \\
\hline Anos/IAC-Foscarin-31 (A/P6) & 1 & $1,044^{\text {ns. }}$ \\
\hline Anos/Palmetto (A/P7) & 1 & $9,396^{\text {n.s }}$ \\
\hline Anos/Paraná (A/P8) & 1 & $15,125^{\text {n.s }}$ \\
\hline Anos/Primavera (A/P9) & 1 & $2876,232^{\star *}$ \\
\hline Anos/SOC81-79 (A/P10) & 1 & $21,125^{\text {n.s }}$ \\
\hline AnosxLngvs.Parent (AxLvs.P) & 1 & $1370,088^{* *}$ \\
\hline Lngvs.Parent/Anol (Lvs.P/Al) & 1 & $1276,056^{* *}$ \\
\hline Lngvs.Parent/Ano2 (Lvs.P/A2) & 1 & $276,507^{\text {ns }}$ \\
\hline AnosxTestvs.Lng+Parent (AxSvs.L,P) & 1 & $80,606^{\mathrm{ns}}$ \\
\hline Testvs.Lng+Parent/Anol (Svs.L,P/Al) & 1 & $31,030^{\text {n.s. }}$ \\
\hline Testvs.Lng+Parent/Ano2 (Svs.L,P/A2) & 1 & $333,134^{\text {ns. }}$ \\
\hline Resíduo (E) & 2778 & 96,742 \\
\hline Total & 3711 & \\
\hline Média (cm) & \multicolumn{2}{|c|}{68.31} \\
\hline C.V. $(\%)$ & \multicolumn{2}{|c|}{14,40} \\
\hline
\end{tabular}


Tabela 11 PG: producão de grãos. Resumo da análise de variância conjunta dos experimentos. e respectivos desdobramentos, com os valores e significância dos quadrados médios. Soja precoce. Piracicaba, experimentos com semeaduras em 03/12/1991 e 02/12/1992.

\begin{tabular}{|c|c|c|}
\hline FV & GL & $\mathrm{QM}$ \\
\hline $\operatorname{Anos}(\mathrm{A})$ & 1 & $1389327,729^{\text {ns. }}$ \\
\hline Repetição/Ano (R/A) & 4 & $506381,105^{* *}$ \\
\hline Tratamentos $(\mathrm{T})$ & 463 & $9670,222^{* *}$ \\
\hline Linhagens (L) & 449 & $9726,531^{*=}$ \\
\hline Cruz (C) & 44 & $27484,455^{* *}$ \\
\hline Lng/Cruz (K) & 405 & $7797,275^{*}$ \\
\hline Lng/Cruz-l (Kl) & 9 & $14515,198^{*}$ \\
\hline Lng/Cruz-2 (K2) & 9 & $3707,371^{\text {n.s. }}$ \\
\hline Lng/Cruz-3 (K3) & 9 & $8890,050^{\text {n.s. }}$ \\
\hline Lng/Cruz-4 (K4) & 9 & $12718,266^{*}$ \\
\hline Lng/Cruz-5 (K5) & 9 & $13428,587^{*}$ \\
\hline Lng/Cruz-6 (K6) & 9 & $3529,477^{\text {ns }}$ \\
\hline Lng/Cruz-7 (K7) & 9 & $8373,574^{\text {n.s. }}$ \\
\hline Lng/Cruz-8(K8) & 9 & $2135,196^{\text {ns }}$ \\
\hline Lng/Cruz-9 (K9) & 9 & $2753,125^{\text {n.s. }}$ \\
\hline Lng/Cruz-10 (K10) & 9 & $6435,985^{\text {n.s. }}$ \\
\hline Lng/Cruz-11 (K11) & 9 & $6616,741^{\text {ns. }}$ \\
\hline Lng/Cruz-12 (K12) & 9 & $5568,745^{\text {ns }}$ \\
\hline Lng/Cruz-13 (K13) & 9 & $4125,670^{\text {n.s. }}$ \\
\hline Lng/Cruz-14 (K14) & 9 & $9244,943^{\text {ns }}$ \\
\hline Lng/Cruz-15 (K15) & 9 & $8058,849^{\text {n.s. }}$ \\
\hline Lng/Cruz-16 (K16) & 9 & $3029,173^{\text {n.s. }}$ \\
\hline Lng/Cruz-17 (K17) & 9 & $8072,333^{\text {n.s. }}$ \\
\hline Lng/Cruz-18 (K18) & 9 & $10625,912^{\text {n.s }}$ \\
\hline Lng/Cruz-19 (K19) & 9 & $14209,555^{*}$ \\
\hline Lng/Cruz-20 (K20) & 9 & $7879,143^{\text {n.s. }}$ \\
\hline Lng/Cruz-21 (K21) & 9 & $2833,359^{\text {ns. }}$ \\
\hline Lng/Cruz-22 (K22) & 9 & $9283,400^{\text {n.s. }}$ \\
\hline Lng/Cruz-23 (K23) & 9 & $17917,186^{* *}$ \\
\hline Lng/Cruz-24 (K24) & 9 & $9916,361^{\text {n.s. }}$ \\
\hline Lng/Cruz-25 (K25) & 9 & $13695,992^{*}$ \\
\hline Lng/Cruz-26 (K26) & 9 & $4132,994^{\text {n.s. }}$ \\
\hline Lng/Cruz-27 (K27) & 9 & $8953,060^{\text {n.s. }}$ \\
\hline Lng/Cruz-28 (K28) & 9 & $15177,254^{*}$ \\
\hline Lng/Cruz-29 (K29) & 9 & $8008,253^{\text {n.s. }}$ \\
\hline Lng/Cruz-30 (K30) & 9 & $3786,173^{\text {n.s. }}$ \\
\hline Lng/Cruz-31 (K31) & 9 & $8998,035^{\text {n.s. }}$ \\
\hline Lng/Cruz-32 (K32) & 9 & $2378,621^{\text {n.s. }}$ \\
\hline Lng/Cruz-33 (K33) & 9 & $4887,717^{\text {ns. }}$ \\
\hline Lng/Cruz-34 (K34) & 9 & $2855,676^{\text {ns. }}$ \\
\hline Lng/Cruz-35 (K35) & 9 & $9648,511^{\text {n.s. }}$ \\
\hline Lng/Cruz-36 (K36) & 9 & $1219,667^{\text {ns }}$ \\
\hline Lng/Cruz-37 (K37) & 9 & $8446,225^{\text {n.s. }}$ \\
\hline Lng/Cruz-38 (K38) & 9 & $6554,783^{\text {n.s. }}$ \\
\hline Lng/Cruz-39 (K39) & 9 & $3775,876^{\text {n.s. }}$ \\
\hline Lng/Cruz-40 (K40) & 9 & $2585,295^{\text {n.s. }}$ \\
\hline Lng/Cruz-41 (K41) & 9 & $15554,206^{*}$ \\
\hline Lng/Cruz-42 (K42) & 9 & $5110,620^{\mathrm{ns}}$ \\
\hline Lng/Cruz-43 (K43) & 9 & $7129,578^{\text {n.s. }}$ \\
\hline Lng/Cruz-44 (K44) & 9 & $19434,404^{x *}$ \\
\hline Lng/Cruz-45 (K45) & 9 & $4676,233^{\text {n.s. }}$ \\
\hline Testemunha (S) & 3 & $219,348^{\text {n.s. }}$ \\
\hline Parentais $(\mathrm{P})$ & 9 & $11980,766^{\text {ns. }}$ \\
\hline Lngvs.Parent (Lvs.P) & 1 & $802,334^{\text {n.s. }}$ \\
\hline Testvs.Lng+Parent (Svs.L,P) & 1 & $813,161^{\text {n.s. }}$ \\
\hline AnosxTrat (AxT) & 463 & $6982,354^{* * *}$ \\
\hline AnosxLng (AxL) & 449 & $6940,747^{* *}$ \\
\hline AnosxCruz (AxC) & 44 & $12246,418^{\text {ns. }}$ \\
\hline
\end{tabular}


Tabela 11 continuação

\begin{tabular}{lcc}
\hline FV & GL & QM \\
\hline AnosxLng/Cruz (AxK) & 405 & $6364,329^{* *}$ \\
AnosxTest (AxS) & 3 & $996,396^{\text {n.s. }}$ \\
AnosxParent (AxP) & 9 & $11148,073^{* *}$ \\
AnosxLngvs.Parent (AxLvs.P) & 1 & $12644,016^{\text {n.s. }}$ \\
AnosxTestvs.Lng+Parent (AxSvs.L,P) & 1 & $468,359^{* *}$ \\
Resíduo (E) & 1852 & 1651,005 \\
\hline Total & 2783 & \\
\hline Média $\left(\mathrm{g} / \mathrm{m}^{2}\right)$ & & 160,02 \\
\hline C.V. $\%)$ & & 25,39 \\
\hline
\end{tabular}


Tabela 12 PG: producão de grãos. Resumo da análise de variância conjunta dos experimentos. e respectivos desdobramentos/ano. os valores e significância dos quadrados médios. Soja precoce. Piracicaba, experimentos com semeaduras em 03/12/1991 e 02/12/1992.

\begin{tabular}{|c|c|c|}
\hline FV & GL & $\mathrm{QM}$ \\
\hline $\operatorname{Anos}(\mathrm{A})$ & 1 & $1389327,729^{\text {n.s }}$ \\
\hline Repetição/Ano (R/A) & 6 & $506381,105^{* *}$ \\
\hline Tratamentos $(\mathrm{T})$ & 463 & $9670,222^{* *}$ \\
\hline Linhagens (L) & 449 & $9726,531^{* *}$ \\
\hline Cruz (C) & 44 & $27484,455^{* *}$ \\
\hline Lng/Cruz (K) & 405 & $7797,275^{*}$ \\
\hline Testemunhas (S) & 3 & $219,348^{\text {n.s. }}$ \\
\hline Parentais $(\mathrm{P})$ & 9 & $11980,766^{\mathrm{ns}}$ \\
\hline Lngvs.Parent (Lvs.P) & 1 & $802,334^{\text {n.s. }}$ \\
\hline Testvs.Lng+Parent (Svs.L,P) & 1 & $813,161^{\text {n.s. }}$ \\
\hline AnosxTrat (AxT) & 463 & $6982,354 * *$ \\
\hline AnosxLng (AxL) & 449 & $6940,747^{* *}$ \\
\hline AnosxCruz (AxC) & 44 & $12246,418^{\text {n.s. }}$ \\
\hline Cruz/Anol (C/Al) & 44 & $27155,497^{* *}$ \\
\hline Cruz/Ano2 (C/A2) & 44 & $12575,376^{* *}$ \\
\hline Anos/Cruzl (A/Cl) & 1 & $39656,646^{* *}$ \\
\hline Anos/Cruz2 (A/C2) & 1 & $18211,216^{* *}$ \\
\hline Anos/Cruz3 (A/C3) & 1 & $25615,921^{* *}$ \\
\hline Anos/Cruz4 (A/C4) & 1 & $24008,000^{\text {"* }}$ \\
\hline Anos/Cruz5 (A/C5) & 1 & $70895,687^{* *}$ \\
\hline Anos/Cruz6 (A/C6) & 1 & $10142,340^{*}$ \\
\hline Anos/Cruz7 (A/C7) & 1 & $62716,320=$ \\
\hline Anos/Cruz8 (A/C8) & 1 & $306,456^{\text {n.s }}$ \\
\hline Anos/Cruz9 (A/C9) & 1 & $5125,243^{\text {r.s. }}$ \\
\hline Anos/Cruz10 (A/C10) & 1 & $15372,482^{* *}$ \\
\hline Anos/Cruz11 (A/C11) & 1 & $66777,379^{* *}$ \\
\hline Anos/Cruz12 (A/C12) & 1 & $43211,327^{* *}$ \\
\hline Anos/Cruzl3 (A/C13) & 1 & $18048,513^{* *}$ \\
\hline Anos/Cruz14 (A/C14) & 1 & $43267,701^{* *}$ \\
\hline Anos/Cruz15 (A/C15) & 1 & $169191,468^{* *}$ \\
\hline Anos/Cruz16 (A/C16) & 1 & $631,996^{\text {n.s. }}$ \\
\hline Anos/Cruzl7 (A/C17) & 1 & $66833,437^{* *}$ \\
\hline Anos/Cruz18 (A/C18) & 1 & $9643,901^{*}$ \\
\hline Anos/Cruz19 (A/C19) & 1 & $22142,214^{* *}$ \\
\hline Anos/Cruz20 (A/C20) & 1 & $4002,810^{\text {n.s. }}$ \\
\hline Anos/Cruz21 (A/C21) & 1 & $1027,382^{\text {n.s. }}$ \\
\hline Anos/Cruz22 (A/C22) & 1 & $28720,563^{* *}$ \\
\hline Anos/Cruz23 (A/C23) & 1 & $13680,600^{* *}$ \\
\hline Anos/Cruz24 (A/C24) & 1 & $86684,845^{* *}$ \\
\hline Anos/Cruz25 (A/C25) & 1 & $79273,534^{* *}$ \\
\hline Anos/Cruz26 (A/C26) & 1 & $3613,366^{\text {n.s }}$ \\
\hline Anos/Cruz27 (A/C27) & 1 & $1170,063^{\text {n.s. }}$ \\
\hline Anos/Cruz28 (A/C28) & 1 & $26939,694^{* *}$ \\
\hline Anos/Cruz29 (A/C29) & 1 & $13049,325^{* *}$ \\
\hline Anos/Cruz30 (A/C30) & 1 & $44156,245^{* *}$ \\
\hline Anos/Cruz31 (A/C31) & 1 & $48331,707^{* *}$ \\
\hline Anos/Cruz32 (A/C32) & 1 & $54807,597^{* *}$ \\
\hline Anos/Cruz33 (A/C33) & 1 & $48936,988^{* *}$ \\
\hline Anos/Cruz34 (A/C34) & 1 & $17519,984^{* *}$ \\
\hline Anos/Cruz35 (A/C35) & 1 & $4553,413^{\text {n.s. }}$ \\
\hline Anos/Cruz36 (A/C36) & 1 & $41071,200 * *$ \\
\hline Anos/Cruz37 (A/C37) & 1 & $142061,896^{* *}$ \\
\hline Anos/Cruz38 (A/C38) & 1 & $6104,248^{*}$ \\
\hline Anos/Cruz39 (A/C39) & 1 & $6057,336^{*}$ \\
\hline Anos/Cruz40 (A/C40) & 1 & $99799,266^{* *}$ \\
\hline Anos/Cruz41 (A/C41) & 1 & $153878,755^{* *}$ \\
\hline Anos/Cruz42 (A/C42) & 1 & $18802,002^{* *}$ \\
\hline Anos/Cruz43 (A/C43) & 1 & $17038,046^{* *}$ \\
\hline
\end{tabular}


Tabela 12 continuação

\begin{tabular}{|c|c|c|}
\hline FV & GL & $\mathrm{QM}$ \\
\hline Anos/Cruz44 (A/C44) & 1 & $59111,764^{n=}$ \\
\hline Anos/Cruz45 (A/C45) & 1 & $188149,920^{* *}$ \\
\hline AnosxLng/Cruz (AxK) & 405 & $6364,329^{* *}$ \\
\hline Lng/Cruz//Anol (L/C//Al) & 405 & $9588,311^{* *}$ \\
\hline Lng/Cruz/Ano2(L/C//A2) & 405 & $4573,293^{* *}$ \\
\hline AnosxTest $(\mathrm{AxS})$ & 3 & $996,396^{\mathrm{ns}}$ \\
\hline Test/Anol (S/Al) & 3 & $562,666^{\text {n.s. }}$ \\
\hline Test/Ano2 (S/A2) & 3 & $653,078^{\text {n.s. }}$ \\
\hline Anos/lAC-Foscarin-31 (A/S1) & 1 & $12180,619^{\prime \prime}$ \\
\hline Anos/IAS-5 (A/S2) & 1 & $1785,375^{\text {n.s. }}$ \\
\hline Anos/Paraná (A/S3) & 1 & $4187,041^{\text {n.s. }}$ \\
\hline Anos/Primavera (A/S4) & 1 & $1992,539^{\text {n.s. }}$ \\
\hline AnosxParent (AxP) & 9 & $11148,073^{n "}$ \\
\hline Parent/Anol (P/Al) & 9 & $20566,214^{\prime *}$ \\
\hline Parent/Ano2 (P/A2) & 9 & $2562,625^{\text {n.s. }}$ \\
\hline Anos/Coker $136(\mathrm{~A} / \mathrm{Pl})$ & 1 & $27368,558^{* *}$ \\
\hline Anos/Década (A/P2) & 1 & $1846,962^{\text {n.s. }}$ \\
\hline Anos/Forrest (A/P3) & 1 & $230,020^{\mathrm{ns}}$ \\
\hline Anos/FT80-1835 (A/P4) & 1 & $2258,548^{\text {ILS. }}$ \\
\hline Anos/Hale 321 (A/P5) & 1 & $13442,666^{* *}$ \\
\hline Anos/1AC-Foscarin-31 (A/P6) & 1 & $164,431^{\text {n.s. }}$ \\
\hline Anos/Palmetto (A/P7) & 1 & $30331,260 "$ \\
\hline Anos/Paraná (A/P8) & 1 & $368,166^{\text {n.s }}$ \\
\hline Anos/Primavera (A/P9) & 1 & $5648,188^{\text {n.s }}$ \\
\hline Anos/SOC81-79(A/P10) & 1 & $22459,178^{\prime *}$ \\
\hline AnosxLngvs.Parent (AxLvs.P) & 1 & $12644,016^{\text {n.s. }}$ \\
\hline Lngvs.Parent/Anol (Lvs.P/A1) & 1 & $3522,173^{\text {n.s. }}$ \\
\hline Lngvs.Parent/Ano2 (Lvs.P/A2) & 1 & 9935,224 \\
\hline AnosxTestvs.Lng+Parent (AxSvs.L,P) & 1 & $468,359^{\prime *}$ \\
\hline Testvs.Lng+Parent/Anol (Svs.L,P/Al) & 1 & $22,371^{\text {n.s. }}$ \\
\hline Testvs.Lng+Parent/Ano2 (Svs.L,P/A2) & 1 & $1248,102^{\mathrm{n.s}}$ \\
\hline Resíduo (E) & 1852 & 1651,005 \\
\hline Total & 2783 & \\
\hline Média $\left(\mathrm{g} / \mathrm{m}^{2}\right)$ & \multicolumn{2}{|c|}{160,02} \\
\hline C.V. $(\%)$ & \multicolumn{2}{|c|}{25,39} \\
\hline
\end{tabular}


Tabela 13 DM: dano mecânico. Resumo da análise de variância conjunta dos experimentos. e respectivos desdobramentos, com os valores e significância dos quadrados médios. Soja precoce. Piracicaba, experimentos com semeaduras em 03/12/1991 e 02/12/1992.

\begin{tabular}{|c|c|c|}
\hline 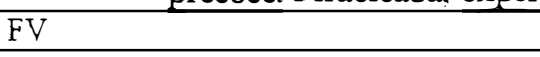 & GL & QM \\
\hline $\operatorname{Anos}(\mathrm{A})$ & 1 & $474,878^{\pi x}$ \\
\hline Repetição/Ano (R/A) & 6 & $25,585^{* 1}$ \\
\hline Tratamentos $(\mathrm{T})$ & 63 & $2,227^{* *}$ \\
\hline Linhagens (L) & 49 & $2,030^{\text {n.s. }}$ \\
\hline Cruz (C) & 4 & $3,149^{\text {n.s }}$ \\
\hline Lng/Cruz (K) & 45 & $1,930^{\text {ns }}$ \\
\hline Lng/Cruz-4 (K4) & 9 & $2,368^{\text {n.s. }}$ \\
\hline Lng/Cruz-13 (K13) & 9 & $0,834^{\text {n.s. }}$ \\
\hline Lng/Cruz-18 (K18) & 9 & $1,699^{\text {n.s. }}$ \\
\hline Lng/Cruz-29 (K29) & 9 & $1,539^{\text {n.s. }}$ \\
\hline Lng/Cruz-44 (K44) & 9 & $3.211^{*}$ \\
\hline Testemunhas (S) & 3 & $2,128^{*}$ \\
\hline Parentais $(\mathrm{P})$ & 9 & $2,948^{\text {ns }}$ \\
\hline Lngvs.Parent (Lvs.P) & 1 & $5,089^{\times x}$ \\
\hline Testvs.Lng+Parent (Svs.L,P) & 1 & $2,851^{\text {n.s. }}$ \\
\hline AnosxTrat (AxT) & 63 & $1.708^{\times x}$ \\
\hline AnosxLng (AxL) & 49 & $1,546^{x x}$ \\
\hline AnosxCruz (AxC) & 4 & $1,912^{\text {ns }}$ \\
\hline AnosxLng/Cruz (AxK) & 45 & $1,514^{*}$ \\
\hline AnosxTest (AxS) & 3 & $0,189^{\text {ns }}$ \\
\hline AnosxParent (AxP) & 9 & $3,340^{-*}$ \\
\hline AnosxLngvs.Parent (AxLvs.P) & 1 & $0,0002^{\text {n.s. }}$ \\
\hline AnosxTestvs.Lng+Parent (AxSvs.L,P) & 1 & $1,228^{\text {n.s. }}$ \\
\hline Resíduo (E) & 378 & 0,551 \\
\hline Total & 511 & \\
\hline Média (udm) & & 2,96 \\
\hline C.V. $(\%)$ & & 25,07 \\
\hline
\end{tabular}


Tabela 14 DM: dano mecânico. Resumo da análise de variância conjunta dos experimentos, e respectivos desdobramentos/ano, os valores e significância dos quadrados médios. Soja precoce. Piracicaba, experimentos com semeaduras em 03/12/1991 e 02/12/1992.

\begin{tabular}{|c|c|c|}
\hline FV & GL & $\mathrm{QM}$ \\
\hline $\operatorname{Anos}(\mathrm{A})$ & 1 & $474,878^{72}$ \\
\hline Repetição/Ano (R/A) & 6 & $25,585^{* *}$ \\
\hline Tratamentos $(\mathrm{T})$ & 63 & $2,227^{2=}$ \\
\hline Linhagens (L) & 49 & $2,030^{\text {n.s. }}$ \\
\hline Cruz (C) & 4 & $3,149^{\mathrm{ns}}$ \\
\hline Lng/Cruz (K) & 45 & $1,930^{\mathrm{ns}}$ \\
\hline Testemunhas (S) & 3 & $2,128^{*}$ \\
\hline Parentais $(\mathrm{P})$ & 9 & $2,948^{\text {n.s. }}$ \\
\hline Lngvs.Parent (Lvs.P) & 1 & $5,089^{=2}$ \\
\hline Testvs.Lng+Parent (Svs.L,P) & 1 & $2,851^{\text {n.s. }}$ \\
\hline AnosxTrat (AxT) & 63 & $1,708^{=*}$ \\
\hline AnosxLng (AxL) & 49 & $1,546^{=2}$ \\
\hline AnosxCruz $(\mathrm{AxC})$ & 4 & $1,912^{\text {n.s. }}$ \\
\hline CruzfAnol (C/Al) & 4 & $4,350^{* *}$ \\
\hline Cruz/Ano2 (C/A2) & 4 & $0,711^{\text {n.s. }}$ \\
\hline Anos/Cruz4 (A/C4) & 1 & $37,414^{x=}$ \\
\hline Anos/Cruz13 (A/C13) & 1 & $94,895^{\times *}$ \\
\hline Anos/Cruz18 (A/C18) & 1 & $69,489^{=x}$ \\
\hline Anos/Cruz29 (A/C29) & 1 & $83,395^{=*}$ \\
\hline Anos/Cruz44 (A/C44) & 1 & $75,874=$ \\
\hline AnosxLng/Cruz (AxK) & 45 & $1,514=$ \\
\hline Lng/Cruz//Anol (L/C//Al) & 45 & $1,135^{x *}$ \\
\hline Lng/Cruz//Ano2(L/C//A2) & 45 & $2,309^{=1}$ \\
\hline AnosxTest (AxS) & 3 & $0,189^{\mathrm{ns}}$ \\
\hline Test/Anol (S/Al) & 3 & $0,677^{\text {n.s. }}$ \\
\hline Test/Ano2 (S/A2) & 3 & $1,640^{*}$ \\
\hline Anos/LAC-Foscarin-31 (A/S1) & 1 & $10,857^{=2}$ \\
\hline Anos/LAS-5 (A/S2) & 1 & $7,742^{=2}$ \\
\hline Anos/Paraná (A/S3) & 1 & $7,087^{=}$ \\
\hline Anos/Primavera (A/S4) & 1 & $5,008^{2=}$ \\
\hline AnosxParent $(\mathrm{AxP})$ & 9 & $3,340^{\prime \prime=}$ \\
\hline ParentAnol (P/Al) & 9 & $1,206^{*}$ \\
\hline Parent/Ano2 (P/A2) & 9 & $5,081^{x=}$ \\
\hline Anos/Coker $136(\mathrm{~A} / \mathrm{P} 1)$ & 1 & $26,100=$ \\
\hline Anos/Década (A/P2) & 1 & $4,636^{x=}$ \\
\hline Anos/Forrest (A/P3) & 1 & $25,205^{==}$ \\
\hline Anos/FT80-1835 (A/P4) & 1 & $22,815^{n=}$ \\
\hline Anos/Hale 321 (A/P5) & 1 & $3,976^{=2}$ \\
\hline Anos/IAC-Foscarin-31 (A/P6) & 1 & $0,186^{\mathrm{ns}}$ \\
\hline Anos/Palmetto (A/P7) & 1 & $18,422^{=-}$ \\
\hline Anos/Paraná (A/P8) & 1 & $0,485^{\text {n.s. }}$ \\
\hline Anos/Primavera (A/P9) & 1 & $3,001^{*}$ \\
\hline Anos/SOC81-79 (A/P10) & 1 & $17,790^{=}$ \\
\hline AnosxLngvs.Parent (AxLvs.P) & 1 & $0,0002^{\text {n.s. }}$ \\
\hline Lngvs.Parent/Anol (Lvs.P/A1) & 1 & $3,909^{x *}$ \\
\hline Lngvs.Parent/Ano2 (Lvs.P/A2) & 1 & $0,168^{\mathrm{ns}}$ \\
\hline AnosxTestvs.Lng+Parent (AxSvs.L.P) & 1 & $1,228^{\mathrm{ns}}$ \\
\hline Testvs.Lng+Parent/Anol (Svs.L,P/Al) & 1 & $2,641^{\star}$ \\
\hline Testvs.Lng+Parent/Ano2 (Svs.L,P/A2) & 1 & $2,450^{*}$ \\
\hline Resíduo (E) & 378 & 0,551 \\
\hline Total & 511 & \\
\hline Média (udm) & & 2,96 \\
\hline C.V. $(\%)$ & & 25,07 \\
\hline
\end{tabular}




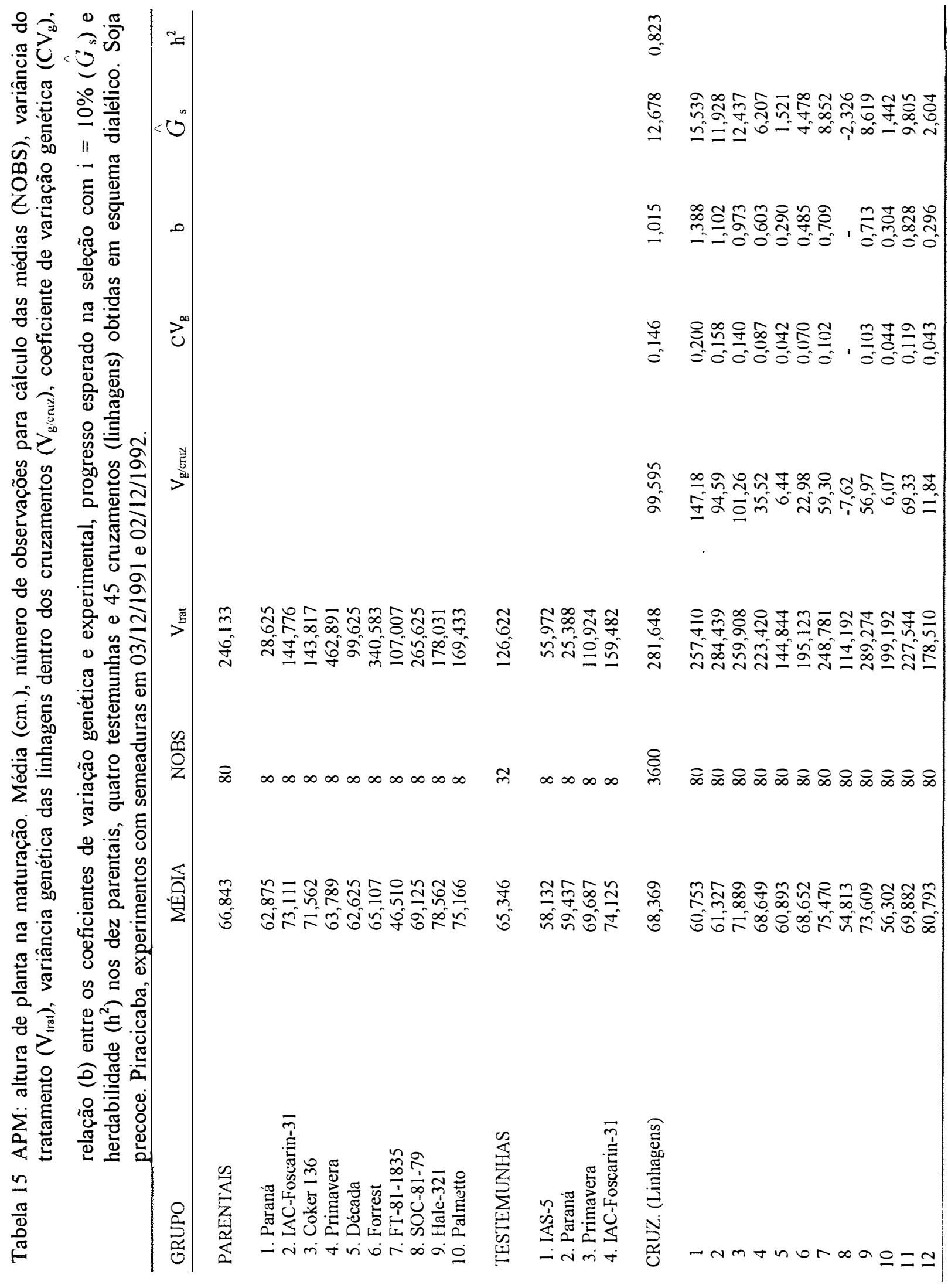




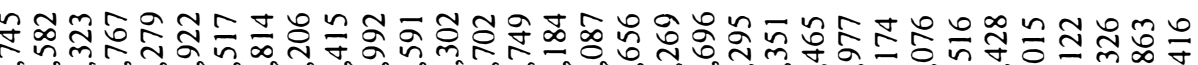

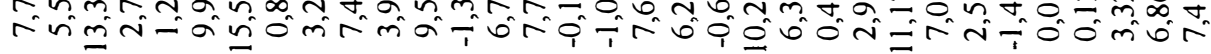

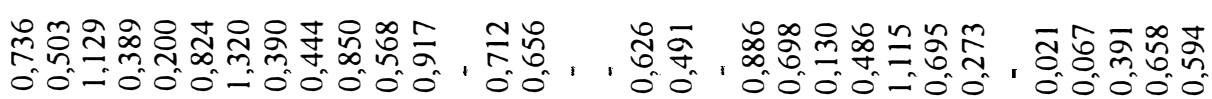

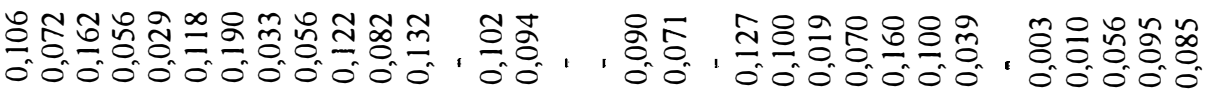

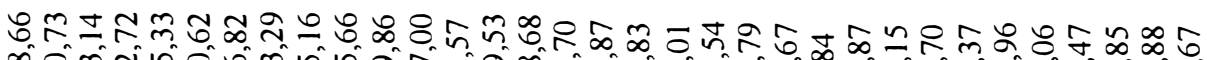

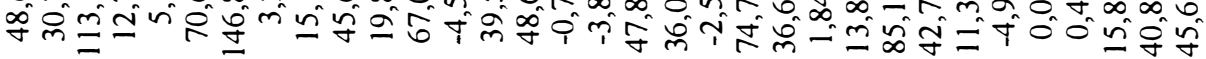

ᄀ సై

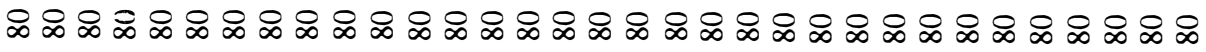

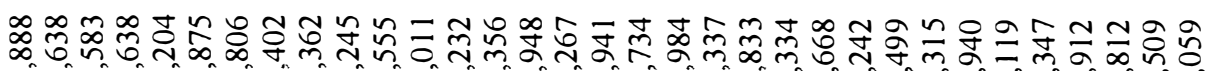

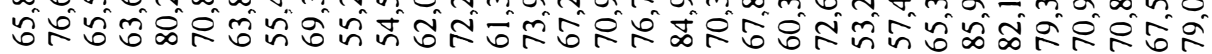




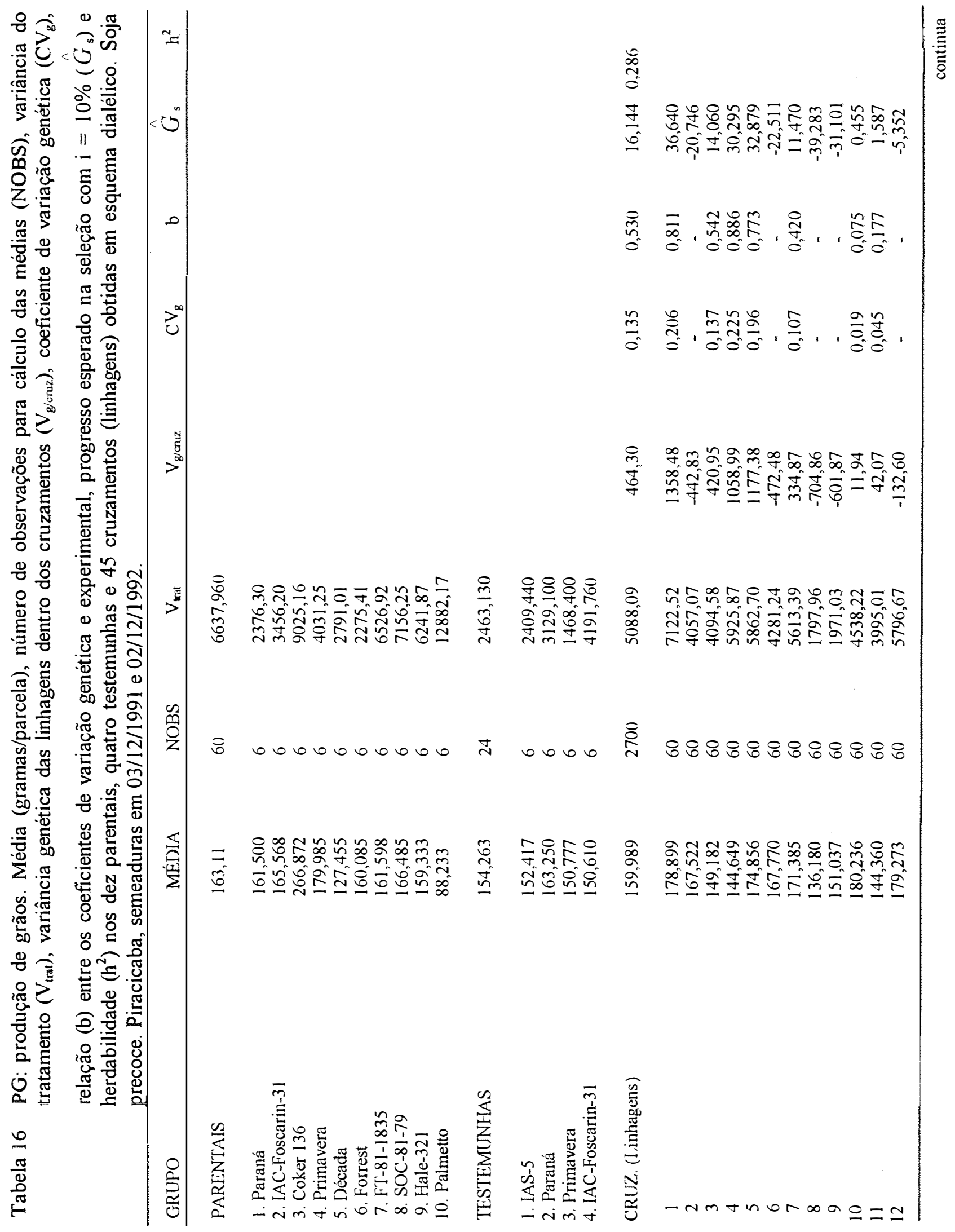




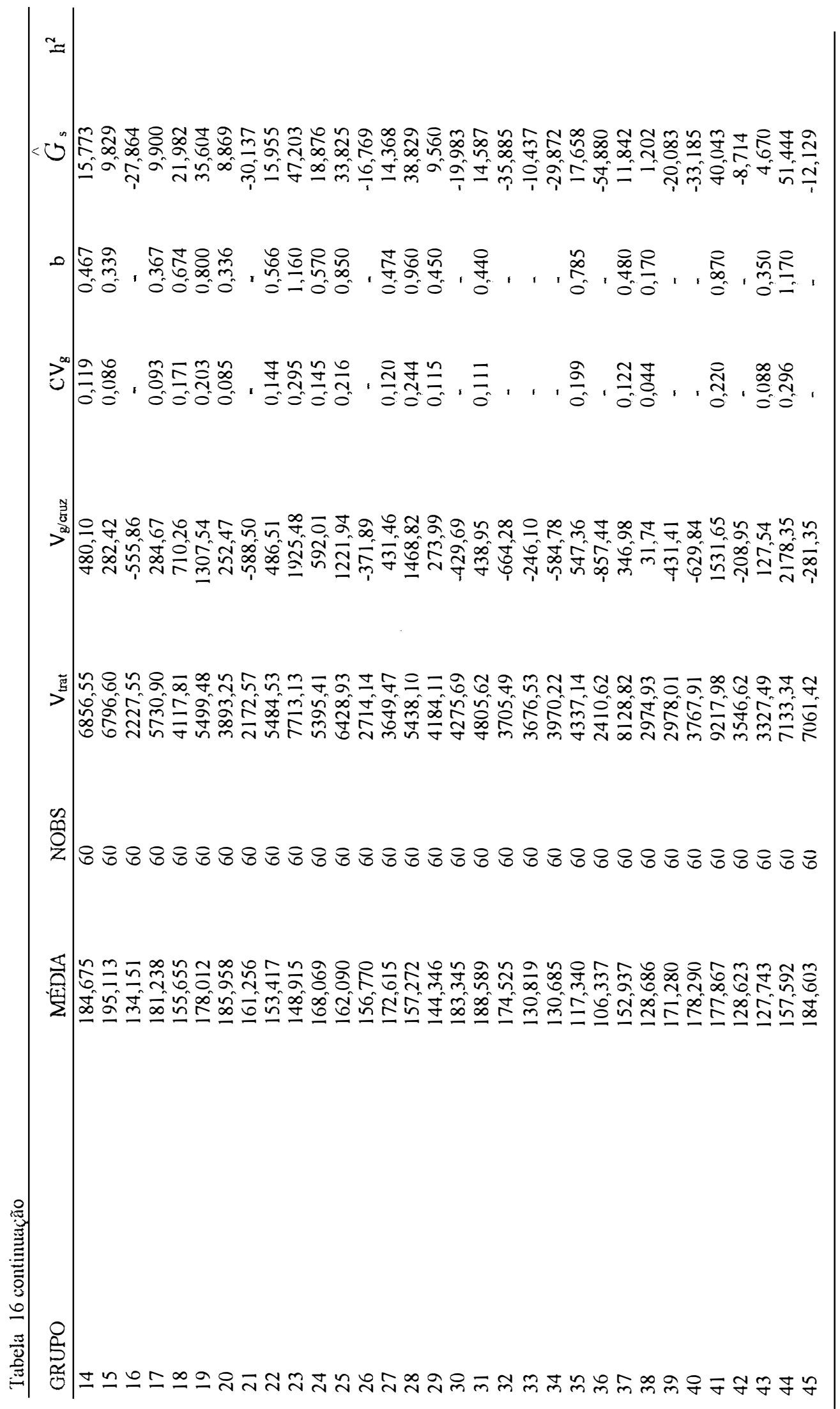




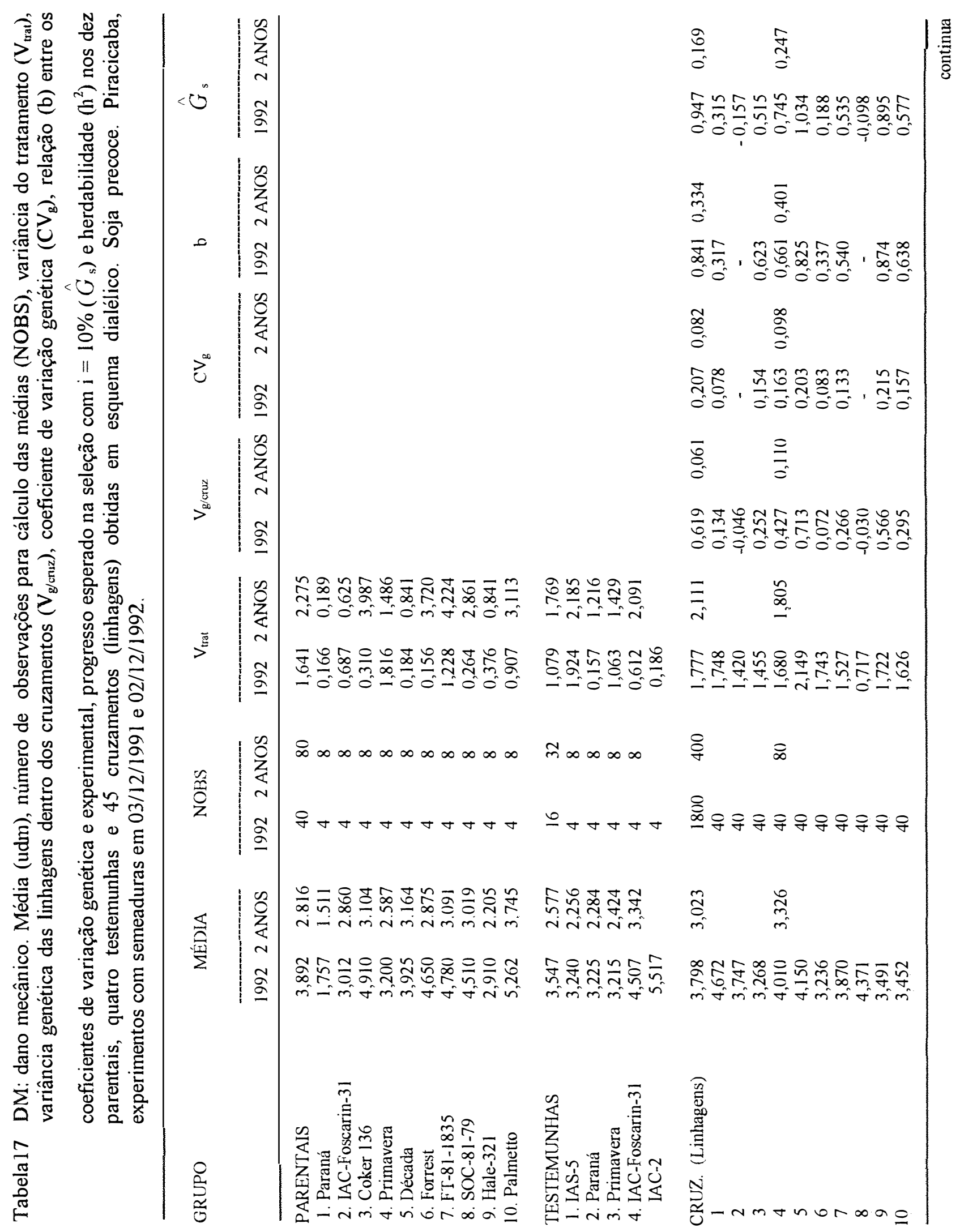




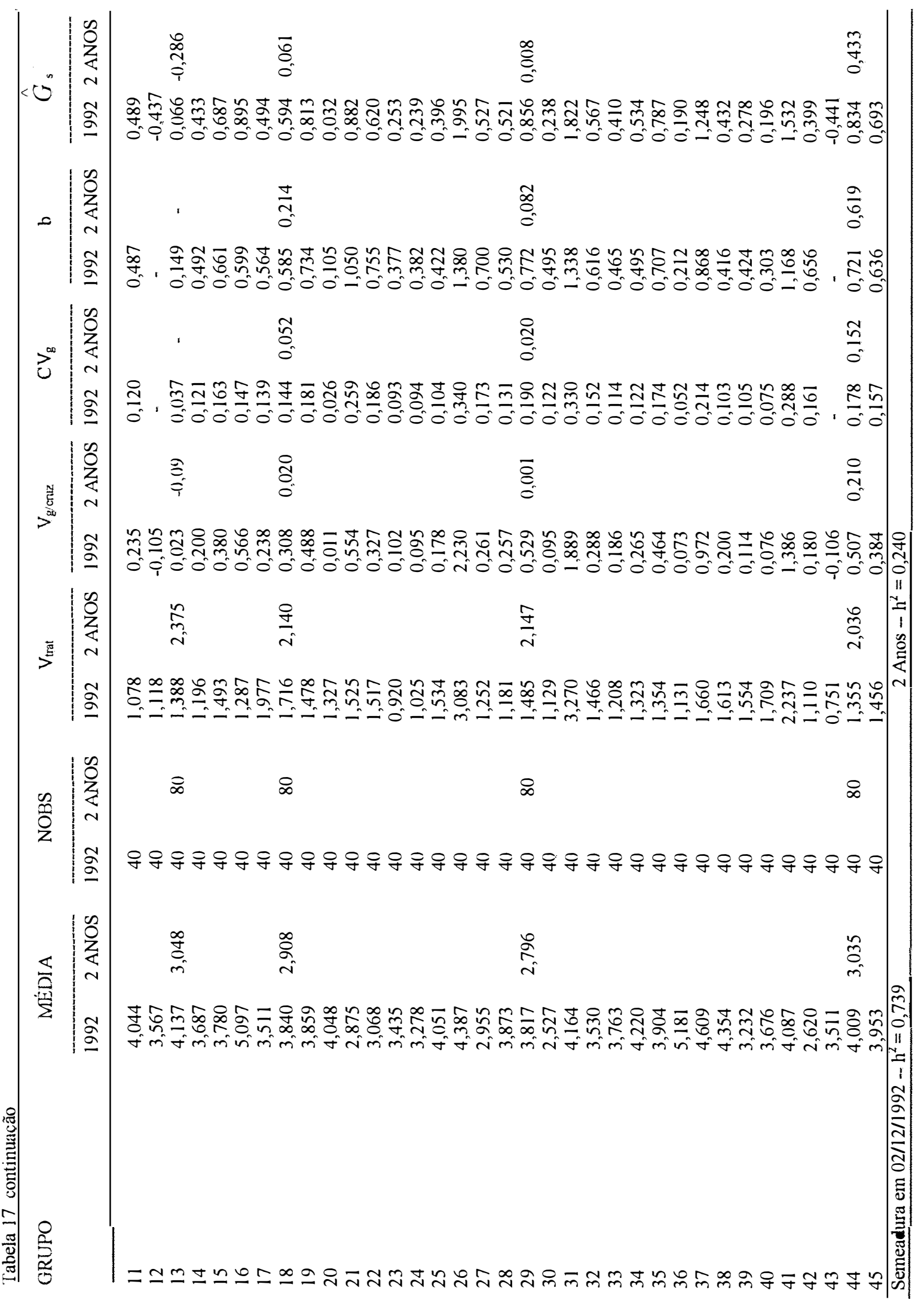


Tabela 18 Grau de associação (correlação fenotípica de ordem - Spearman) entre as variáveis dano mecânico (DM); germinação (G) e sementes duras (SD). Soja precoce. Piracicaba, experimentos com semeaduras em 03/12/1991 e 02/12/1992.

\begin{tabular}{|c|c|c|c|c|c|c|}
\hline \multirow[t]{2}{*}{ GRUPO } & \multicolumn{2}{|c|}{$\mathrm{DMxG}$} & \multicolumn{2}{|c|}{ DMxSD } & \multicolumn{2}{|c|}{$\mathrm{GxSD}^{\mathrm{a}}$} \\
\hline & $03 / 12 / 1991$ & $02 / 12 / 1992$ & $03 / 12 / 1991$ & $02 / 12 / 1992$ & $03 / 12 / 1991$ & $02 / 12 / 1992$ \\
\hline Lng+Parent + Test $\mathrm{t}^{\mathrm{b}}$ & -0.386 & $-0,034$ & 0.092 & -0.009 & 0.139 & $-0,078$ \\
\hline \multicolumn{7}{|l|}{ Linhagens $^{c}$} \\
\hline Cruz 4 & $-0,225$ & -0.136 & 0.109 & 0.250 & 0,417 & $-0,071$ \\
\hline Cruz 13 & $-0,481$ & $-0,056$ & $=$ & 0,007 & - & 0,153 \\
\hline Cruz 18 & -0.448 & $-0,021$ & 0.070 & -0.185 & 0.328 & $-0,122$ \\
\hline Cruz 29 & $-0,486$ & 0,235 & 0,144 & $-0,084$ & $-0,022$ & 0,025 \\
\hline Cruz 44 & -0.344 & $-0,002$ & 0,019 & -0.028 & 0,116 & $-0,029$ \\
\hline Parental $^{d}$ & $-0,127$ & $-0,038$ & 0.199 & 0,005 & -0.136 & $-0,299$ \\
\hline Testemunha $^{\mathrm{e}}$ & -0.556 & 0.259 & 0,069 & -0.364 & 0.171 & 0,084 \\
\hline \multicolumn{7}{|l|}{${ }^{\mathrm{a}} \mathrm{G}=\operatorname{Arcsen} \sqrt{\%}$} \\
\hline \multicolumn{7}{|l|}{$\mathrm{SD}=\operatorname{Arcsen} \sqrt{\%}$} \\
\hline \multicolumn{3}{|c|}{ b03/12/1991 = 256 observações } & \multicolumn{4}{|c|}{${ }^{\mathrm{d}} 03 / 12 / 1991=40$ observações } \\
\hline \multicolumn{3}{|c|}{$02 / 12 / 1992=256$ observações } & \multicolumn{4}{|c|}{$02 / 12 / 1992=40$ observações } \\
\hline \multicolumn{3}{|c|}{ '03/12/1991 = 40 observações } & \multicolumn{4}{|c|}{${ }^{\mathrm{e}} 03 / 12 / 1991=16$ observações } \\
\hline \multicolumn{3}{|c|}{$02 / 12 / 1992=40$ observações } & \multicolumn{4}{|c|}{ 02/12/1992 = 16 observações } \\
\hline
\end{tabular}




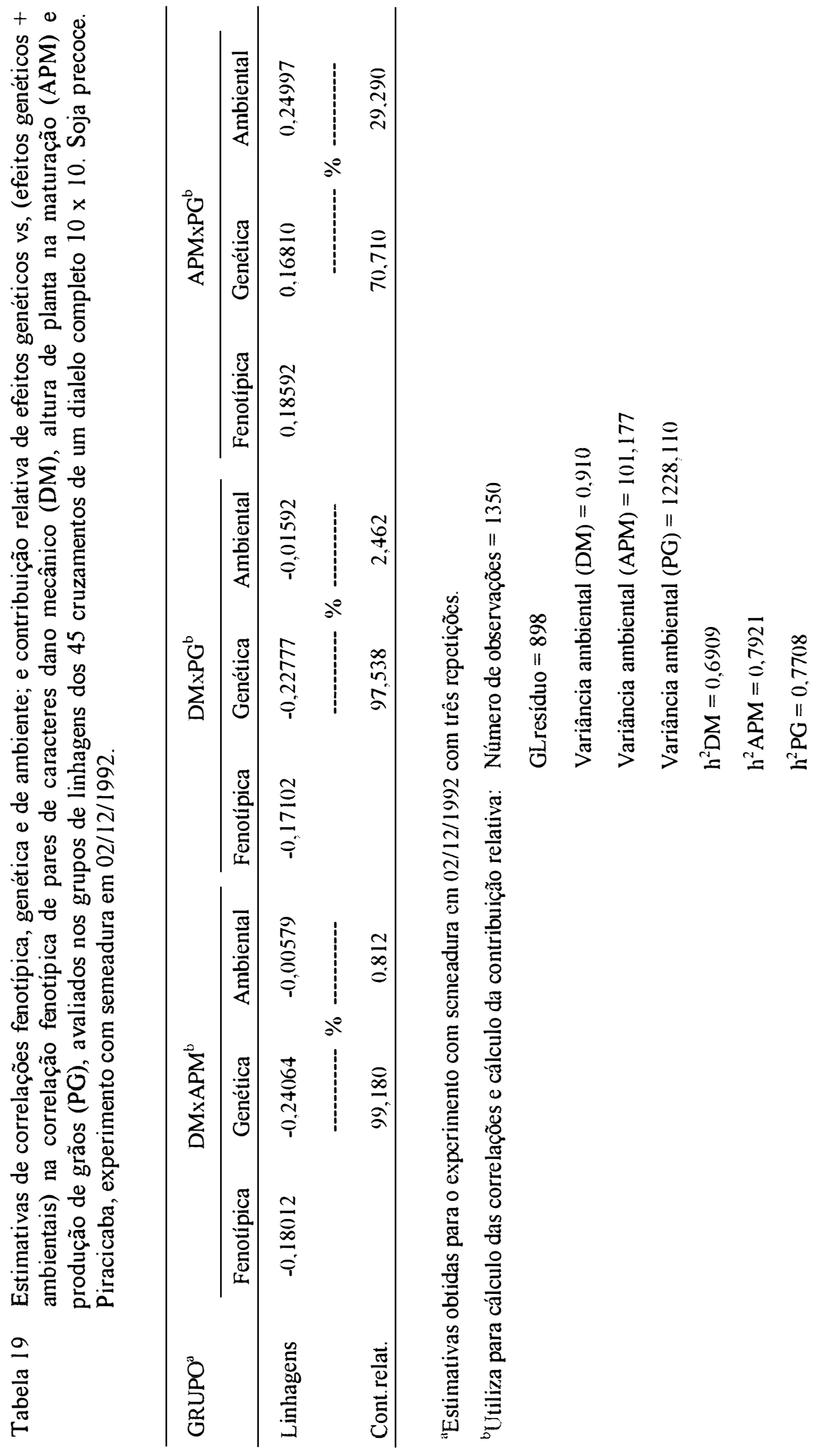




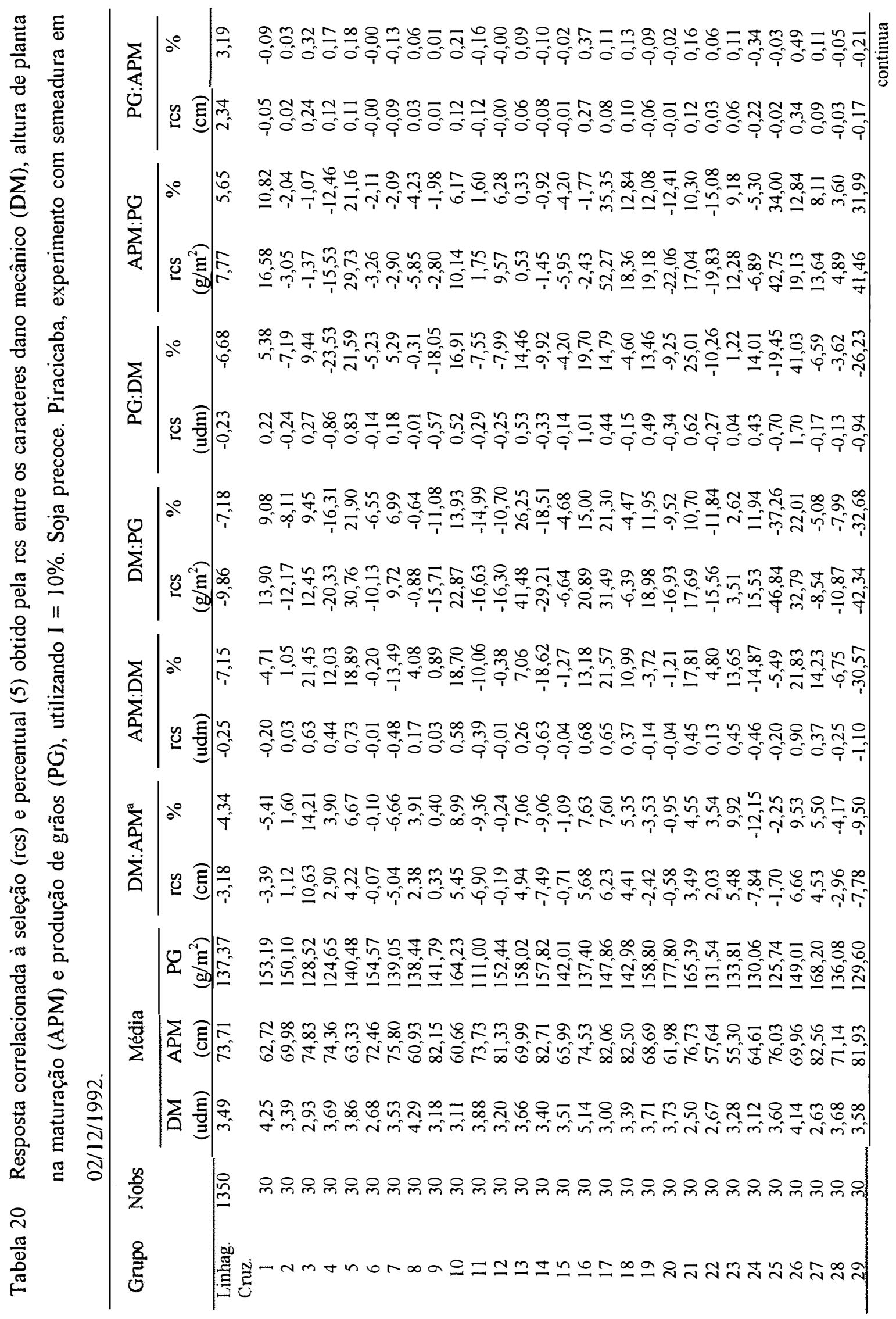




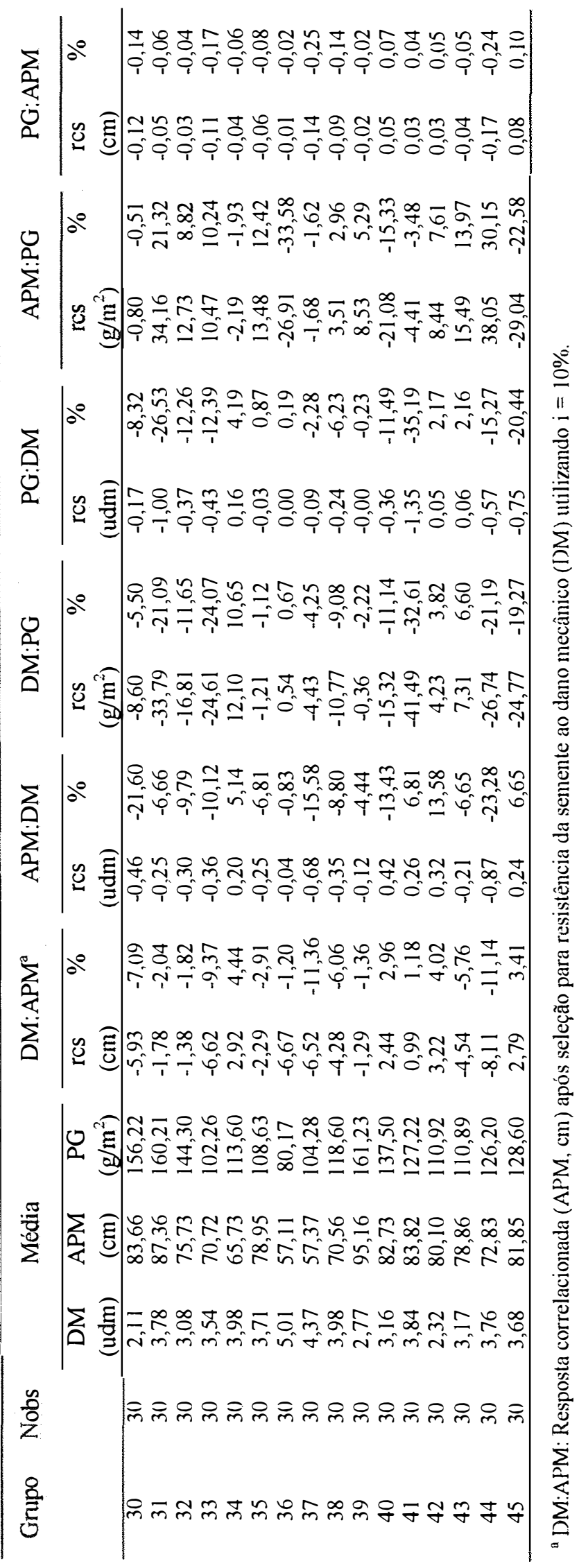


Tabela 21 Coeficientes de determinação $\left(\mathrm{R}^{2}\right)$ das análises de regressão linear múltiplas entre a variável dependente dano mecânico $(\mathrm{DM})$ e as variáveis independentes: sementes quebradas (SQ), sementes danificadas (SD) e sementes intumescidas (SI). Piracicaba, experimentos com semeaduras em 03/12/1991 e 02/12/1992.

\begin{tabular}{|c|c|c|c|c|c|c|c|}
\hline \multirow[b]{2}{*}{ DM } & \multirow[b]{2}{*}{$\mathrm{N}^{\mathrm{a}}$} & \multicolumn{2}{|c|}{ SQ } & \multicolumn{2}{|c|}{ SD } & \multicolumn{2}{|c|}{ SI } \\
\hline & & $\overline{\mathrm{R}^{2}}$ parcial $^{\mathrm{b}}$ & $\mathrm{R}^{2}$ modelo ${ }^{\mathrm{C}}$ & $\mathrm{R}^{2}$ parcial & $\mathrm{R}^{2}$ modelo ${ }^{\mathrm{d}}$ & $\mathrm{R}^{2}$ parcial & $\mathrm{R}^{2}$ modelo ${ }^{\mathrm{e}}$ \\
\hline \multicolumn{8}{|l|}{$\overline{\text { ANOS }}$} \\
\hline 1991/92 & 256 & 0.590 & 0,590 & 0,114 & 0.704 & 0.037 & 0,741 \\
\hline $1992 / 93$ & 1856 & 0.508 & 0,508 & 0,273 & 0,781 & 0,011 & 0,792 \\
\hline \multicolumn{8}{|l|}{$\begin{array}{l}\text { Cruzamentos } \\
1991 / 92\end{array}$} \\
\hline 4 & 40 & 0.073 & 0,073 & 0.495 & 0,568 & 0,006 & 0,574 \\
\hline 13 & 40 & 0,137 & 0,137 & 0,751 & 0,888 & 0,043 & 0,931 \\
\hline 18 & 40 & 0.079 & 0,079 & 0,709 & 0.788 & 0,061 & 0,849 \\
\hline 29 & 40 & 0.060 & 0,060 & 0,644 & 0,704 & - & - \\
\hline 44 & 40 & 0.437 & 0,437 & 0.352 & 0.789 & 0.043 & 0,832 \\
\hline Parentais & 40 & 0.128 & 0.128 & 0,524 & 0,652 & 0.109 & 0.761 \\
\hline Testemunhas & 16 & 0.164 & 0,164 & 0,547 & 0,711 & 0,042 & 0,753 \\
\hline \multicolumn{8}{|l|}{$\begin{array}{l}\text { Cruzamentos } \\
1992 / 93\end{array}$} \\
\hline 1 & 40 & 0.404 & 0,404 & 0,201 & 0,605 & - & - \\
\hline 2 & 40 & 0,627 & 0,627 & 0,244 & 0,871 & 0,008 & 0,879 \\
\hline 3 & 40 & 0,577 & 0,577 & 0,096 & 0,674 & - & - \\
\hline 4 & 40 & 0.622 & 0,622 & 0,114 & 0,736 & 0,008 & 0.744 \\
\hline 5 & 40 & 0,452 & 0,452 & 0,251 & 0.703 & - & - \\
\hline 6 & 40 & 0,166 & 0,166 & 0,702 & 0,868 & 0,007 & 0,875 \\
\hline 7 & 40 & 0.442 & 0,442 & 0,298 & 0,740 & - & - \\
\hline 8 & 40 & 0.318 & 0.318 & 0,312 & 0.630 & - & - \\
\hline 9 & 40 & $0,06,7$ & 0,067 & 0,438 & 0.505 & 0,022 & 0,527 \\
\hline 10 & 40 & 0.234 & 0,234 & 0,519 & 0.753 & - & - \\
\hline 11 & 40 & 0.139 & 0,139 & 0,387 & 0,526 & 0,032 & 0,558 \\
\hline 12 & 40 & 0.518 & 0.518 & 0.376 & 0.894 & 0,023 & 0,917 \\
\hline 13 & 40 & 0.697 & 0,697 & 0,290 & 0,987 & 0,012 & 0,999 \\
\hline 14 & 40 & 0,206 & 0,206 & 0,649 & 0.855 & - & - \\
\hline 15 & 40 & 0,341 & 0,341 & 0,644 & 0,985 & 0,014 & 0,999 \\
\hline 16 & 40 & 0.388 & 0.388 & 0.204 & 0.592 & - & - \\
\hline 17 & 40 & 0.688 & 0,688 & 0,254 & 0,942 & 0,011 & 0,953 \\
\hline 18 & 40 & 0,188 & 0,188 & 0,630 & 0.818 & - & - \\
\hline 19 & 40 & 0,521 & 0,521 & 0,238 & 0,759 & 0,033 & 0,792 \\
\hline 20 & 40 & 0.423 & 0,423 & 0.489 & 0.912 & 0,015 & 0,927 \\
\hline 21 & 40 & 0,652 & 0,652 & 0,102 & 0,754 & - & - \\
\hline 22 & 40 & 0.069 & 0,069 & 0,463 & 0,532 & 0,022 & 0,554 \\
\hline 23 & 40 & 0.170 & 0,170 & 0,639 & 0,809 & 0,009 & 0,818 \\
\hline 24 & 40 & 0.375 & 0,375 & 0.513 & 0.888 & 0.008 & 0.896 \\
\hline 25 & 40 & 0.456 & 0,456 & 0,466 & 0.922 & 0,011 & 0,933 \\
\hline 26 & 40 & 0,604 & 0,604 & 0,165 & 0,769 & 0,034 & 0,803 \\
\hline 27 & 40 & 0,261 & 0,261 & 0,719 & 0.980 & 0,019 & 0,999 \\
\hline 28 & 40 & 0.504 & 0,504 & 0,230 & 0,734 & 0,040 & 0,774 \\
\hline 29 & 40 & 0.163 & 0,161 & 0,317 & 0,478 & 0,076 & 0,554 \\
\hline
\end{tabular}


Tabela 21 continuação

\begin{tabular}{cccccccc}
\hline & & \multicolumn{2}{c}{$\mathrm{SQ}$} & \multicolumn{2}{c}{$\mathrm{SD}$} & \multicolumn{2}{c}{$\mathrm{SI}$} \\
\cline { 3 - 8 } $\mathrm{DM}$ & $\mathrm{N}^{\mathrm{a}}$ & $\mathrm{R}^{2}$ parcial & $\mathrm{R}^{2}$ modelo & $\mathrm{R}^{2}$ parcial & $\mathrm{R}^{2}$ modelo & $\mathrm{R}^{2}$ parcial & $\mathrm{R}^{2}$ modelo \\
\hline 30 & 40 & 0,200 & 0,200 & 0,744 & 0,944 & 0,025 & 0,969 \\
31 & 40 & 0,807 & 0,807 & 0,144 & 0,951 & 0,014 & 0,965 \\
32 & 40 & 0,633 & 0,633 & 0,268 & 0,901 & 0,006 & 0,907 \\
33 & 40 & 0,218 & 0,218 & 0,500 & 0,718 & 0,058 & 0,776 \\
34 & 40 & 0,267 & 0,267 & 0,396 & 0,663 & 0,033 & 0,696 \\
35 & 40 & 0,166 & 0,166 & 0,589 & 0,755 & 0,044 & 0,799 \\
36 & 40 & 0,599 & 0,599 & 0,389 & 0,988 & 0,011 & 0,999 \\
37 & 40 & 0,614 & 0,614 & 0,203 & 0,817 & 0,003 & 0,820 \\
38 & 40 & 0,546 & 0,546 & 0,208 & 0,754 & - & - \\
39 & 40 & 0,648 & 0,648 & 0,226 & 0,874 & 0,011 & 0,885 \\
40 & 40 & 0,252 & 0,252 & 0,737 & 0,989 & 0,010 & 0,999 \\
41 & 40 & 0,487 & 0,487 & 0,192 & 0,679 & - & - \\
42 & 40 & 0,592 & 0,592 & 0,178 & 0,770 & 0,033 & 0,803 \\
43 & 40 & 0.599 & 0,599 & $0,37,7$ & 0,976 & 0,023 & 0,999 \\
44 & 40 & 0,394 & 0,394 & 0,087 & 0,481 & 0,065 & 0,546 \\
45 & 40 & 0.528 & 0,528 & 0,126 & 0,654 & 0.006 & 0,660 \\
Parentais & 40 & 0,082 & 0,082 & 0,331 & 0,413 & 0.022 & 0,435 \\
Testemunhas & 16 & 0.094 & 0.094 & 0,878 & 0,972 & 0,025 & 0,997 \\
\hline
\end{tabular}

${ }^{a} \mathrm{~N}$ : número de observações;

${ }^{b} R^{2}$ parcial: coeficiente de determinação individual das variáveis independentes $S Q$, SD e SI:

${ }^{c} \mathrm{R}^{2}$ modelo: coeficiente de determinação do modelo contendo apenas a variável dependente SQ;

${ }^{d} R^{2}$ modelo: coeficiente de determinação do modelo contendo as variáveis dependentes SQ e SD e

${ }^{e} \mathrm{R}^{2}$ modelo: coeficiente de determinação do modelo contendo as variáveis dependentes SQ, SD e SI. 

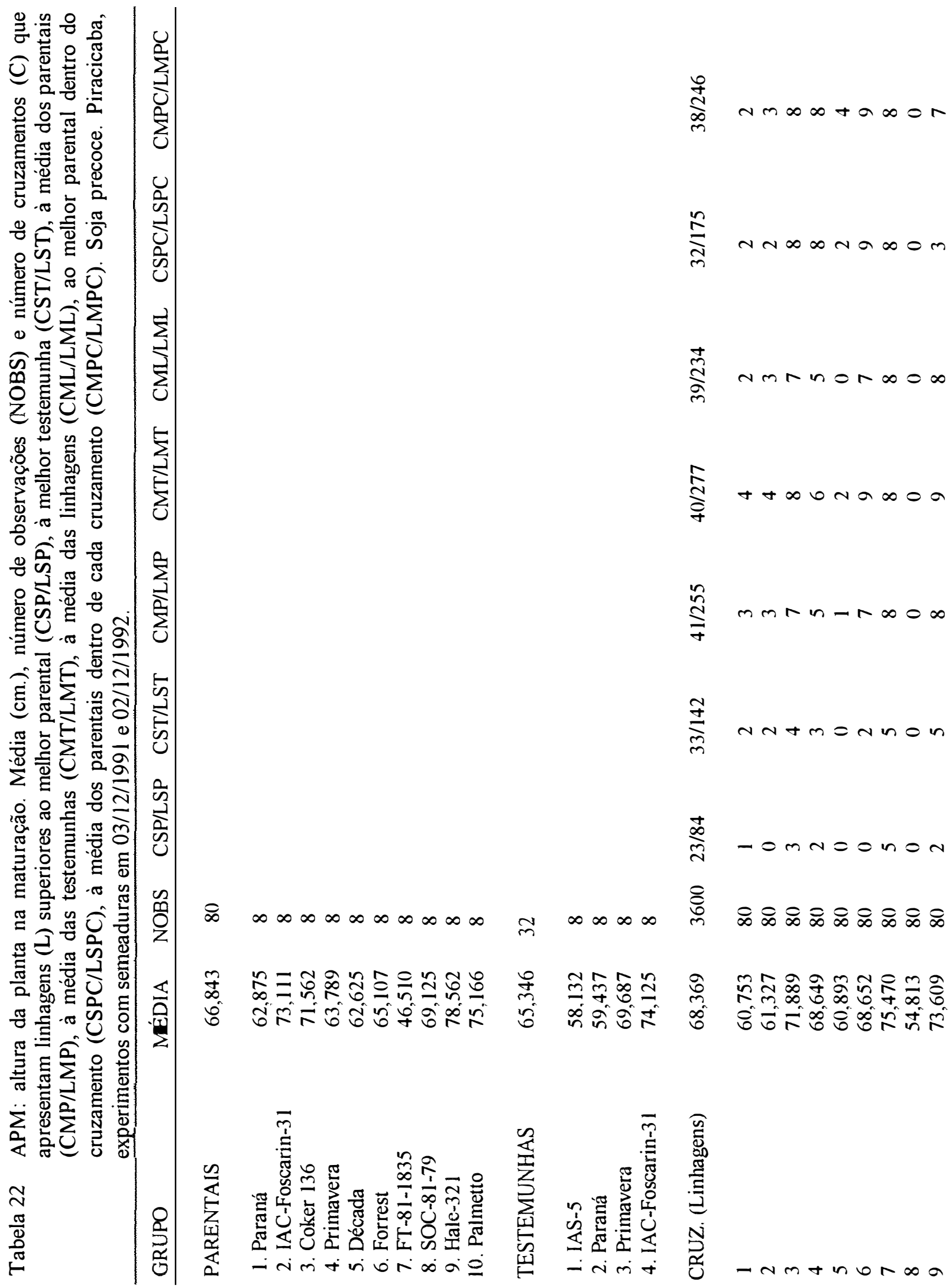

苂

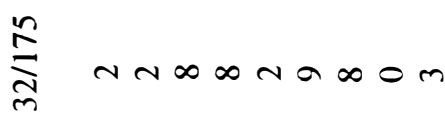

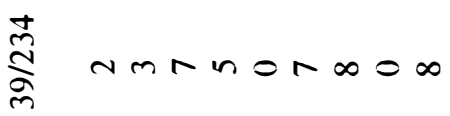

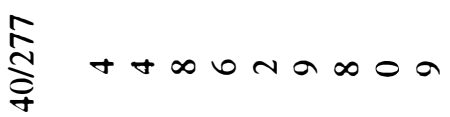

$\stackrel{n}{i} m m N n-N \infty 0 \infty$

$\stackrel{\sim}{I}_{m} N n+m=N n 0 n$

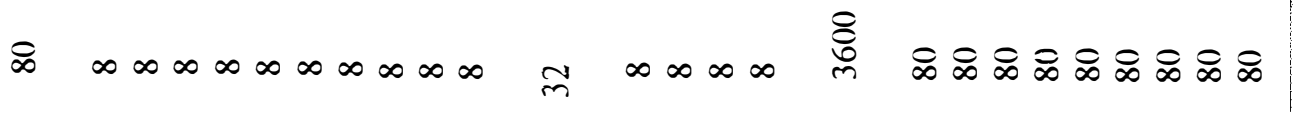

m

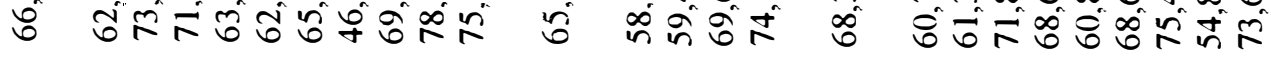

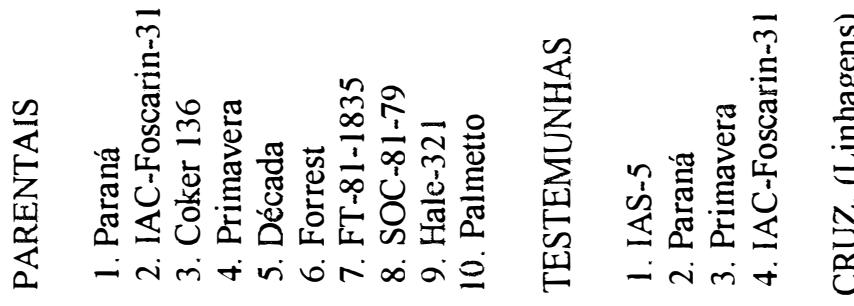
$-\sim m+n$ t $-\infty a$ 


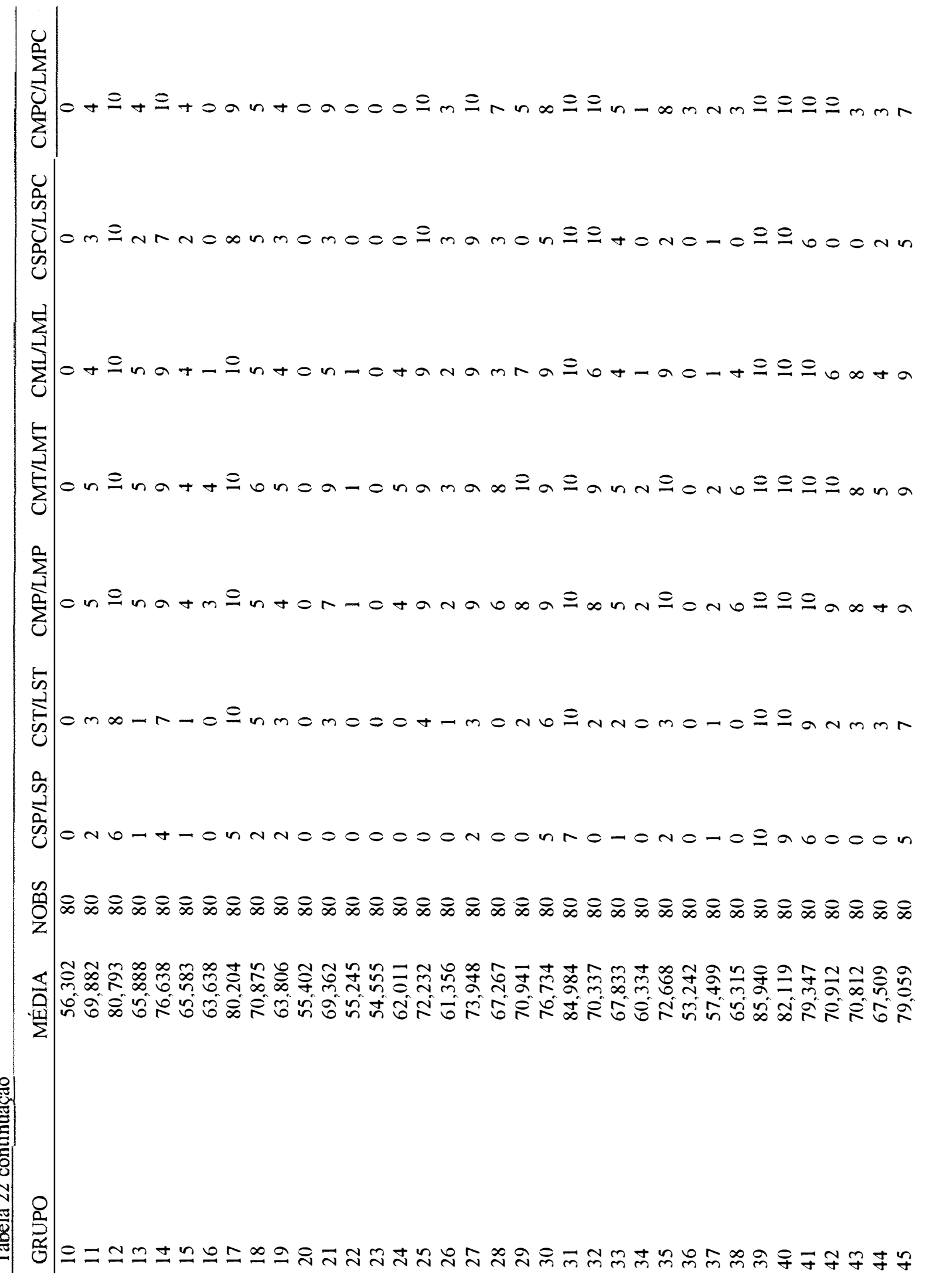




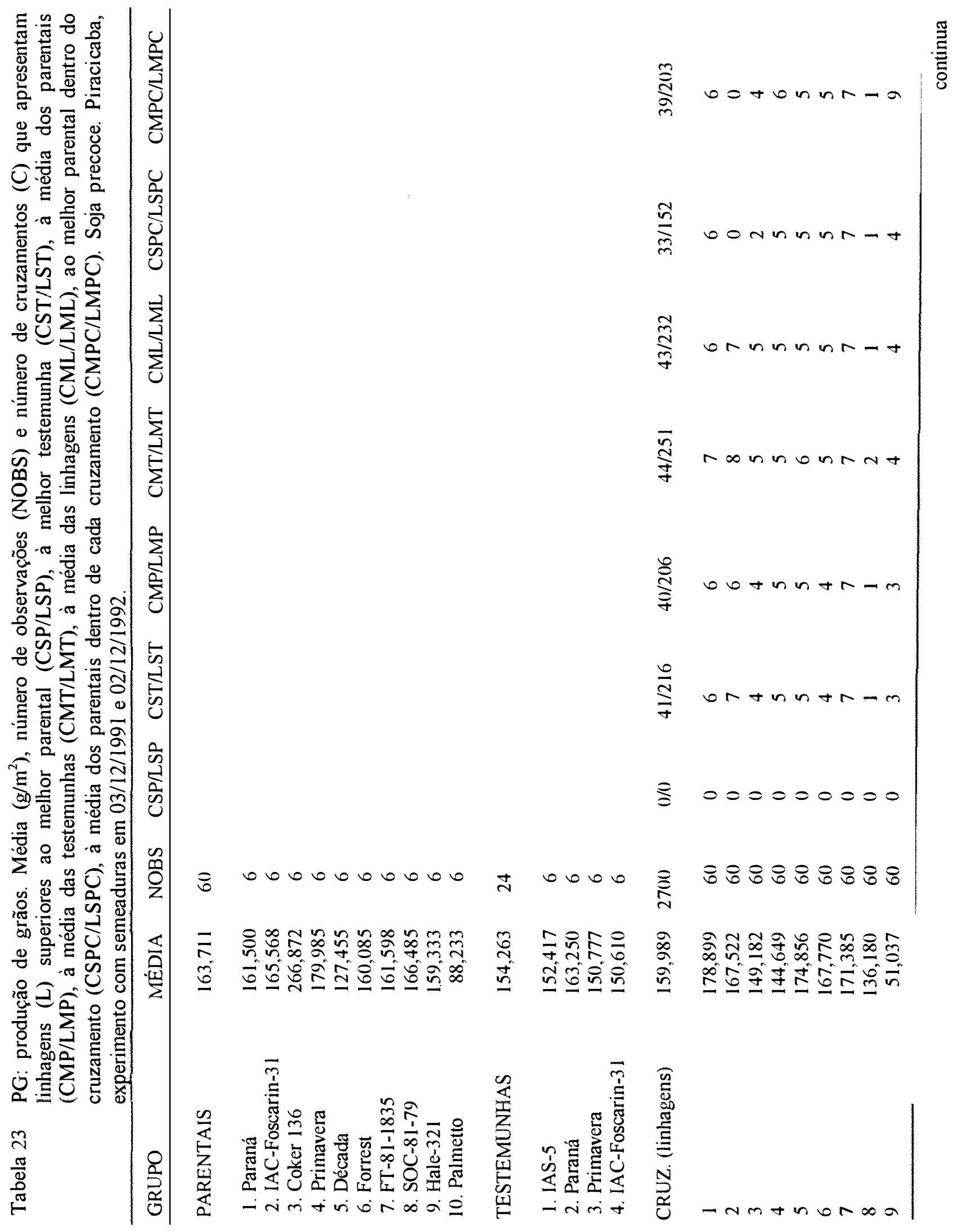




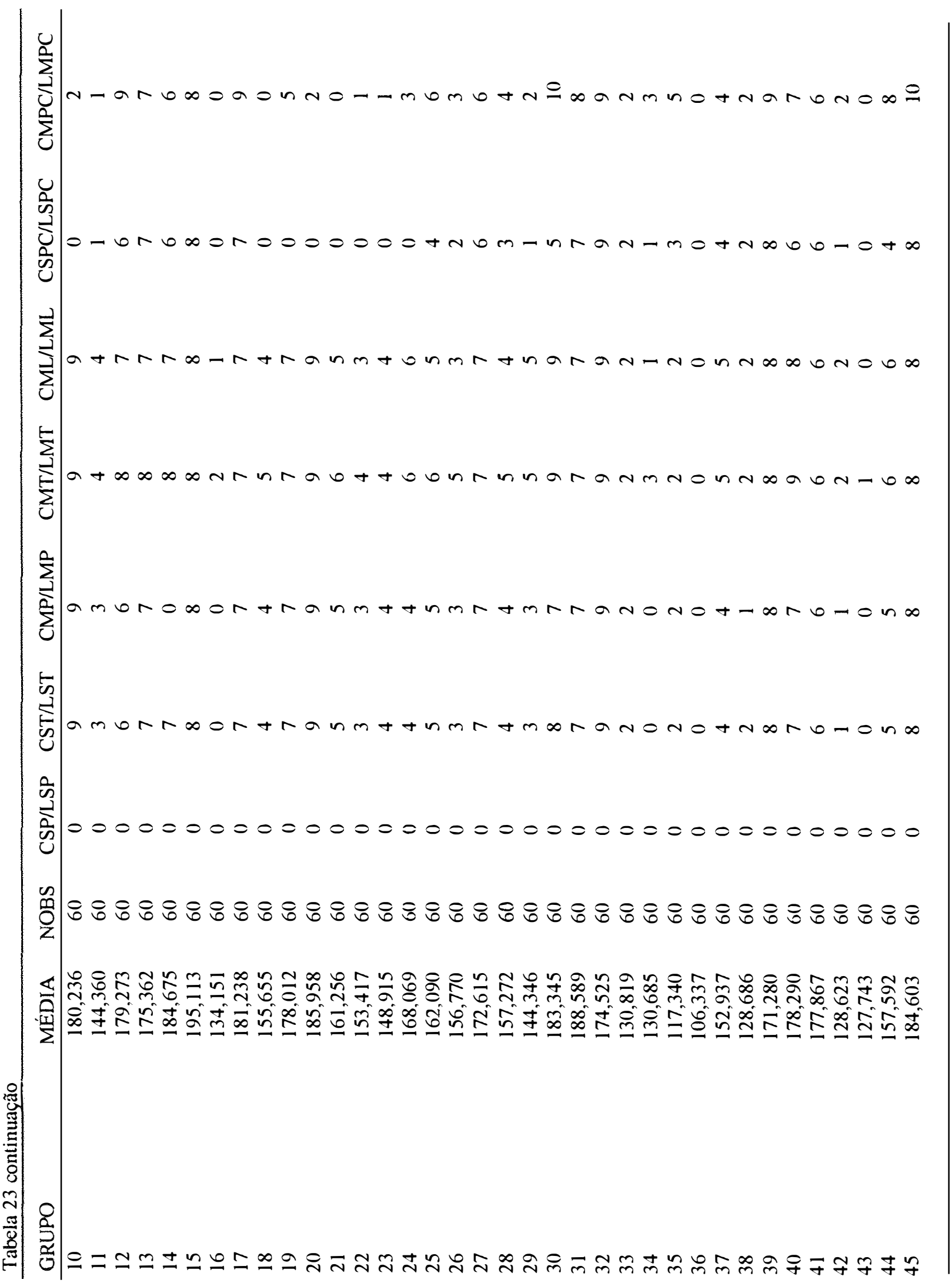




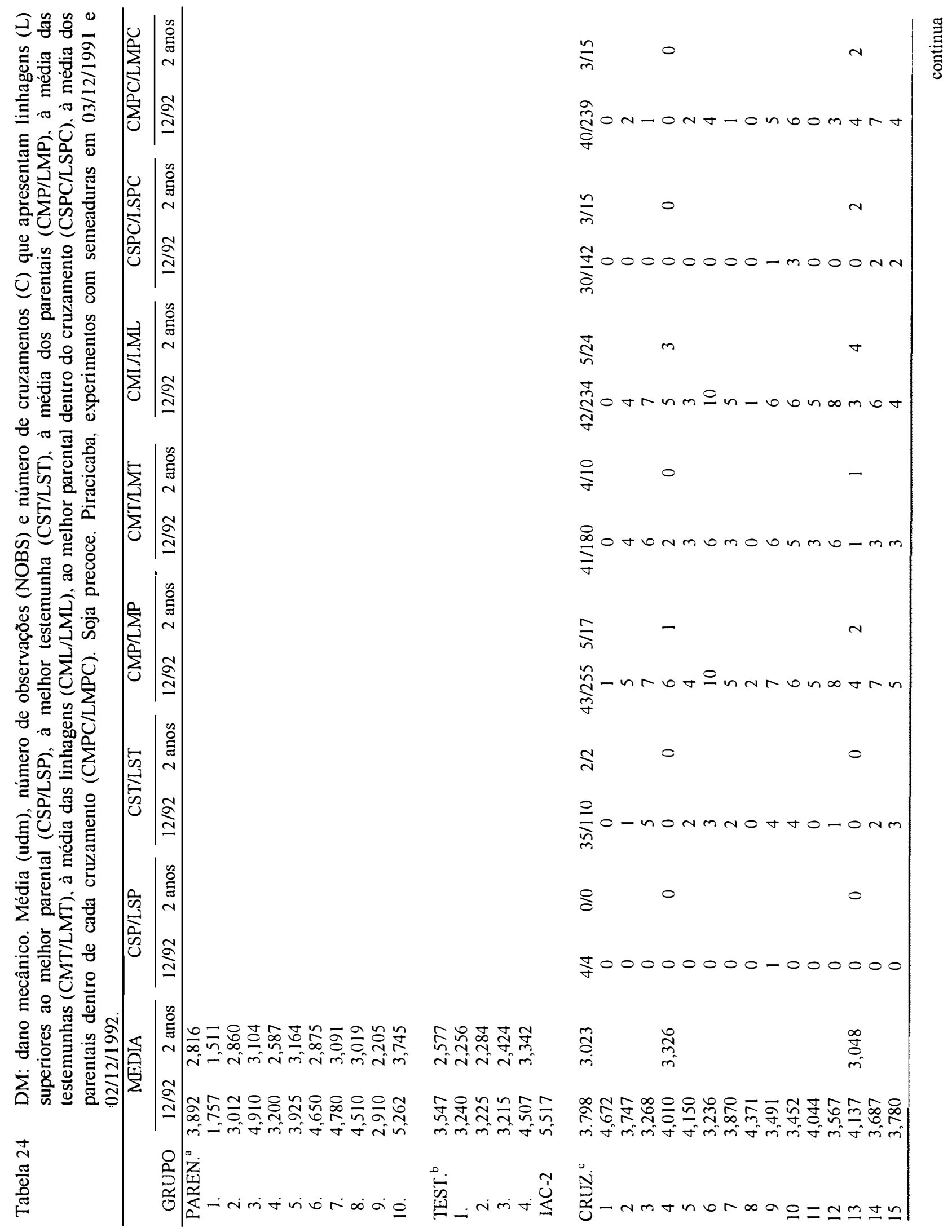




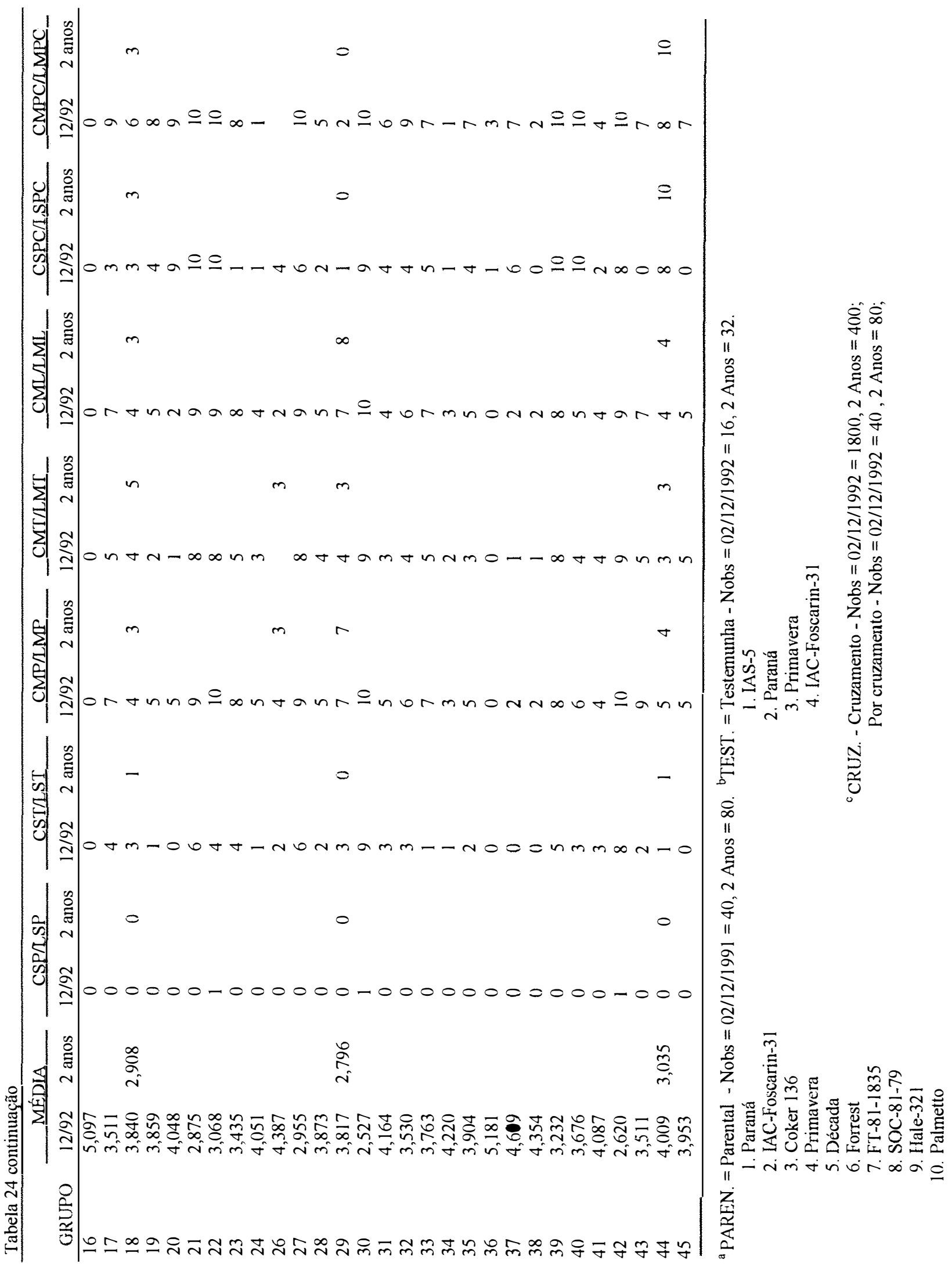




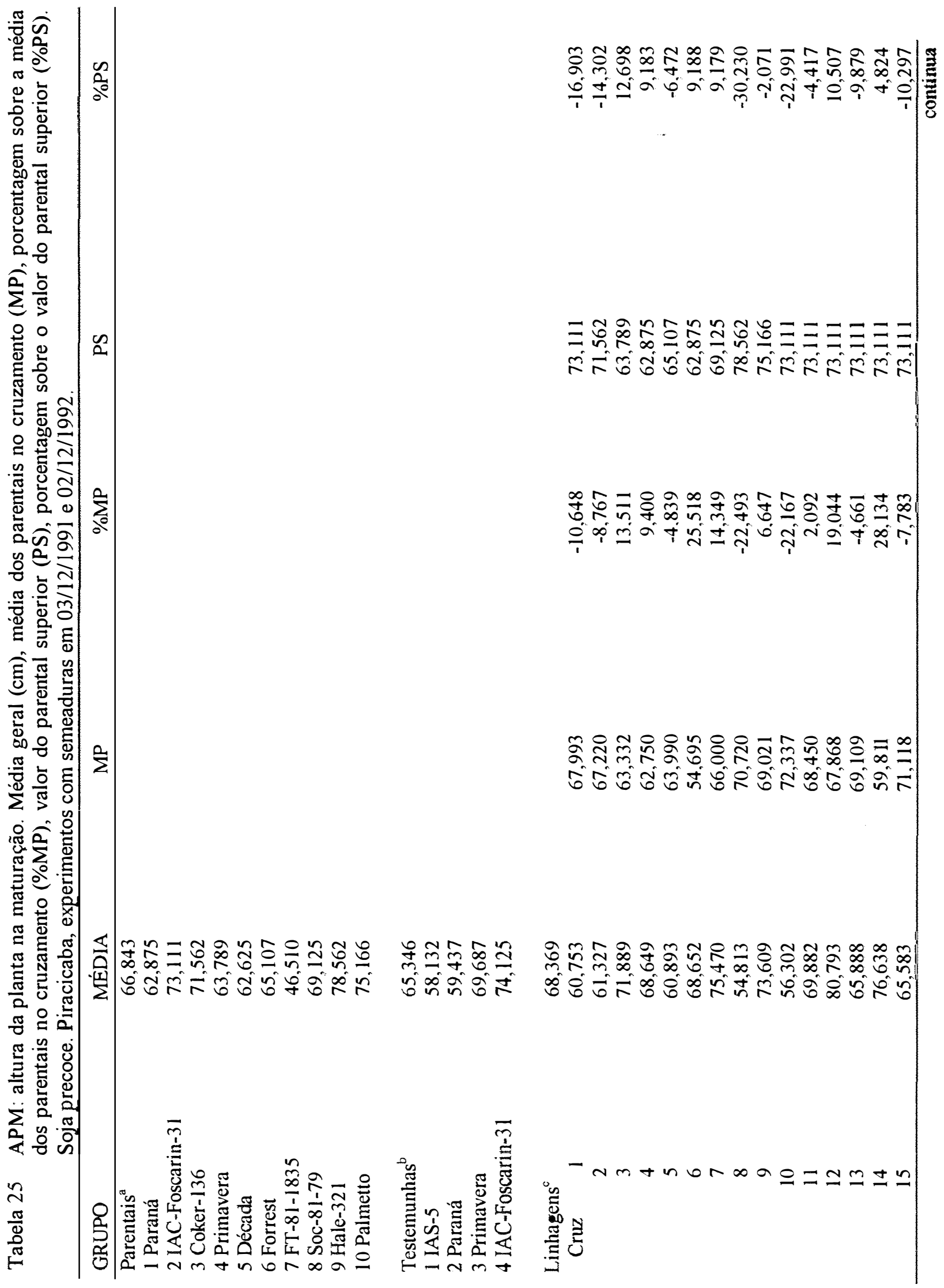




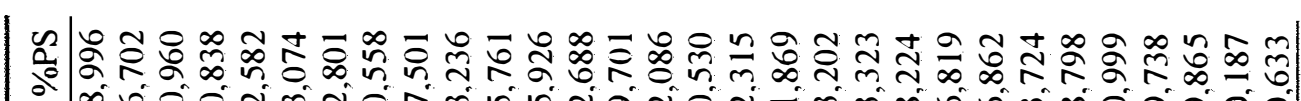
क人ष

ص 於

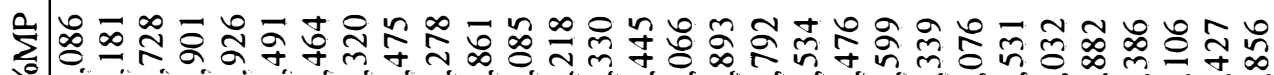
-

q

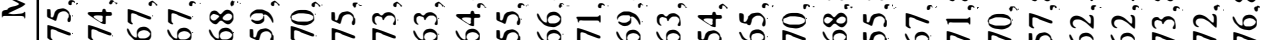

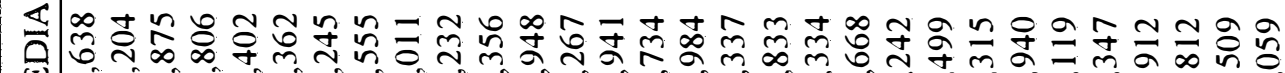

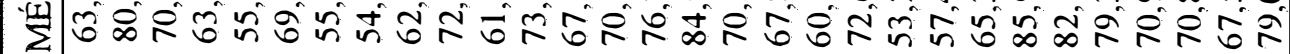

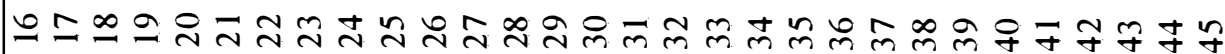




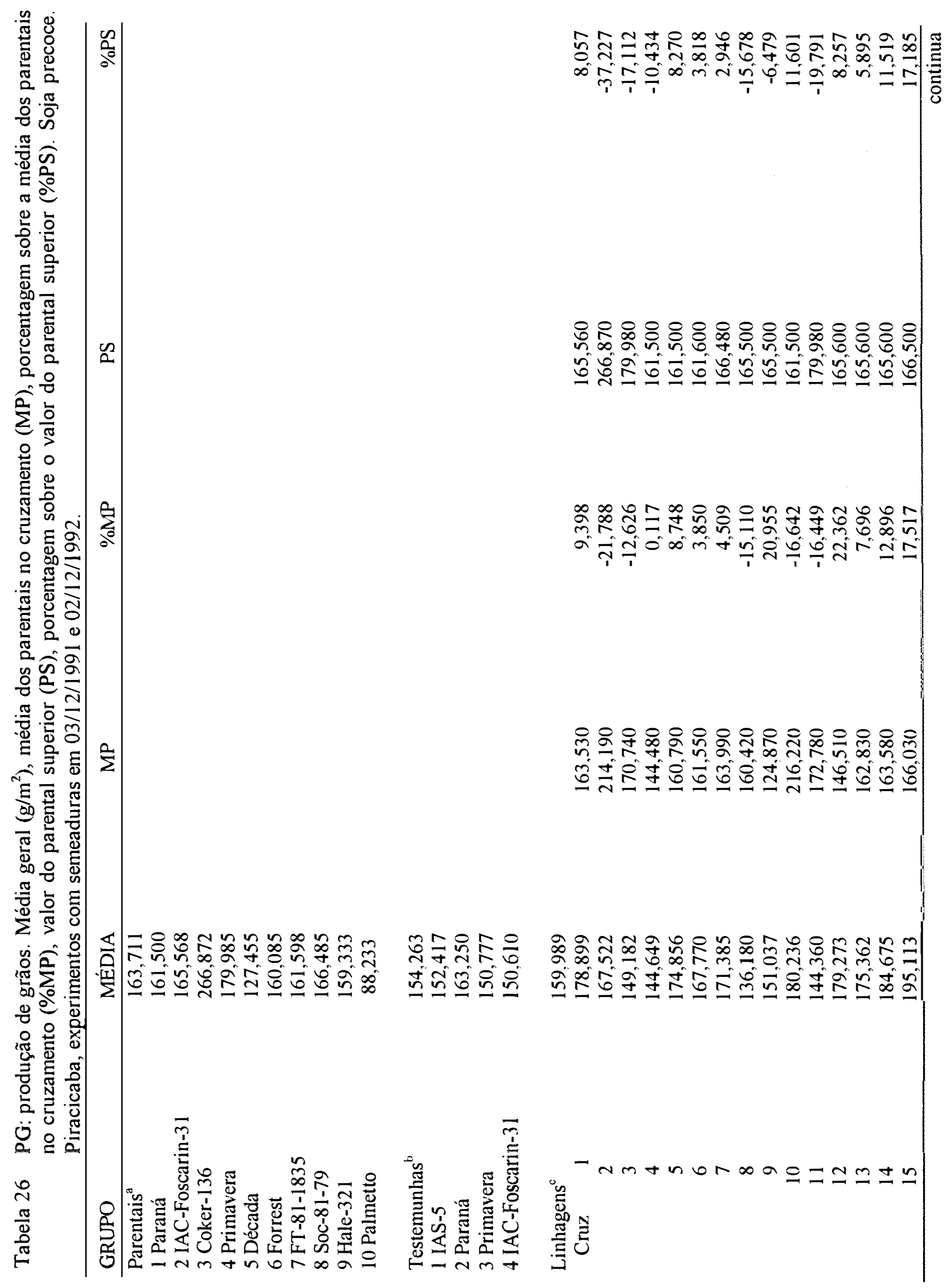




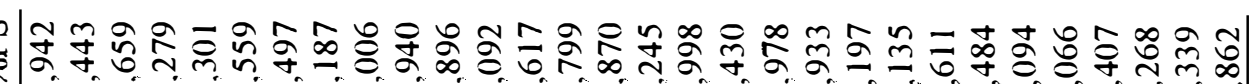

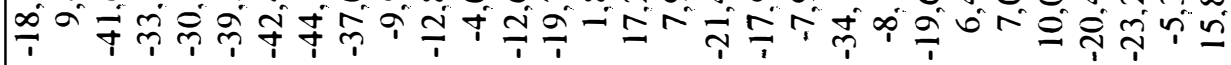

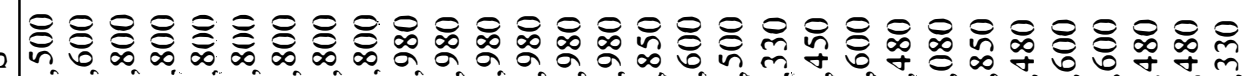

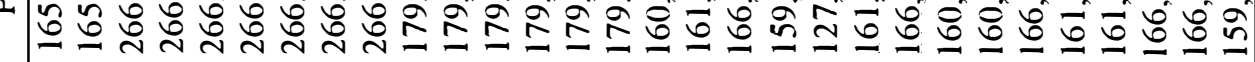

$\sum_{0}$

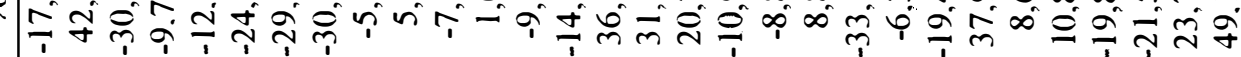

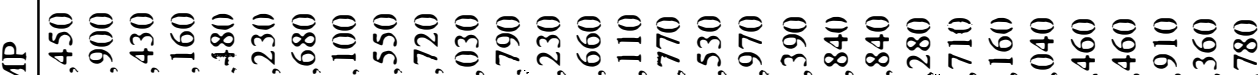

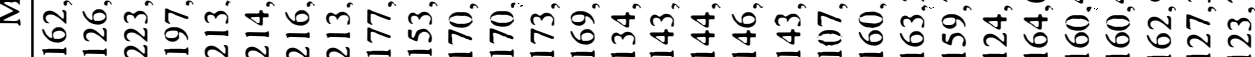

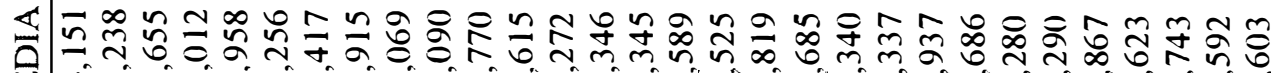

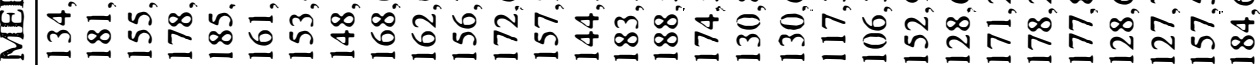




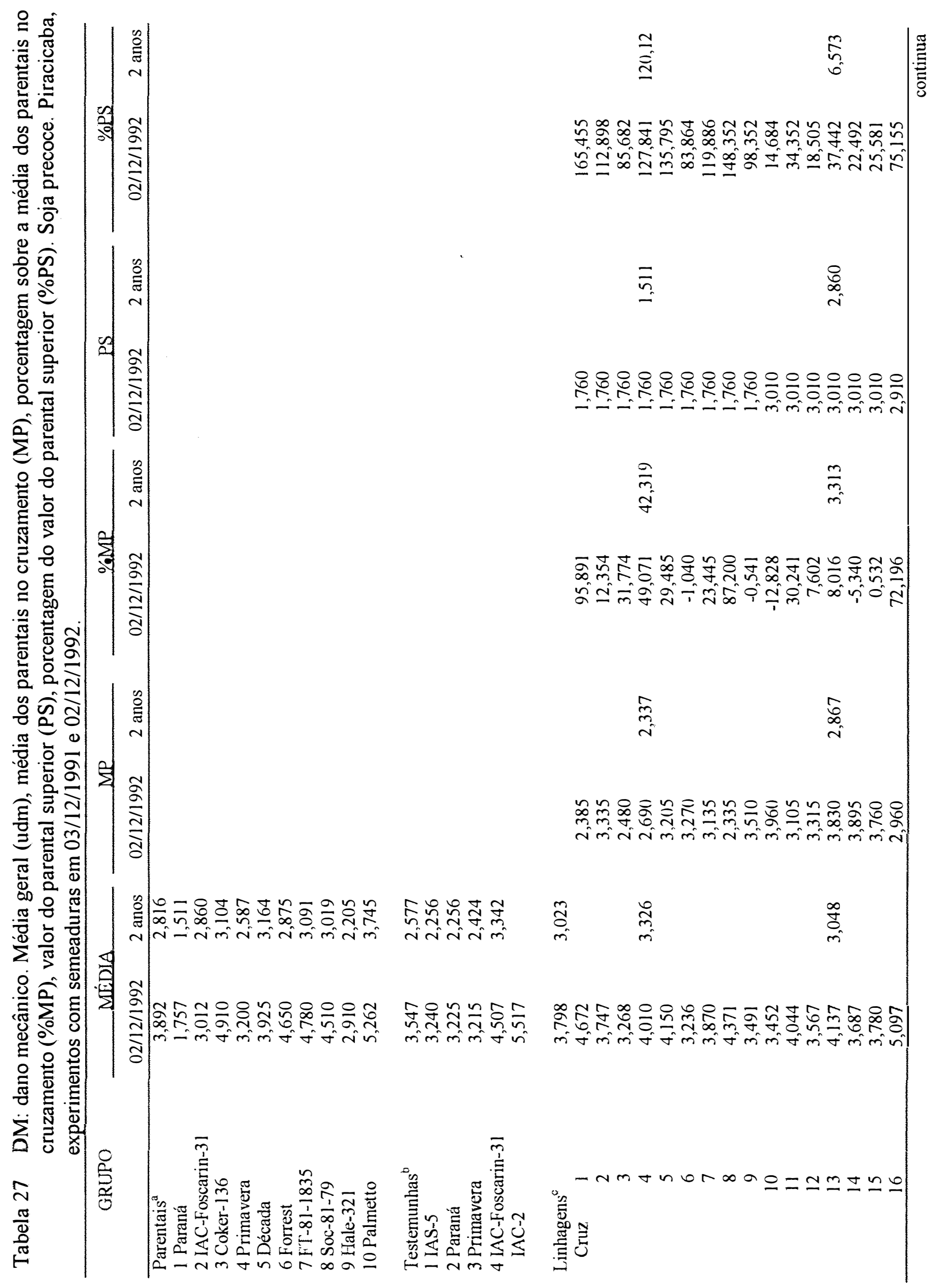




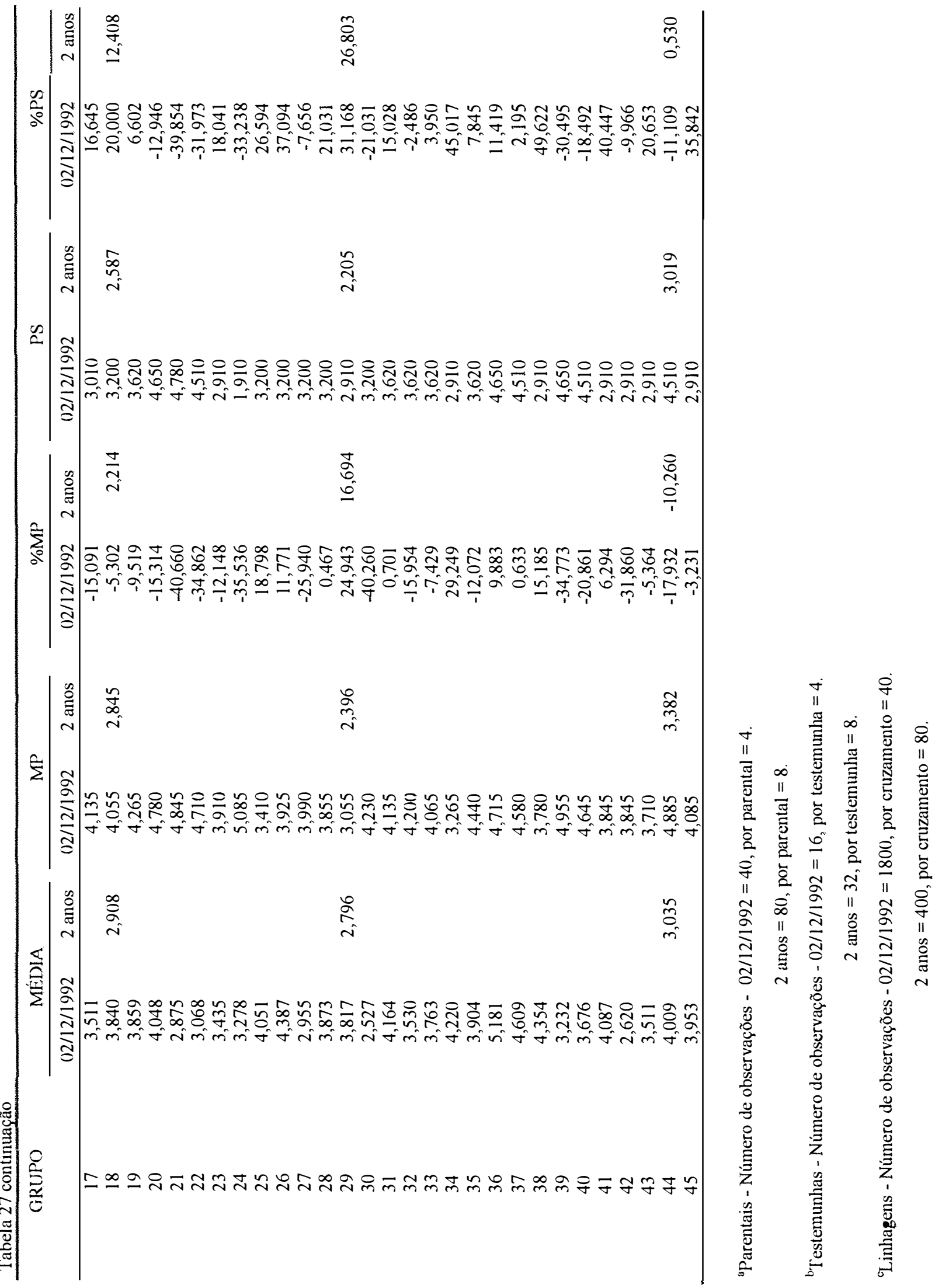


APÊNDICES 
Apêndice 1 Identificação dos cruzamentos obtidos pelo dialelo entre dez parentais.

\begin{tabular}{|c|c|c|}
\hline Número do cruzamento & \multicolumn{2}{|c|}{ Combinação parental de cruzamento } \\
\hline 1 & Paraná & x IAC-Foscarin-31 \\
\hline 2 & Paraná & x Coker-136 \\
\hline 3 & Paraná & $\mathrm{x}$ Primavera \\
\hline 4 & Paraná & x Década \\
\hline 5 & Paraná & $\mathrm{x}$ Forrest \\
\hline 6 & Paraná & x FT $-81-1835$ \\
\hline 7 & Paraná & x SOC-81-79 \\
\hline 8 & Paraná & x Hale-321 \\
\hline 9 & Paraná & x Palmetto \\
\hline 10 & IAC-Foscarin-31 & x Coker-136 \\
\hline 11 & IAC-Foscarin-31 & $\mathrm{x}$ Primavera \\
\hline 12 & Década & x I AC-Foscarin-31 \\
\hline 13 & IAC-Foscarin-31 & $\mathrm{x}$ Forrest \\
\hline 14 & IAC-Foscarin-3 1 & x FT-81-1835 \\
\hline 15 & IAC-Foscarin-31 & x SOC-81-79 \\
\hline 16 & IAC-Foscarin-31 & x Hale-321 \\
\hline 17 & IAC-Foscarin-3 1 & x Palmetto \\
\hline 18 & Coker-136 & $\mathrm{x}$ Primavera \\
\hline 19 & Coker-136 & x Década \\
\hline 20 & Forrest & x Coker-136 \\
\hline 21 & Coker-136 & x FT-81-1835 \\
\hline 22 & SOC-81-79 & x Coker-136 \\
\hline 23 & Coker-136 & x Hale-321 \\
\hline 24 & Palmetto & x Coker-136 \\
\hline 25 & Década & $\mathrm{x}$ Primavera \\
\hline 26 & Forrest & $\mathrm{x}$ Primavera \\
\hline 27 & FT-81-1835 & $\mathrm{x}$ Primavera \\
\hline 28 & SOC-81-79 & $\mathrm{x}$ Primavera \\
\hline 29 & Hale-321 & $\mathrm{x}$ Primavera \\
\hline 30 & Palmetto & $\mathrm{x}$ Primavera \\
\hline 31 & Forrest & x Década \\
\hline 32 & Década & x FT-81-1835 \\
\hline 33 & SOC-81-79 & x Década \\
\hline 34 & Hale-321 & x Década \\
\hline 35 & Palmetto & x Década \\
\hline 36 & Forrest & x FT-81-1835 \\
\hline 37 & Forrest & x SOC-81-79 \\
\hline 38 & Hale-321 & $\mathrm{x}$ Forrest \\
\hline 39 & Forrest & x Palmetto \\
\hline 40 & FT-81-1835 & x SOC-81-79 \\
\hline 41 & FT-81-1835 & x Hale-321 \\
\hline 42 & Palmetto & x FT-81-1835 \\
\hline 43 & SOC-81-79 & x Hale-321 \\
\hline 44 & SOC-81-79 & x Palmetto \\
\hline 45 & Hale-321 & x Palmetto \\
\hline
\end{tabular}




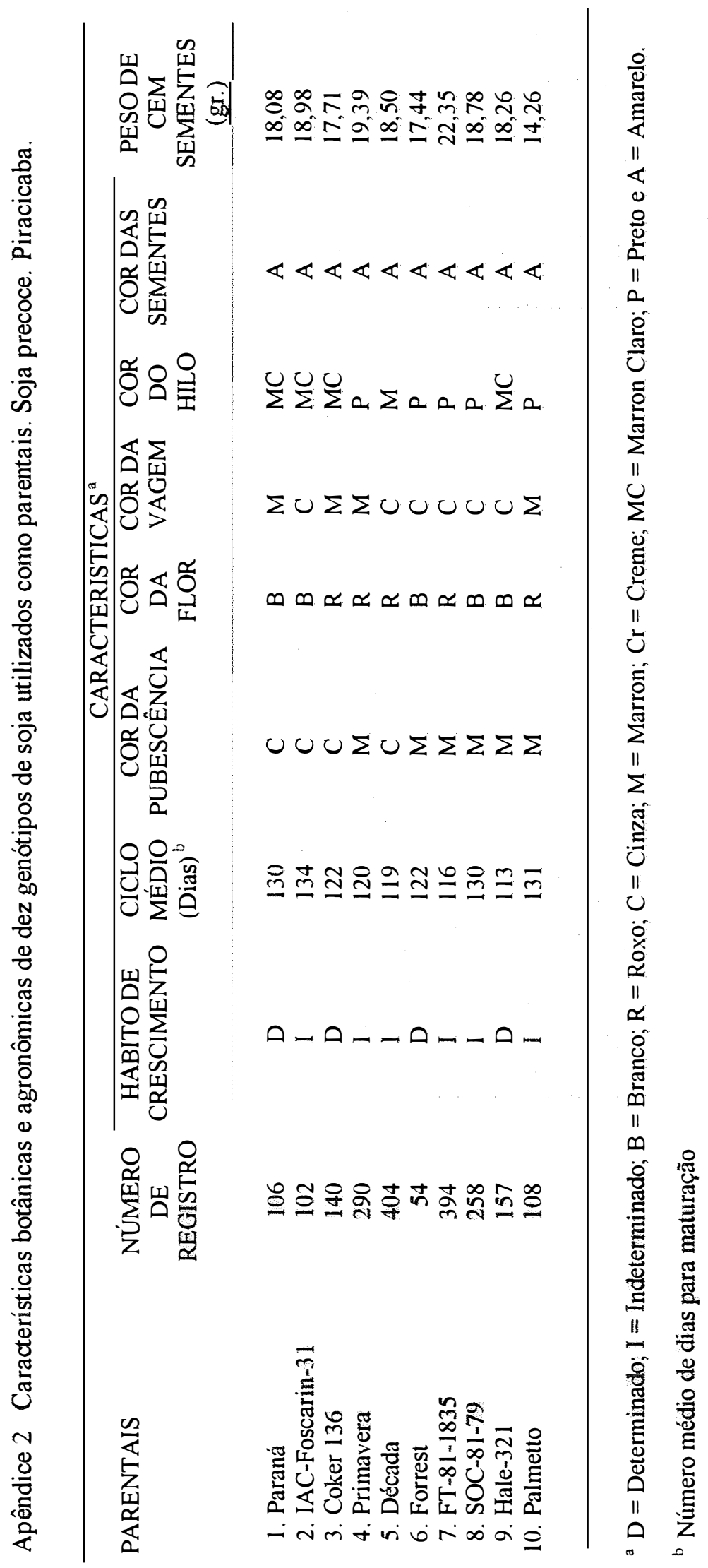

